UNIVERSIDADE DE BRASÍLIA - UNB

FACULDADE DE EDUCAÇÃO FÍSICA

PROGRAMA DE PÓS-GRADUAÇÃO STRICTO SENSU EM EDUCAÇÃO FÍSICA

COMPARAÇÃO ENTRE ÍNDICES DA ADIPOSIDADE CORPORAL NA PREDIÇÃO DE FATORES DE RISCO CARDIOMETABÓLICO E NA FUNCIONALIDADE DE MULHERES IDOSAS

André Bonadias Gadelha

BRASÍLIA

2015 


\title{
COMPARAÇÃO ENTRE ÍNDICES DA ADIPOSIDADE CORPORAL NA PREDIÇÃO DE FATORES DE RISCO CARDIOMETABÓLICO E NA FUNCIONALIDADE DE MULHERES IDOSAS
}

\author{
ANDRÉ BONADIAS GADELHA
}

Dissertação apresentada ao Programa de Mestrado em Educação Física da Universidade de Brasília como requisito para obtenção do grau de Mestre em Educação Física.

ORIENTADOR: Dr. RICARDO MORENO LIMA 


\section{AGRADECIMENTOS}

Primeiramente, agradeço a Deus pela vida. Em seguida, gostaria de agradecer aos meus familiares, em especial ao Sr. Ulisses Gadelha de Albuquerque, que sempre foi um pai exemplar e à minha esposa Juliana Costa Shiraishi que me ajudou muito durante esses anos de convivência e continua me ensinando muito sobre a vida. Estes terão a minha gratidão e admiração eterna. Agradeço aos meus filhos Amanda e Augusto que iluminam a minha vida; e à minha irmã Lívia que sempre acreditou em mim.

Agradeço ao meu orientador professor Dr. Ricardo Moreno Lima por todos os ensinamentos e ao Grupo de Estudos em Fisiologia do Exercício e Saúde por todo o apoio oferecido. Agradeço a Coordenação de Aperfeiçoamento de Pessoal de Nível Superior pela bolsa de estudos e ao programa de pós-graduação em educação física da Universidade de Brasília por possibilitar esta formação. Por fim, agradeço a todos os professores, funcionários da instituição e colegas por todos os momentos de convivência. 


\section{SUMÁRIO}

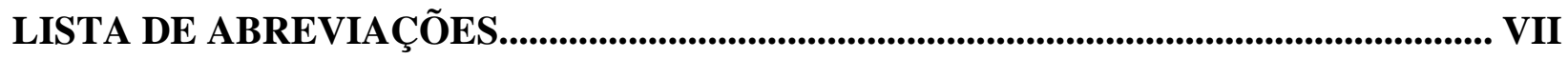

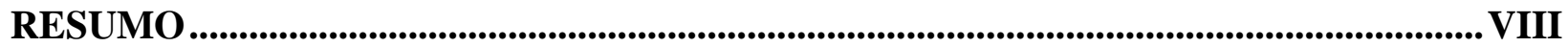



1. INTRODUÇÃ

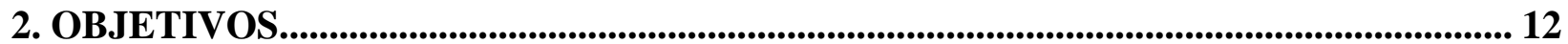

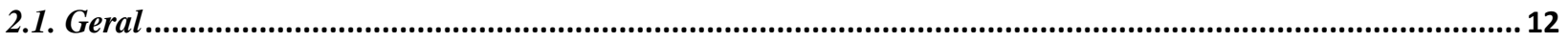

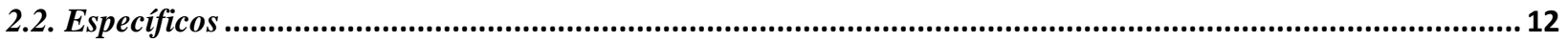

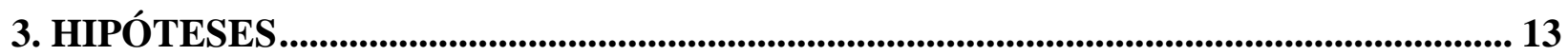

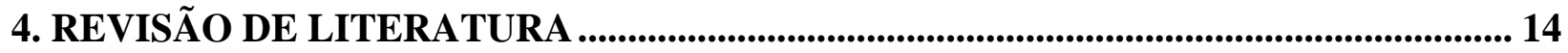

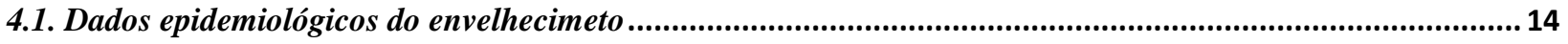

4.2. O processo de envelhecimento ...................................................................................................................... 18

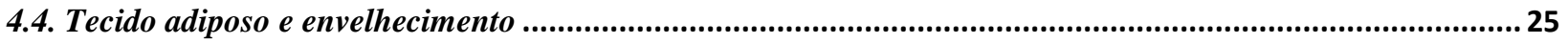

4.5. CONSEQUÊNCIAS DO EXCESSO DE GORDURA CORPORAL............................... 27

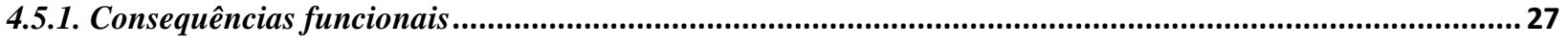

4.5.2. Consequências cardiovasculares e metabólicas ...............................................................................................29

4.6. ENVELHECIMENTO E MARCADORES CARDIOMETABÓLICOS ........................ 31

4.7. ÍNDICES DA GORDURA CORPORAL .......................................................................... 34

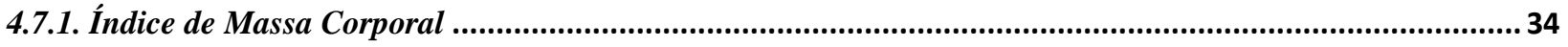

4.7.2. Circunferência de Cintura e Relação Cintura Estatura ................................................................................. 35

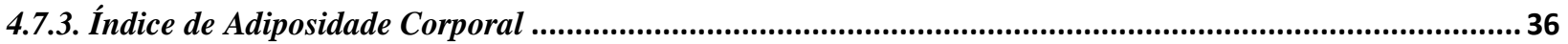




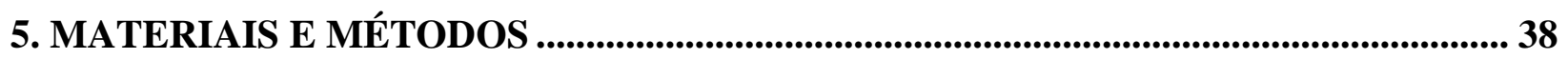

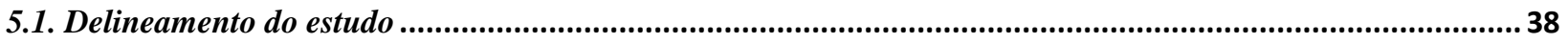

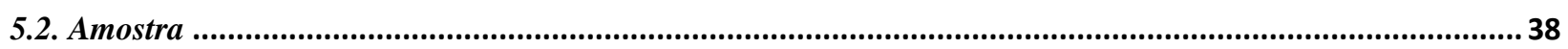



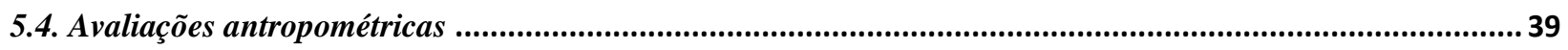

5.5. Nivel de atividade física ................................................................................................................................. 41

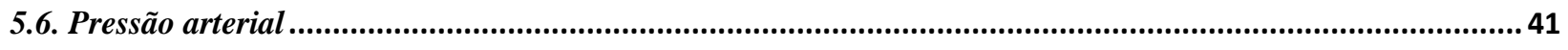

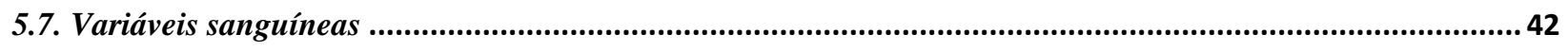

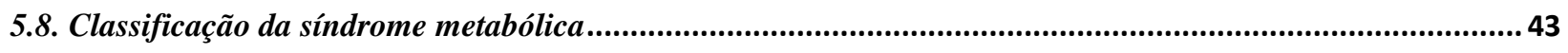

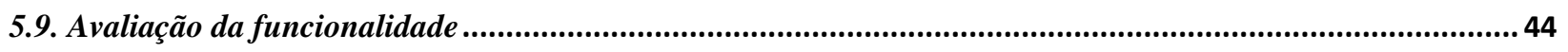

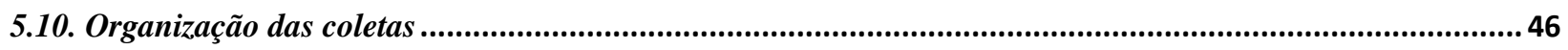

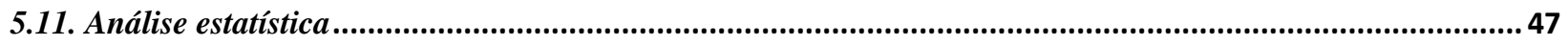

6. RESULTADOS …...................................................................................................................................... 49

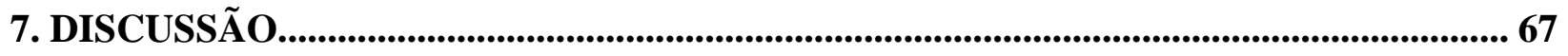

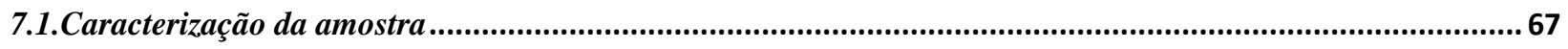

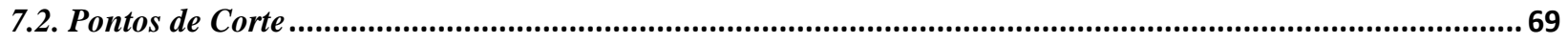



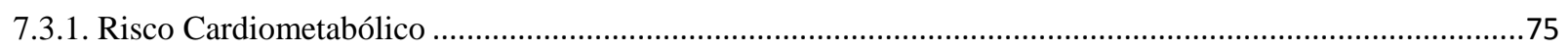

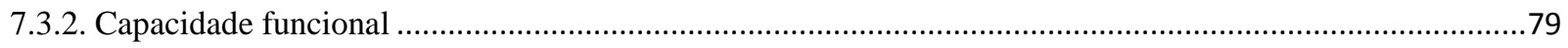

7.4. Mecanismos responsáveis pela associação entre adiposidade e risco cardiometabólico..................................83

7.5. Mecanismos responsáveis pela associação entre adiposidade e funcionalidade............................................85

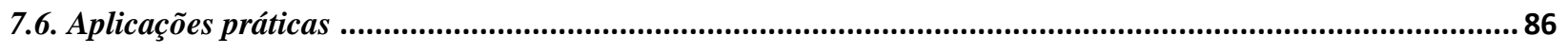






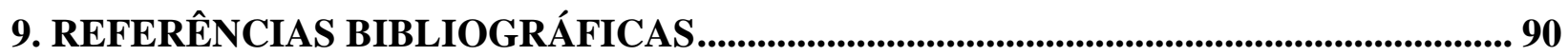

10.1. Anexo A - Termo de Consentimento Livre e Esclarecido .................................................................... 107

10.2. Anexo B - Registro de aceite no comitê de ética em pesquisa ............................................................... 108

10.3. Anexo C-Questionário internacional de atividade física (IPAQ - versão curta) . .................................... 109

10.4. Anexo D - Produção científica/Artigo científico ................................................................................. 112

10.4.1. Strength, muscle quality and markers of cardiometabolic risk in older women ................................112

10.5. Anexo E - Produção científica/Artigo científico ...................................................................................... 113

10.5.1. Session rating of perceived exertion following resistance exercise with blood flow restriction. ..............113

10.6. Anexo F - Produção científica/Artigo científico ....................................................................................... 114

10.6.1. Associação entre força, sarcopenia e obesidade sarcopénica com o desempenho funcional de idosas.....114

10.7. Anexo G-Produção científica/Artigo científico .................................................................................... 115

10.7.1. Sarcopenia and sarcopenic obesity classifications and cardiometabolic risks in older women.................115

10.8. Anexo H - Produção científica/Artigo científico ..................................................................................... 116

10.8.1. Diferenças entre os gêneros na resistência à fadiga e na recuperação do treinamento de força. ...............116

10.9. Anexo I - Produção científica/Resumo publicado em anais de congresso ...............................................117

Efeitos da prática sistematizada de hatha yoga sobre indicadores da aptidão física de adultos jovens ........117

10.10. Anexo J - Produção científica/Resumo publicado em anais de congresso ............................................. 118 Respostas cardiovasculares agudas no treinamento resistido com e sem restrição do fluxo sanguíneo em adultos jovens .118 


\section{LISTA DE ABREVIAÇÕES}

$\mathrm{CC}=$ Circunferência de Cintura

DEXA = Absortometria de Raio- $x$ de Dupla Energia

$\mathrm{FEF}=$ Faculdade de Educação Física

GEFS = Grupo de Estudos em Fisiologia do Exercício e Saúde

$\mathrm{HDL}=$ High Density Lipoprotein (lipoproteína de alta densidade)

HOMA: Homeostatic Model Assessment

IAC = Índice de Adiposidade Corporal

$\mathrm{IC}=$ Índice de Conicidade

IMC = Índice de Massa Corporal

IPAQ = Questionário Internacional de Atividade Física

$\mathrm{LDL}=$ Low Density Lipoprotein (Lipoproteína de baixa densidade)

OMS = Organização Mundial da Saúde

PAS = Pressão Arterial Sistólica

$\mathrm{PAD}=$ Pressão Arterial Diastólica

PAM = Pressão Arterial Média

$\mathrm{PCR}=$ Proteína $\mathrm{C}$-reativa

$\mathrm{RCE}=$ Relação Cintura Estatura

RCQ = Relação Cintura Quadril

SM = Síndrome Metabólica

TCLE $=$ Termo de Consentimento Livre e Esclarecido

UnB = Universidade de Brasília 


\section{RESUMO}

OBJETIVO: Comparar os principais índices da adiposidade corporal na predição de fatores de risco cardiometabólico e na funcionalidade de mulheres idosas. MÉTODOS: Uma amostra representativa de mulheres idosas residentes no Distrito Federal ( $n=149 ; 67.17 \pm 6.12$ anos) foi submetida a avaliação da composição corporal por meio do DEXA e outros 5 índices antropométricos (circunferência de cintura CC, relação cintura estatura - RCE, índice de massa corporal - IMC, índice de adiposidade corporal - IAC e índice de conicidade - IC). A pressão arterial foi medida por método oscilométrico e análise sanguínea foi conduzida para perfil glicêmico, perfil lipídico e proteína C-reativa. A classificação da síndrome metabólica (SM) adotada obedeceu aos critérios do NCEP-ATP III. Os testes funcionais de levantar e sentar, agilidade e caminhada de 6 minutos foram conduzidos em subgrupo aleatorizado ( $n=87)$. A correlação de Pearson foi utilizada para identificar o relacionamento entre as variáveis e o teste $t$ para amostras independentes para comparar os sujeitos classificados com e sem os desfechos de SM e de incapacidade funcional. Definiu-se pontos de corte específicos para cada índice de adiposidade a partir da curva ROC e o odds ratio foi calculado para os desfechos de desordem metabólica e funcionalidade baixa. RESULTADOS: Exceto para colesterol total e LDL, as variáveis de risco cardiometabólico apresentaram correlação significativa com pelo menos um dos índices da adiposidade. SM e capacidade funcional baixa apresentaram prevalência de $29.5 \%$ e de $36.8 \%$, respectivamente. O grupo classificado com o desfecho de SM apresentou condição cardiometabólica inferior em comparação ao grupo de referência, com exceção de colesterol total e LDL. Os testes de Levantar e Sentar, Caminhada de 6 minutos e Agilidade apresentaram associação mais consistente com CC ( $r=-0.345 ; \mathrm{p}<0.01)$, RCE ( $\mathrm{r}=-$ 0.417; $\mathrm{p}<0.01)$ e IAC $(\mathrm{r}=0.296 ; \mathrm{p}<0.01)$, respectivamente. Na comparação entre as curvas ROC, a CC apresentou-se maior que \%G ( $\mathrm{p}<0.001)$, IAC ( $<<0.001)$, IC ( $<<0.02)$, IMC ( $<<0.04)$. O odds ratio para os desfechos de SM e incapacidade funcional foi maior para CC (OR=18.62; IC: 6.71-51.69) e RCE (OR=7.75; IC:0.95-63.17), respectivamente. CONCLUSÃO: Com base nos resultados apresentados, conclui-se que os índices da adiposidade que consideraram a gordura abdominal em seus cálculos apresentaram maior poder discriminatório e relacionamento mais consistente com os fatores de risco cardiometabólico e com a funcionalidade em amostra composta por mulheres idosas.

Palavras-Chaves: Envelhecimento, Síndrome Metabólica, Obesidade, Capacidade Funcional. 


\section{ABSTRACT}

OBJECTIVE: To compare the main fatness indexes to predict cardiometabolic risk factors and functionality of older women. METHODS: A representative sample of older women from Federal District ( $n=149 ; 67.17 \pm 6.12$ years) underwent to body composition assessment by DXA and other 5 anthropometric indexes (Waist Circumference - WC, Waist-to-Height Ratio - WHtR, Body Mass IndexBMI, Body Adiposity Index - BAI, and Conicity Index - CI). Blood pressure was evaluated by oscillometric method and blood sample was collected to glycemic profile, lipid profile, and C-reactive protein. Metabolic Syndrome (MetS) classification criteria was NCEP-ATP III. 30-s chair stand, 8-foot up-and-go, and 6-minute walk were performed in a randomized subsample $(n=87)$. Pearson's correlation was applied to identify the relationship between variables and the t test to independent samples to compare the subjects classified with and without MetS and disability. Odds ratio was calculated for outcomes of metabolic disorders and low functionality. RESULTS: Except for total cholesterol and LDLcholesterol, cardiometabolic risk variables showed significant correlation with at least one of fatness indexes studied. MetS and low functional capacity prevalence was set $29.5 \%$ and $36.8 \%$, respectively. The MetS group presented inferior cardiometabolic condition when compared with the reference group, except to total cholesterol and LDL-cholesterol. 30-s chair stand, 6-minute walk, and 8-foot up-and-go showed better consistent association with WC ( $r=-0.345 ; p<0.01)$, WHtR $(r=-0.417 ; p<0.01)$, and BAI $(r=0.296 ; p<0.01)$, respectively. In compare among ROC curves, the WC presented larger than fatness ( $p<0.001), B A I(p<0.001), C I(p<0.02), B M I(p<0.04)$. Odds ratio to MetS and disability outcomes were higher to WC (OR=18.62; CI: 6.71-51.69) and WHtR (OR=7.75; CI:0.95-63.17), respectively. CONCLUSION: Based on the presented results, it was concluded that the indexes of fatness which considered abdominal fat in its calculation had higher discriminatory power and more consistent relationship with cardiometabolic risk factors and with functionality in older women.

Key-Words: Aging, Metabolic Syndrome, Obesity, Functional Capacity. 


\section{INTRODUÇÃO}

A expectativa de vida da população mundial está aumentando e esta tendência também pode ser observada na população brasileira. Espera-se que, em 2025, o Brasil seja o sexto país com o maior percentual de indivíduos idosos no mundo (Lebrão, 2007). Contudo, é sabido que o processo de envelhecimento humano está associado a mudanças importantes nas funções fisiológicas destes indivíduos, principalmente do sexo feminino (Waters e Baumgartner, 2011; Prado, Wells et al., 2012). Estas mudanças podem influenciar alterações negativas na composição corporal, por exemplo, com o avançar da idade observa-se um acúmulo de massa gorda, sendo que esta condição pode comprometer a saúde e o modo de vida desta população (Canning, Brown et al., 2014).

O aumento da gordura corporal vem sendo associado a indicadores negativos de saúde em diversas populações, inclusive de idosos. Segundo a Organização Mundial da Saúde (OMS) (2002), quando excessivo, o acúmulo de gordura corporal com implicações à saúde, é reconhecido como obesidade. A obesidade está associada ao risco aumentado de desenvolvimento de doenças cardiovasculares e metabólicas (Mancini, Geloneze et al., 2010; Chughtai, Morgan et al., 2011; Hirani, 2011). Além disso, o excesso de massa corporal tem sido reportado como influenciador negativo da funcionalidade de indivíduos com idade avançada. É bem estabelecido que a obesidade avaliada pelo índice de massa corporal (IMC) e/ou circunferência de cintura (CC), está associada à mobilidade reduzida de indivíduos idosos (Hubert, Bloch et al., 1993; Ensrud, Nevitt et al., 1994; Galanos, Pieper et al., 1994; Launer, Harris et al., 1994; Jenkins, 2004). Nesse sentido, Angleman et al (2006) demonstraram que a distribuição da gordura corporal parece ser um importante indicador da mobilidade, valorizando a avaliação da CC em relação ao IMC, por ser diretamente relacionada a gordura visceral. Neste sentido, faz-se necessário um melhor entendimento das avaliações de composição corporal na população idosa.

Atualmente, a absortometria de raio-x de dupla energia (DEXA) é considerada o método padrão ouro, que permite a análise da composição corporal de seres humanos. Embora apresente resultados satisfatórios para a análise da composição corporal, o uso do DEXA torna-se inviável 
para avaliações clínicas em populações numerosas (Villareal, Apovian et al., 2005). Portanto, é crescente o interesse em investigar o poder preditivo de avaliações clínicas de baixo custo e fácil aplicação. Em meio a este cenário, alguns índices da adiposidade corporal têm sido amplamente utilizados para predizer fatores de risco cardiometabólico da população como um todo. As avaliações antropométricas mais utilizadas são: $\mathrm{IMC}, \mathrm{CC}$, relação cintura estatura (RCE), índice de conicidade (IC) e índice de adiposidade corporal (IAC).

Recentemente, estudos apresentaram que o risco cardiometabólico está associado ao IMC (Chuang, Li et al., 2012), CC (Félix-Redondo, Grau et al., 2013) e RCE (Wakabayashi, 2012) de diversas populações. Já o IC apresentou associação com o risco coronariano de indivíduos brasileiros (Pitanga e Lessa, 2005), entretanto Shidfar et al (2012) encontraram resultados controversos em uma amostra composta por iranianas de várias idades. Gupta e Kapoor (2014) identificaram um ponto de corte para discriminar o risco cardiovascular de mulheres indianas a partir do IAC, entretanto, trata-se de uma temática incipiente e não foram encontrados outros estudos que avaliassem o poder preditivo do IAC nas variáveis supracitadas.

Embora as avaliações antropométricas sejam reconhecidas em um contexto clínico, há uma lacuna na literatura no que diz respeito à comparação destes métodos na predição da capacidade funcional e risco cardiometabólico de mulheres idosas. 


\section{OBJETIVOS}

\subsection{Geral}

Comparar os principais índices da adiposidade corporal na predição de fatores de risco cardiometabólico e na funcionalidade de mulheres idosas.

\subsection{Específicos}

Verificar a associação dos índices da adiposidade corporal (percentual de gordura, IAC, IMC, CC, IC, RCE) com as variáveis de risco cardiometabólico (perfil lipídico, pressão arterial, insulinemia, proteína C-reativa) de mulheres idosas;

Verificar a associação dos índices da adiposidade corporal (percentual de gordura, IAC, IMC, CC, IC, RCE) com a funcionalidade de mulheres idosas;

Predizer fatores de risco cardiometabólicos e incapacidade funcional em mulheres idosas a partir de indicadores antropométricos por analise de sensibilidade e especificidade dos pontos de corte;

Calcular a razão de possibilidades das classificações propostas pelos índices da adiposidade corporal com os fatores de risco cardiometabólico e com a funcionalidade de mulheres idosas; e

Comparar as classificações propostas pelos índices da adiposidade corporal e seus fatores de risco cardiometabólico e funcionalidade de mulheres idosas. 


\section{HIPÓTESES}

$\mathrm{H}_{1}$ - Serão observadas associações entre os índices da adiposidade corporal com os fatores de risco cardiometabólico e com a funcionalidade de mulheres idosas.

$\mathrm{H}_{2}$ - Serão observadas diferenças entre o poder discriminatório dos índices da adiposidade corporal para fatores de risco cardiometabólico e funcionalidade de mulheres idosas. 


\section{REVISÃO DE LITERATURA}

\subsection{Dados epidemiológicos do envelhecimeto}

De acordo a OMS, há uma tendência mundial de envelhecimento populacional. $\mathrm{Na}$ metade do século XX, havia, no mundo, cerca de 14 milhões de pessoas com idade superior a 80 anos, sendo que esse número deverá alcançar os 400 milhões em 2050. As figuras 1 e 2, a seguir, ilustram o percentual de idosos em diferentes regiões do mundo em 2012 e a projeção para 2050.

Percentage of the total population aged 60 or over, 2012

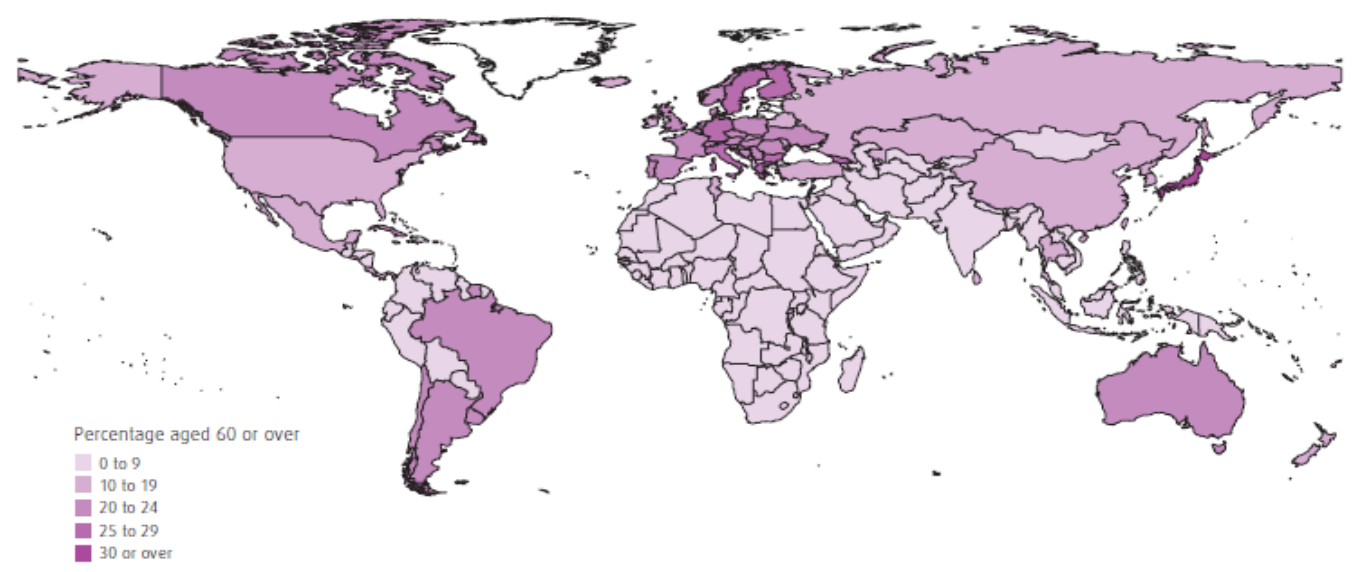

Figura 1. Percentual da população total com idade de 60 anos ou mais em 2012. Fonte: OMS, 2012.

Percentage of the total population aged 60 or over, 2050

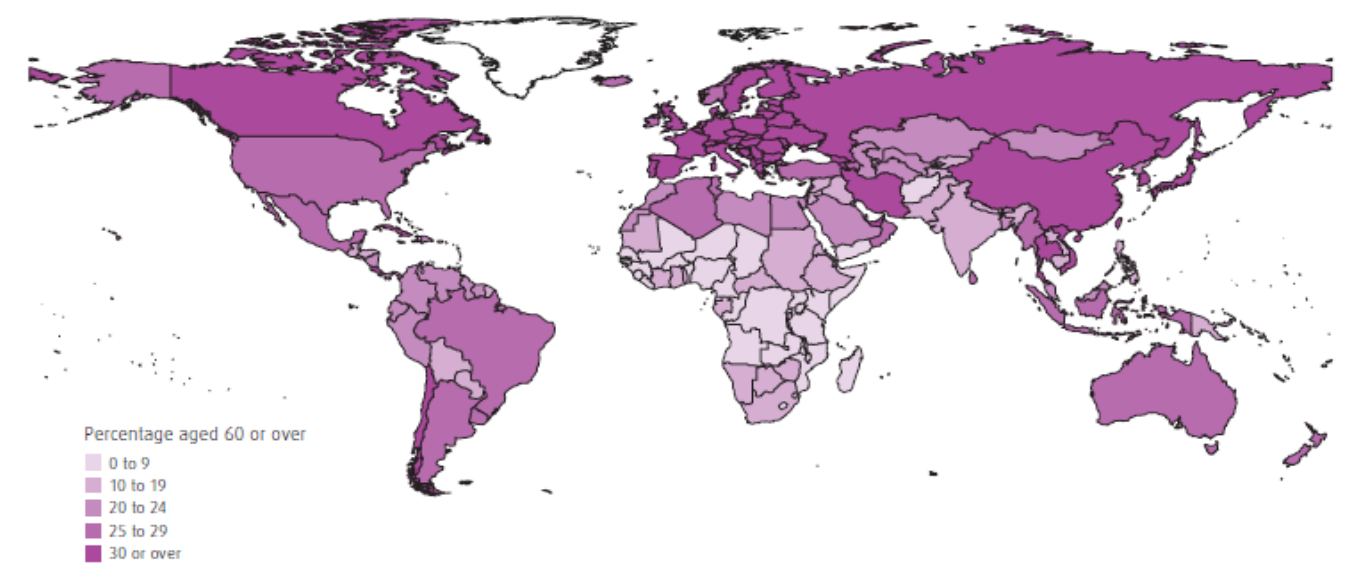


Figura 2. Estimativa percentual da população total com idade de 60 anos ou mais em 2050. Fonte: OMS, 2012.

Nas últimas cinco décadas, a população brasileira passou por transições decorrentes de mudanças nos níveis de mortalidade e natalidade em ritmos desproporcionais, o que levou a um envelhecimento da mesma (Lebrão, 2007). De acordo com Periago (2005), no início do século XXI viviam na região das Américas cerca de 2.228.900 idosos nonagenários, e espera-se que na metade do século este número esteja próximo a 13.903.000.

Em 2007, o Brasil possuía mais de 180 milhões de habitantes, dos quais aproximadamente $8 \%$ tinham idade igual ou superior a 65 anos (Lebrão, 2007). Atualmente, o Brasil possui cerca de 21 milhões de idosos e as estimativas sobre essa população seguem a tendência mundial, que apontam para um número maior do que 33 milhões de idosos no ano 2025, tornando o nosso país o sexto maior percentual populacional de idosos no mundo (Freitas, Py et al., 2011).

Ilustração. Resultados do Universo do Censo Demográfico 2010. População residente, por situação do domicílio e sexo, segundo os grupos de idade - Brasil - 2010.

\begin{tabular}{|c|c|c|c|c|c|c|c|c|c|}
\hline \multirow{4}{*}{ Grupos de idade } & \multicolumn{9}{|c|}{ Populaçäo residente } \\
\hline & \multirow{3}{*}{ Total } & \multirow{3}{*}{ Homens } & \multirow{3}{*}{ Mulheres } & \multicolumn{6}{|c|}{ Situação do domicilio e sexo } \\
\hline & & & & \multicolumn{3}{|c|}{ Urbana } & \multicolumn{3}{|c|}{ Rural } \\
\hline & & & & Total & Homens & Muheres & Total & Homens & Mulheres \\
\hline 60 a 64 anos & 6509120 & 3041035 & 3468085 & 5474944 & 2479882 & 2995062 & 1034176 & 561153 & 473023 \\
\hline 65 a 69 anos & 4840810 & 2224065 & 2616745 & 4040016 & 1792798 & 2247218 & 800794 & 431267 & 369527 \\
\hline 70 a 74 anos & 3741636 & 1667372 & 2074264 & 3142173 & 1349329 & 1792844 & 599463 & 318043 & 281420 \\
\hline 75 a 79 anos & 2563447 & 1090517 & 1472930 & 2174038 & 889908 & 1284130 & 389409 & 200609 & 188800 \\
\hline 80 a 84 anos & 1666972 & 668623 & 998349 & 1423603 & 546865 & 876738 & 243369 & 121758 & 121611 \\
\hline 85 a 89 anos & 819483 & 310759 & 508724 & 695385 & 251112 & 444273 & 124098 & 59647 & 64451 \\
\hline 90 a 94 anos & 326558 & 114964 & 211594 & 273348 & 90960 & 182388 & 53210 & 24004 & 29206 \\
\hline 95 a 99 anos & 98335 & 31529 & 66806 & 81121 & 24365 & 56756 & 17214 & 7164 & 10050 \\
\hline 100 anos ou mais & 24236 & 7247 & 16989 & 19766 & 5562 & 14204 & 4470 & 1685 & 2785 \\
\hline
\end{tabular}

Fonte: IBGE, 2010.

Um fenômeno que acompanha o envelhecimento da população é a feminização da velhice (Lebrão, 2007). De acordo com Kowal et al (2012), a expectativa de vida da população mundial é de 66 anos para os homens e de 71 para as mulheres. Nas Américas, os números passam para 73 e 79 anos para homens e mulheres, respectivamente. Já a expectativa de vida do brasileiro, de 
acordo com os últimos dados do IBGE, é de 72.7 anos, sendo de 69 para os homens e de 76.5 para as mulheres. O censo de 2000 acusou, para a mesma faixa etária, 82 homens para cada 100 mulheres. No grupo acima de 80 anos, estima-se que, em 2050, teremos duas idosas para cada idoso. Segundo Lebrão et al (2007), as possíveis explicações para esse fenômeno são multicausais, como as diferenças biológicas, as diferenças de exposição às causas de risco de trabalho, diferenças no consumo de álcool e de tabaco, bem como diferenças de atitudes em relação à doença e à incapacidade. A figura 3 ilustra as diferenças populacionais no Brasil em 1950 e no ano 2000 segundo a idade e o sexo.

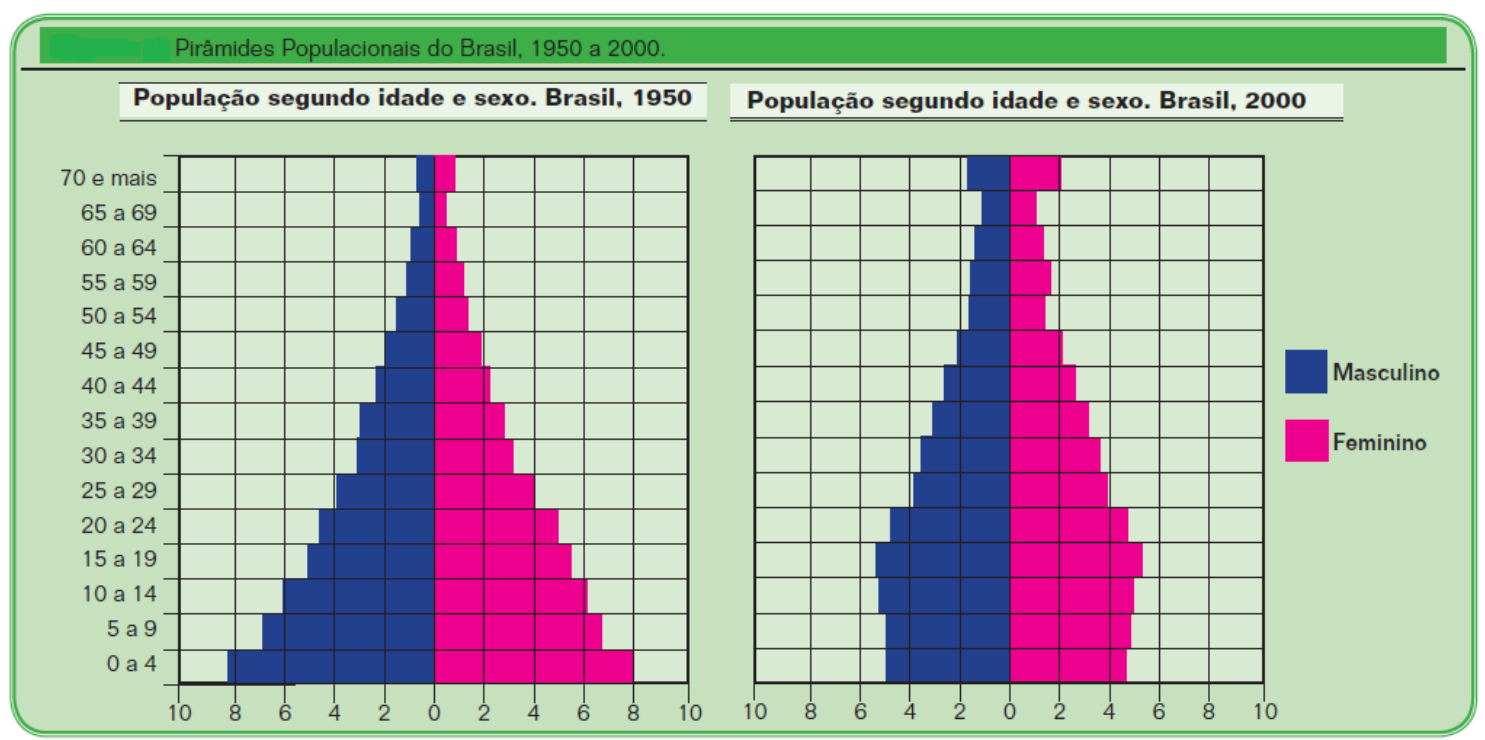

Figura 3. Pirâmides populacionais no Brasil em 1950 e 2000. Fonte: LEBRÃO, 2007.

Diante do crescimento da população idosa, é crescente a preocupação com os problemas associados à saúde, uma vez que, com o avanço da idade, a incidência de doenças que ocorrem durante o processo de envelhecimento também aumenta. Sendo assim, o perfil de mortalidade típico de uma população jovem (i.e., doenças infectocontagiosas) tende a se alterar para um cenário caracterizado por doenças crônicas não transmissíveis próprias das faixas etárias mais avançadas. De acordo com Karsch (2003), os idosos oneram mais os serviços de saúde, sendo que as internações hospitalares e o tempo de ocupação no leito são mais frequentes. Adicionalmente, as doenças nos idosos se prolongam por vários anos e exigem acompanhamento constante e exames periódicos. Nesse sentido, as alterações demográficas e epidemiológicas ora 
relatadas demandam custos mais elevados à saúde pública, em decorrência das modificações nas funções fisiológicas que ocorrem com o envelhecimento (Lima-Costa e Veras, 2003).

O estudo das alterações fisiológicas decorrentes do envelhecimento propicia um melhor entendimento da biologia da população idosa, possibilitando a implementação de intervenções preventivas e terapêuticas otimizadas. 


\subsection{O processo de envelhecimento}

Existem mais de 300 teorias que se dedicam às explicações orgânicas do processo de envelhecimento humano, contudo não há um consenso na literatura científica sobre a temática. Atualmente, o crescimento da população idosa, no Brasil e no mundo (ver dados epidemiológicos do envelhecimento), tem aumentado o interesse da comunidade científica em compreender os reais motivos do envelhecimento. Vale ressaltar que nesta etapa da vida são observadas alterações importantes, as quais influenciam o dia-a-dia dos indivíduos (Farinatti, 2002). Porém, a origem deste fenômeno, que varia de forma individual entre sujeitos da mesma espécie, ainda é desconhecida (Mota, Figueiredo et al., 2004).

Dentre as inúmeras teorias propostas pelos pesquisadores, estão as de natureza estocástica que se justificam pela explicação de diversos mecanismos como a deterioração dos sistemas decorrente da idade avançada e ao acúmulo de danos moleculares de origem não programada (Jeckel-Neto, Cunha et al., 2002). Jeckel-Neto (2002) e Farinatti (2002) fizeram um levantamento, por revisão de literatura, de algumas das teorias estocásticas mais conhecidas, como: teoria do erro catastrófico, teoria do uso e desgaste, teoria das proteínas alteradas, teoria das mutações somáticas, teoria da não diferenciação, teoria do estresse oxidativo e dos radicais livres, teoria da lipofuscina, teoria do acúmulo de dentritos e teoria dos eventos de alterações pós-traducionais.

Além das teorias estocáticas, existem também as teorias de natureza sistêmica. Em oposição à primeira teoria, que relaciona a senescência aos eventos orgânicos não programados e aleatórios, nas teorias sistêmicas, o envelhecimento é atribuído às cascatas de acontecimentos fisiológicos integrados e coordenados dos genes e sua interação com o meio (Farinatti, 2002). Jeckel-Neto (2002) e Farinatti (2002) também fizeram um levantamento de algumas das principais teorias sistêmicas descritas na literatura, tais como: teorias metabólicas, teoria da apoptose celular e tecidual, teoria da fagocitose, teoria de alterações neuroendócrinas, teoria do sistema imune e teoria das alterações de expressões genéticas.

Apesar de abordarem explicações distintas para o mesmo fenômeno, grande parte das teorias supramencionadas apresentam como ponto chave as alterações importantes na síntese de proteínas, que por sua vez têm como consequência uma disfunção celular e tecidual dos sistemas 
envolvidos. Digno de nota, é importante enfatizar que não há consenso sobre a temática, e que a ausência de conceitos sólidos sobre o processo de envelhecimento é um empecilho para a formulação de uma teoria matriz que explique e integre as alterações orgânicas decorrentes do processo de envelhecimento (Jeckel-Neto, Cunha et al., 2002).

Embora ainda não exista uma explicação em nível consensual sobre o que gera o envelhecimento humano, é sabido que este é um processo contínuo que acarreta perdas em diversos sistemas fisiológicos (Gallagher, Visser et al., 1997; Lindle, Metter et al., 1997; Connelly, Rice et al., 1999; Frontera, Hughes et al., 2000). Este processo é progressivo e irreversível e pode ser observado a partir da maturação sexual até a morte. O envelhecimento está ligado a fatores biológicos e psicossociais (Litvoc e Brito, 2004) e pode ser classificado em primário, secundário e terciário (Birren e Schroots, 1996).

O envelhecimento primário pode ser compreendido pelo processo de perdas naturais aos quais todos os seres humanos serão submetidos, sendo este predeterminado geneticamente (Jeckel-Neto, Cunha et al., 2002) e referente às alterações, em geral, advindas da idade avançada de uma espécie, neste caso os humanos, sendo este independente das influências ambientais (Spirduso, 2005). No envelhecimento secundário, há uma interação entre o processo natural descrito no envelhecimento primário somado às alterações ambientais (Spirduso, 2005). O envelhecimento secundário é também conhecido como envelhecimento patológico e se refere especificamente às doenças que não são predeterminadas pelo envelhecimento primário, sendo esta soma de fatores naturais e ambientais um catalisador dos processos básicos envolvidos no envelhecimento (Spirduso, 2005). Por fim, o envelhecimento terciário pode ser caracterizado pelas perdas físicas, cognitivas e patológicas acumuladas durante a vida e decorrentes de idade avançada (Birren e Schroots, 1996). Para Jeckel-Neto e Cunha et al., (2002), um sujeito atinge esta idade avançada e pode ser considerado idoso a partir da sexta década de vida.

Existem classificações que diferenciam os indivíduos com idade avançada em relação ao seu nível de funcionalidade. Segundo Shephard (2003), estes indivíduos podem ser classificados nas seguintes categorias funcionais: meia-idade, velhice, velhice avançada e velhice muito avançada.

A partir da quarta década de vida, já são observadas perdas importantes nos sistemas biológicos que se refletem em alterações na funcionalidade. Shephard (2003) classifica como 
meia-idade os sujeitos com idade entre 40 e 65 anos. O mesmo autor descreve que neste intervalo etário, são apresentados declínios funcionais relativos de até 30\% decorrentes de perdas nos principais sistemas biológicos. Após meados da sexta década de vida até os 75 anos de idade, Shephard (2003) classifica as perdas funcionais deste intervalo como velhice. Neste momento, em geral, não são descritas variações extremas na homeostase dos sistemas, entretanto, as perdas funcionais são mais importantes do que no período anterior (Shephard, 2003). Em seguida, o mesmo autor descreve o intervalo de 75 a 85 anos de idade como velhice avançada, e é neste período que as perdas funcionais são exacerbadas e influenciam negativamente as atividades instrumentais da vida diária. Na velhice muito avançada, ou seja, idade >85 anos, grande parte desta população apresentam perdas na independência funcional, o que acarretam em mobilização de familiares ou cuidados especializados de profissionais e instituições apropriados (Shephard, 2003).

Embora, existam outras classificações para descrever o processo de envelhecimento, é relevante destacar que após os 60 anos de idade há um declínio contínuo nas funções fisiológicas em todos os seres humanos. Porém, existem sujeitos que apresentam menor sensibilidade a estes declínios. Sendo assim, observa-se na literatura uma divisão entre envelhecimento cronológico e envelhecimento biológico-funcional (Paschoal, 2002; Shephard, 2003). O primeiro está relacionado à faixa etária do sujeito. Já o segundo representa a forma individual que cada ser responde ao avançar da idade (Farinatti, 2002; Shephard, 2003). Por exemplo, é possível que um

sujeito de 80 anos apresente funcionalidade superior quando comparado a um indivíduo de 65 anos. Os fatores que irão influenciar estão relacionados aos tipos de envelhecimento (primário, secundário e terciário) e, somados ao estilo de vida de cada indivíduo, que extrapolam apenas o envelhecimento etário (Shephard, 2003).

\subsection{Alterações morfofuncionais}

As alterações morfológicas decorrentes do processo de envelhecimento podem influenciar diretamente a funcionalidade dos sistemas fisiológicos (Mcardle, 2008; Hall, 2012). Em relação às alterações cardiovasculares do sujeito com idade avançada, destacam-se as alterações referentes ao próprio sistema cardiovascular e suas interações com o sistema 
respiratório, às modificações do sistema nervoso, em especial o autônomo (Machado e Campos, 1993), e às alterações de composição corporal, como a perda progressiva de massa magra (Rosenberg, 1989) e o concomitante aumento de massa gorda (Waters e Baumgartner, 2011).

O sistema cardiovascular é compreendido pelo coração e os condutos vasculares orgânicos conhecidos como: artérias, arteríolas, capilares, veias e vênulas (Netter, 2008). Este sistema tem como objetivo realizar a manutenção da homeostase (Mcardle, 2008; Hall, 2012), pois a circulação sanguínea permite a comunicação entre os demais sistemas fisiológicos a partir do transporte de nutrientes, hormônios, células de defesa, produtos metabólicos e seus tampões, além da facilitação da termorregulação (Velloso e Di Lorenzo, 2004). Esta interação dinâmica e constante do sistema cardiovascular com diversos outros componentes pode dificultar a distinção das alterações advindas do processo de envelhecimento e das alterações provocadas por patologias, já que nesta população (>60 anos) mais de 50\% dos indivíduos apresentam alguma cardiopatia (Velloso e Di Lorenzo, 2004). O processo de envelhecimento do sistema cardiovascular ocorre por meio do próprio desgaste dos órgãos e tecidos envolvidos e por meio das alterações estruturais que fazem a manutenção deste sistema (Affiune, 2002; Velloso e Di Lorenzo, 2004).

Uma alteração morfológica importante do sistema cardiovascular é o aumento do coração. Diferentemente dos demais tecidos do corpo, este órgão aumenta com o avançar da idade em aproximadamente 1,0 e 1,5 grama por ano de vida, nos homens e nas mulheres, respectivamente (Velloso e Di Lorenzo, 2004). Segundo Affiune (2002) o enrijecimento arterial e outros componentes que influenciam o aumento da resistência vascular periférica, decorrentes do envelhecimento, proporcionam um trabalho cardíaco aumentado, tendo como consequência a hipertrofia concêntrica deste órgão. O mesmo autor se refere à outra adaptação importante que é o aumento da espessura do septo interventricular, que não é acompanhada pela parede do ventrículo esquerdo. Ainda no miocárdio, pode-se observar degeneração deste tecido, maior depósito de gordura atrial e aumento de colágeno (Affiune, 2002).

Além do miocárdio, o processo de envelhecimento influencia alterações importantes no endocárdio e no pericárdio. No primeiro, a partir da sexta década de vida, há infiltração de gordura, mais evidente na câmara cardíaca esquerda, e ocorre também um espessamento desta 
região com aumento de fibras colágenas. Após a oitava década de vida, as alterações escleróticas (i.e., maior rigidez tecidual) são observadas em todas as câmaras (Kaufmann, De Figueiredo et al., 2001; Affiune, 2002). Já no pericárdio, as modificações decorrentes do desgaste progressivo culminam em um espessamento generalizado e aumento da taxa de gordura local (Affiune, 2002). A comunicação do coração com os vasos sanguíneos é precedida de valvas específicas que também se modificam com o processo de envelhecimento. $\mathrm{O}$ avançar da idade implica em calcificação e degeneração das valvas mitrais e aórticas (Kaufmann, De Figueiredo et al., 2001). Ademais, há um aumento da rigidez e formação de nódulos no bordo de fechamento das valvas tricúspide e mitral.

Os dutos vasculares também apresentam alterações decorrentes do processo de envelhecimento. As modificações ocorrem em nível estrutural e apresentam implicações importantes na fisiologia vascular. Com o avançar da idade, há um espessamento do endotélio e concomitante calcificação da musculatura lisa, aumento de depósito de colágeno, e isto acarreta reduções na propagação do conteúdo sanguíneo, menor complacência e aumento da resistência vascular periférica (Kaufmann, De Figueiredo et al., 2001).

O funcionamento do sistema cardiovascular é dependente de um bom funcionamento de sua condutibilidade elétrica. A contração do músculo cardíaco é precedida de impulsos elétricos originados no nódulo sinusal, sendo esta estrutura responsável por marcar o ritmo dos impulsos elétricos que darão origem à contração deste músculo (Mcardle, 2008; Hall, 2012). O envelhecimento e a redução das células do nódulo sinusal impõem alterações na condução cardíaca que podem comprometer o nódulo atrioventricular e o feixe de his (Affiune, 2002; Netter, 2008). Estas modificações na condução elétrica do coração favorecem o surgimento de arritmias e doença do nódulo sinusal (Costa, Porto et al., 2001; Affiune, 2002). Outra modificação que contribui para alteração do ritmo sinusal é a infiltração de gordura entre as células do nódulo sinusal e a musculatura subjacente (Costa, Porto et al., 2001; Affiune, 2002). Embora estas adaptações de condução possam gerar arritmias benignas, em diversos casos, os distúrbios do ritmo cardíaco podem desencadear problemas mais graves, como bloqueios de ramos com consequentes bloqueios atrioventriculares, conduzindo o indivíduo a síncopes súbitas e convulsões (Costa, Porto et al., 2001). 
Os estímulos cardiovasculares adequados dependem da interação entre sistema cardiovascular e sistema nervoso autônomo (Machado e Campos, 1993). Um indivíduo idoso apresenta níveis elevados de norepinefrina, o que pode ocasionar prejuízo nos receptores beta e assim prejudicar a contratibilidade do miocárdio (Affiune, 2002). Por exemplo, durante o esforço físico, a resposta fisiológica natural para uma demanda sanguínea aumentada é o aumento concomitante do débito cardíaco. Em adultos saudáveis, isto ocorre por aumento da frequência cardíaca. Entretanto, nos indivíduos idosos, esta estimulação simpática é afetada pela redução de receptores beta-adrenérgicos. Sendo assim, com o envelhecimento, o aumento do débito cardíaco frente ao esforço físico ocorre por dilatação cardíaca que implica em aumento do volume de ejeção (Affiune, 2002). Ademais, são observados déficits na função vasodilatadora e na sensibilidade dos barorreceptores desta mesma população (Affiune, 2002).

Em indivíduos idosos, outra adaptação importante é a alteração da composição corporal. Com o avançar da idade, observa-se uma perda progressiva de massa muscular esquelética (Rosenberg, 1989) e concomitante aumento da massa gorda (Newman, Kupelian et al., 2003). A perda importante de massa magra durante o processo de envelhecimento é denominada sarcopenia (Rosenberg, 1989). Já a perda desta massa magra, somada ao aumento da massa gorda, é reconhecida como obesidade sarcopênica (Waters e Baumgartner, 2011).

A sarcopenia está diretamente associada à redução de força e potência muscular em indivíduos idosos (Roubenoff e Castaneda, 2001). Atualmente, alguns cálculos baseados na composição corporal e dados antropométricos possibilitam a identificação da sarcopenia. Dentre os mais utilizados, está o índice proposto por Baumgartner (1998), que divide a massa livre de gordura do esqueleto apendicular, medida por DEXA, pela estatura elevada ao quadrado. O valor de corte para este índice é de 2 desvios padrão abaixo dos dados de referência de uma população de adultos jovens norte americanos. Embora seja reconhecido, trata-se de um método sofisticado de avaliação da composição corporal, que em muitos casos torna-se inviável. Ademais, não há consenso em relação às avaliações clínicas da sarcopenia.

Na obesidade sarcopênica, o cálculo leva em consideração a musculatura esquelética e a massa gorda do indivíduo. Antes deste tipo de abordagem, eram considerados sarcopênicos apenas os idosos com massa corporal total baixa, o que excluía os indivíduos com excesso de 
gordura corporal. Portanto, os sujeitos obesos com massa magra inadequada são classificados como obesos sarcopênicos (Newman, Kupelian et al., 2003). Sugere-se que esta condição seja um indicador de saúde mais importante do que a classificação da obesidade ou da sarcopenia de forma isolada (Prado, Lieffers et al., 2008; Prado, Wells et al., 2012).

As mudanças na composição corporal têm origem multifatorial. As enfermidades ou a inatividade física podem levar a reduções da massa muscular, enquanto a massa gorda é preservada (Han, Tajar et al., 2011). A combinação de redução na atividade física, uma menor taxa metabólica de repouso e ingestão inalterada de alimentos pode aumentar a probabilidade do processo de sarcopenia (Elia, Ritz et al., 2000). Além disso, há uma possível contribuição das alterações hormonais decorrentes do envelhecimento, principalmente as reduções de hormônios de crescimento e testosterona. O indivíduo idoso também apresenta menor resposta de hormônios da tireoide, responsáveis pelo metabolismo, e da leptina que é um importante regulador da forme (Reaven, 1988). O somatório destes diversos fatores pode conduzir o indivíduo a um círculo vicioso progressivo tanto de perda de massa magra como de acúmulo de gordura. A redução de massa muscular esquelética, além de proporcionar perda funcional da força (Roubenoff e Castaneda, 2001), proporciona também uma redução no tecido responsivo à insulina, representando uma capacidade metabólica reduzida (Prado, Wells et al., 2012), aumentando o risco de resistência à insulina e de síndrome metabólica (SM). Com maior acúmulo de gordura, existe aumento de citocinas pro inflamatórias, que por sua vez promovem resistência à insulina. Notavelmente, o acúmulo de gordura, nesta faixa etária, ocorre de forma mais ampla na região intra-abdominal do que de forma subcutânea (Cetin e Nasr, 2014). 


\subsection{Tecido adiposo e envelhecimento}

O envelhecimento está associado a mudanças consideráveis na composição corporal. De 20 a 70 anos de idade, observa-se a redução de massa livre de gordura por pelo menos $40 \%$ (Flynn, Nolph et al., 1989; Baumgartner, Stauber et al., 1995; Muller, Elahi et al., 1996; Gallagher, Visser et al., 1997). Concomitantemente, há um aumento de gordura corporal que atinge o pico entre 60 e 70 anos de idade. O envelhecimento também está associado com a redistribuição destes componentes. Por exemplo, há um aumento de gordura intra-abdominal em relação à subcutânea e maior redução da massa magra periférica quando comparada à central (Beaufrere e Morio, 2000), justificando assim o modelo de avaliação de sarcopenia proposto por Baumgartner (Baumgartner, Koehler et al., 1998). Além da sarcopenia, este acúmulo de gordura, quando excessivo, pode transformar um indivíduo normal em obeso.

A etimologia da palavra obesidade tem a origem grega Pimelose, sendo Pimele $=$ gordura + Ose $=$ processo mórbido. Segundo a OMS, a obesidade pode ser definida como o excesso de gordura corporal acumulada com implicações à saúde (Organization, 2002). Portanto, os métodos que avaliam a composição corporal são de extrema importância. Atualmente, os métodos (padrão ouro) que permitem a análise da composição corporal, são: DEXA e pesagem hidrostática. Embora apresentem resultados satisfatórios para a análise da composição corporal, tornam-se inviáveis para avaliações clínicas em populações numerosas (Villareal, Apovian et al., 2005). Neste sentido, o IMC torna-se um indicador de obesidade de baixo custo e fácil implementação, sobretudo para sujeitos idosos, pois se sabe que, nesta população, quando há aumento da massa corporal total, normalmente é uma consequência do acúmulo de gordura no organismo (Villareal, Apovian et al., 2005).

Atualmente, o número de pessoas obesas tem aumentado em diversos países do mundo. Nos últimos 30 anos, a prevalência de obesidade (IMC >30) tem aumentado em todas as categorias de idade de estadunidenses (Kuczmarski, Flegal et al., 1994; Flegal, Carroll et al., 1998; Hedley, Ogden et al., 2004). A quantidade de pessoas obesas com mais de 60 anos tem aumentado de forma importante, tanto de forma relativa quanto absoluta. Em 1991, 14,7\% de pessoas nos EUA que tinham entre 60 e 69 anos de idade e 11,4\% daqueles com mais de 70 anos eram obesos (Mokdad, Serdula et al., 1999). Dez anos depois, a prevalência de obesidade nestes 
grupos de idade aumentou para 22,9\% e 15,5\%, respectivamente (Mokdad, Bowman et al., 2001). No Brasil, o número de pessoas obesas triplicou entre 1974 e 1996 (Monteiro e Conde, 2000), sendo considerados com excesso de peso ou obesos 47,3\% dos homens e 38,8\% das mulheres (Gigante, Barros et al., 1997; Gigante, Moura et al., 2009). Na população de idosos, Cabrera e Jacob Filho (2001) analisaram 847 brasileiros de ambos os sexos (>60 anos) e observaram que $9,3 \%$ dos homens e $23,8 \%$ das mulheres eram obesos.

Dados de estudos populacionais demonstram que a média da massa corporal e IMC aumentam gradualmente durante a maior parte da vida adulta e atingem valores pico entre $50 \mathrm{e}$ 60 anos de idade em homens e mulheres (Kuskowska-Wolk e Rössner, 1990; Flegal, Carroll et al., 1998; Mokdad, Bowman et al., 2001; Flegal, Carroll et al., 2002; Hedley, Ogden et al., 2004). Os mesmos estudos também demonstram que após a sexta década de vida, há uma tendência ao decréscimo destes índices. Entretanto, estas observações foram obtidas em estudos transversais, sendo este um possível viés, pois as pessoas obesas apresentam maiores taxas de mortalidade em idades mais jovens (Manson, Willett et al., 1995). Portanto, a mortalidade prematura de jovens obesos e adultos de meia idade podem mascarar o decréscimo na média da massa corporal e IMC nos sujeitos sobreviventes que chegaram até a terceira idade (Villareal, Apovian et al., 2005). De fato, os dados de estudos longitudinais sugerem que a massa corporal e o IMC não se alteram ou são reduzidos de forma modesta nos idosos (Kannel, Gordon et al., 1979; Rissanen, Heliövaara et al., 1987; Grinker, Tucker et al., 1995; Fogelholm, Kujala et al., 2000). 


\subsection{CONSEQUÊNCIAS DO EXCESSO DE GORDURA CORPORAL}

\subsubsection{Consequências funcionais}

É sabido que o processo de envelhecimento humano implica em redução progressiva da funcionalidade. Este fenômeno é explicado parcialmente pela perda de massa livre de gordura, aumento de disfunções, artrite e mudanças comportamentais (Ensrud, Nevitt et al., 1994; Jordan, Luta et al., 1996). Estas complicações afetam a qualidade de vida e as atividades da vida diária do idoso (Ensrud, Nevitt et al., 1994; Villareal, Banks et al., 2004). Na terceira idade, a fragilidade ocorre quando há prejuízos graves na função fisiológica e consequente redução de suas reservas (Ory, Schechtman et al., 1993). Esta condição está associada a limitações em atividades da vida diária. Além disso, sabe-se que o excesso de gordura corporal contribui para diversas consequências adversas no organismo humano (Villareal, Apovian et al., 2005). Sendo assim, estudos demonstraram haver relação inversa entre índices de funcionalidade com sobrepeso e obesidade em sujeitos com idade avançada (Sarkisian, Liu et al., 2000; Villareal, Banks et al., 2004; Blaum, Xue et al., 2005).

Um estudo conduzido por Villareal et al (2004) demonstrou que $96 \%$ de idosos com o IMC >30 eram frágeis, pois apresentavam baixo consumo de oxigênio e capacidade de realizar atividades da vida diária prejudicada (Jette e Cleary, 1987). Recentemente, Hergenroeder et al (2011) avaliaram a função física de 50 mulheres sedentárias (>50 anos) divididas por meio das classificações do IMC (peso normal, sobrepeso, obesidade grau I, II e III). Neste estudo, a funcionalidade foi avaliada de duas maneiras, sendo uma autorrelatada e a outra por uma bateria de testes. Os testes funcionais aplicados foram: caminhada de 6 minutos, tempo para se levantar de uma cadeira e velocidade da marcha. Ao compararem as classificações do IMC, as mulheres obesas apresentaram menor função física autorrelatada do que as mulheres com peso normal e sobrepeso. Em relação aos testes aplicados, as mulheres obesas apresentaram menor velocidade da marcha, caminharam menor distância e apresentaram os piores escores para levantar-se de uma cadeira. Os autores concluíram que o IMC foi inversamente proporcional ao desempenho funcional (Hergenroeder, Brach et al., 2011).

Em um estudo longitudinal, um grupo de pesquisa norte americano, observou o IMC e a limitação de mobilidade de homens e mulheres com idade avançada (70 a 79 anos). 
Notavelmente, o IMC foi calculado em idades pregressas, por autorrelato da massa corporal total, e em seguida foi avaliado se o aumento neste índice durante a vida foi um preditor de alteração na mobilidade de 2.845 sujeitos. Neste estudo, os autores acompanharam os relatos de limitação da mobilidade 2 vezes por ano durante 7 anos. Os autores concluíram que o aumento precoce do IMC, em classificação de sobrepeso ou obesidade, contribui para um risco aumentado de limitação de mobilidade em idades avançadas (Houston, Ding et al., 2009). Em outro estudo, conduzido apenas em mulheres (70 a 79 anos), a obesidade foi associada com marcadores de risco de fragilidade aumentados determinados principalmente por fraqueza, lentidão e exaustão (Blaum, Xue et al., 2005).

Outros estudos que avaliaram a capacidade funcional por meio da mobilidade auto reportada, em idosos acima do peso e eutróficos, encontraram mobilidade reduzida para os sujeitos mais pesados (Hubert, Bloch et al., 1993; Ensrud, Nevitt et al., 1994; Galanos, Pieper et al., 1994; Launer, Harris et al., 1994; Jenkins, 2004). Para Sarkisian et al (2000) a identificação da obesidade é um de oito fatores de risco modificáveis que apresentam predição para o declínio funcional em atividades básicas ou vigorosas entre mulheres idosas. Segundo Apovian et al (2002), a cada acréscimo de $3 \mathrm{~kg} / \mathrm{m}^{2}$ no IMC de indivíduos idosos, há um decréscimo de 1 ponto em testes de capacidade funcional. Adicionalmente, o excesso de gordura corporal e IMC >30 estão associados com disfunção física e são preditivos de um declínio no status funcional e incapacidade futura (Visser, Langlois et al., 1998; Davison, Ford et al., 2002; Jensen e Friedmann, 2002). Além disso, idosos com IMC >30 representam um custo aumentado em cuidados com a saúde quando comparados aos não obesos (Zizza, Herring et al., 2002).

Além das análises supracitadas, a distribuição da gordura corporal parece ser um indicador importante da mobilidade. Angleman et al (2006) acompanharam por 5 anos um grupo de 1.030 mulheres e 888 homens (55 a 74 anos) e encontraram associação importante da CC e incapacidade física. Os autores concluem que com o aumento da CC, que é um marcador de obesidade abdominal, é possível predizer um risco para aumento da incapacidade física. Ademais, os autores sugerem a avaliação pela $\mathrm{CC}$ como preditor de riscos relacionados à obesidade para monitoramento epidemiológico e tratamentos clínicos (Angleman, Harris et al., 2006). 


\subsubsection{Consequências cardiovasculares e metabólicas}

É bem estabelecido que a obesidade esteja associada com o aumento de doenças cardiovasculares, dislipidemia, hipertensão, diabetes tipo 2 e mortalidade (Shields e Tjepkema, 2006). O indivíduo obeso apresenta risco aumentado para desenvolver doenças cardiovasculares, como: doença arterial coronariana, acidente vascular cerebral, infarto do miocárdio, hipertensão arterial, fibrilação atrial, anginas e insuficiência cardíaca congestiva (Mancini, Geloneze et al., 2010).

Ao observar homens e mulheres com diabetes do tipo 2, dados do Framingham Heart Study demonstraram que o risco para doença cardiovascular era maior em indivíduos obesos do que nos que apresentavam valores normais para a massa corporal (Hubert, Feinleib et al., 1983). Balkau et al (2007) demonstraram que o IMC e a CC são medidas preditivas para o risco de doenças cardiovasculares e diabetes tipo 2. Ao determinar o risco médico da obesidade, PiSunyer (2009) observou o IMC e a hipertensão arterial de uma amostra composta por mais de 30 mil sujeitos, de ambos os sexos, sendo o risco para hipertensão maior para os sujeitos que apresentaram alterações (aumento) do IMC durante duas décadas de análise. Chughtai et al (2011) observaram a composição corporal de 441 indivíduos (55 a 85 anos) com alto risco cardiovascular. Os autores concluíram que elevadas taxas de gordura intraperitoneal (i.e., visceral) está associada ao aumento do espessamento da aorta torácica, sendo esta, uma condição que promove eventos cardiovasculares adversos (Chughtai, Morgan et al., 2011).

Alguns estudos sugerem que há uma associação forte entre obesidade e a prevalência de algumas condições metabólicas (Penn, Fischer et al., 2009; Hirani, 2011). Entretanto, existem estudos que sugerem que a associação entre obesidade e risco metabólico pode se tornar forte ou fraca com a idade, dependendo do fator de risco observado (Alexander, Landsman et al., 2008; Vyssoulis, Karpanou et al., 2011). Recentemente, um estudo conduzido por pesquisadores canadenses investigou a influência da idade na relação entre obesidade e morbidades associadas ao envelhecimento (Canning, Brown et al., 2014). Os autores apresentaram associação mais forte entre obesidade e condição metabólica prevalente, diabetes e dislipidemia, em sujeitos jovens e de meia idade do que em idosos (Canning, Brown et al., 2014). Adicionalmente, o aumento da gordura intramuscular e intra-hepática em indivíduos idosos está associado à resistência a 
insulina (Cree, Newcomer et al., 2004). Já Zamboni et al (2005) afirma haver um crescimento do número de comorbidades com a obesidade, independentemente da idade.

As doenças mais fortemente associadas com a obesidade são a SM e diabetes tipo 2 (Han, Tajar et al., 2011). Estudos têm mostrado que, em idosos, a obesidade mensurada pela CC está associada com hiperglicemia e dislipidemia (Haarbo, Hassager et al., 1989; Corona, Mannucci et al., 2009). As anormalidades metabólicas podem ocorrer em pessoas idosas por meio de mecanismos complexos que envolvem um declínio em hormônios sexuais pelo envelhecimento. Por exemplo, o hipogonadismo de início tardio, em homens, o qual é mais comum naqueles que são obesos, está relacionado à SM (Corona, Mannucci et al., 2009). Estes mecanismos também são complexos em mulheres, pois os hormônios femininos podem contribuir para a manutenção do tecido adiposo. Portanto, as mulheres pós-menopáusicas, que são obesas, têm maiores concentrações de estrogênio do que as não obesas e isto pode levar a anormalidades metabólicas (Cignarella, Kratz et al., 2010). Por outro lado, níveis elevados de estrogênio em obesas pósmenopáusicas podem protegê-las contra a osteoporose, aumentando a densidade mineral óssea. Os indivíduos idosos com massa corporal elevada possuem mais tecido adiposo, especialmente aqueles que se tornam obesos nas fases iniciais da vida, que apresentam um grande risco de osteoartrite de joelho (Felson, Anderson et al., 1988; Gelber, Hochberg et al., 1999). Por fim, a obesidade na população idosa, pode contribuir para incapacidade e problemas físicos (Zamboni, Mazzali et al., 2005), fatores de risco cardiovasculares (Gelber, Hochberg et al., 1999; Turcato, Bosello et al., 2000), hipertensão (Iwao, Iwao et al., 2000) e determinados tipos de câncer, mais comuns em idosos com a CC aumentada. 


\subsection{Envelhecimento e marcadores cardiometabólicos}

As doenças comuns da terceira idade são melhores tratadas e controladas se diagnosticadas precocemente, sendo elas detectadas e classificadas de acordo com os seus respectivos marcadores de risco. As mais diversas doenças que acometem os sistemas cardiovascular e metabólico são referenciadas e percebidas por marcadores de risco sanguíneos conhecidos, como por exemplo: perfil lipídico, proteína C-reativa (PCR), pressão arterial, insulinemia e glicemia. A análise destas variáveis demonstra ser uma alternativa eficiente no monitoramento dos níveis de saúde cardiometabólica (Lima, Moreira et al., 2005; Fernandes, Christofaro et al., 2011; Vieira, Carvalho et al., 2011).

Níveis elevados de concentrações de lipoproteína de baixa densidade (LDL) na corrente sanguínea fazem com que essa molécula entre na lacuna subendotelial e, uma vez lá inserida, seja oxidada por radicais livres. Esse LDL oxidado provoca danos às estruturas próximas, fazendo com que diversos monócitos sejam recrutados para sua eliminação e formem as denominadas "células espumosas", após a absorção deste LDL oxidado. Estas células liberam substâncias tóxicas causando lesão no endotélio, hipertrofia e hiperplasia do músculo liso. Esse processo acarreta também a ativação e agregação de plaquetas, pois prejudica a produção/disponibilidade do óxido nítrico, desencadeando redução da luz do vaso e gerando isquemia de tecidos e órgãos. Com a evolução desse processo inflamatório, a doença se consolida e progride até fases mais avançados da aterosclerose (Fernandes, Christofaro et al., 2011).

Outra variável que também é utilizada no monitoramento da saúde cardiometabólica é a PCR. Esta proteína faz parte da família das pentraxinas, assim denominadas porque são formadas por cinco unidades iguais, as quais estão dispostas de forma não covalente como pentâmeros cíclicos em torno de uma cavidade para a ligação de cálcio. A PCR dá início a diversas funções biológicas, incluindo precipitação, fagocitose, opsonização e aglutinação bacteriana. Entre as atividades de maior importância, destacam-se: a habilidade de se unir a substratos, ligando-se e modulando a função fagocitária dos leucócitos. Essas funções sugerem que a PCR tem papel fundamental em mecanismos imunológicos e inflamatórios e evidências indicam que diversas doenças cardiovasculares acontecem não somente devido ao depósito excessivo de colesterol 
(hipótese lipídica), mas também decorrente de processo inflamatório crônico (Vieira, Carvalho et al., 2011).

Segundo dados experimentais, o processo inflamatório está fortemente relacionado na origem, na evolução e na ruptura da placa aterosclerótica (Lima, Moreira et al., 2005). Nesse contexto, a PCR é classificada como marcador inflamatório validado como preditor de risco cardiovascular em indivíduos aparentemente saudáveis. Essa predição é independente dos níveis de colesterol plasmático e da presença de outros fatores de risco para a aterosclerose. Concentrações de até $3 \mathrm{mg}$ de PCR por litro de plasma sanguíneo classificam os indivíduos fora do grupo de alto risco, de acordo com o seu status inflamatório, sendo este o valor utilizado como ponto de corte para identificar ou não, o alto risco cardiometabólico (Lima, Moreira et al., 2005).

A pressão arterial também é um marcador de risco cardiometabólico. A pressão arterial é definida como a força exercida pelo sangue contra as paredes das artérias durante um ciclo cardíaco, configurando-se em uma síndrome multifatorial e multicausal associada a distúrbios hormonais e metabólicos. Os aumentos na pressão arterial que acompanham o passar dos anos ocorrem em função de alterações vasculares, como a perda de tecido elástico, acúmulo de tecido conjuntivo e depósito de cálcio, tendo como consequência o enrijecimento e espessamento de artérias e arteríolas (Negrão e Barretto, 2005).

A medida da pressão arterial pode classificar o indivíduo em normotenso, pré-hipertenso ou hipertenso. Estão inseridos entre os normotensos os sujeitos que apresentarem valores de pressão arterial < 120 e $80 \mathrm{~mm} \mathrm{Hg}$ para pressão arterial sistólica (PAS) e diastólica (PAD), respectivamente. Os indivíduos pré-hipertensos são os que apresentam níveis de PAS e/ ou PAD entre 120-139 mm Hg e entre 80-89 mm Hg, respectivamente. Apesar desses indivíduos não estarem enquadrados em uma categoria de pressão considerada como patológica - como a hipertensão - estratégias de controle da pressão arterial são necessárias para esta população, uma vez que estes têm 2 vezes mais chance de desenvolver hipertensão do que indivíduos com níveis de pressão arterial inferiores a 120/80 mm Hg (Chobanian, Bakris et al., 2003). Já os hipertensos, são aqueles que apresentam $\geq 140$ e $90 \mathrm{~mm} \mathrm{Hg}$ para PAS e/ou PAD, respectivamente.

As variáveis insulinemia (i.e, taxa de insulina no sangue) e glicemia (i.e, taxa de glicose no sangue) também estão envolvidas nos níveis de saúde do sistema cardiometabólico. Embora o 
defeito primário no desenvolvimento de diabetes do tipo 2 ainda seja pouco conhecido, impedimentos na ação insulínica no músculo esquelético têm sido claramente estabelecidos como defeito precoce na patogênese do diabetes insulinodependente. O transporte e metabolismo da glicose são regulados pela via de sinalização insulínica. O sinal de transdução insulínico é mediado por uma série de fosforilações em cascatas, sendo que a estimulação insulínica induz uma rápida fosforização do receptor de insulina e seus substratos, incluindo substrato-1 do receptor de insulina e seus resíduos de tirosina seguida pela ativação da enzima PI 3-kinase (Krook, Wallberg-Henriksson et al., 2004).

A partir da cascata insulínica ocorre então a translocação da molécula transportadora de glicose 4 (GLUT4), do meio intracelular para a membrana celular (Krook, Wallberg-Henriksson et al., 2004). Como no diabetes insulinodependente a translocação do GLUT4 e a função celular de captação de glicose estão prejudicadas, há o quadro de hiperglicemia crônica. A causa da resistência à insulina pode estar relacionada a diversos fatores, onde uma hiperinsulinemia compensatória inicial pode potencializar a manutenção da glicemia em valores normais. Todavia, em estágios mais avançados do diabetes isso pode não ocorrer de forma satisfatória, resultando no quadro de intolerância à glicose, levando o indivíduo ao diabetes do tipo 2 descompensado (Hawley e Houmard, 2004).

Segundo a Associação Americana de Diabetes (2010), os procedimentos adotados para o diagnóstico são as medidas da glicose sanguíneas, após jejum de oito e doze horas, e o teste de tolerância à glicose, após a administração de 75 gramas de glicose anidra por via oral, com medidas de glicose nos tempos 0 e 120 minutos após a ingestão. Os critérios recentes para a classificação são: para normalidade glicemia em jejum < 100 mg.dL-1 , entre 100-125 mg.dL-1 para pré-diabetes e para diabetes $\geq 126 \mathrm{mg}$.dL-1. 


\section{7. ÍNDICES DA GORDURA CORPORAL}

\subsection{1. Índice de Massa Corporal}

Ao observar o crescimento e o desenvolvimento humano, ainda no século XIV, o matemático belga Adolf Quetelet propôs um índice baseado na interdependência do aumento da massa corporal com a estatura. No século seguinte, o mesmo cálculo foi denominado de índice de massa corporal (Eknoyan, 2008). Atualmente, o IMC é um dos índices mais utilizados para relativizar a massa corporal de um indivíduo. Neste índice, o sujeito pode ser classificado em: abaixo do peso (IMC $<18,5 \mathrm{~kg} / \mathrm{m}^{2}$ ), normal (IMC entre 18,5 e $24,9 \mathrm{~kg} / \mathrm{m}^{2}$ ), sobrepeso (IMC entre 25 e $29,9 \mathrm{~kg} / \mathrm{m}^{2}$ ) e obeso (IMC $\geq 30 \mathrm{~kg} / \mathrm{m}^{2}$ ). Trata-se de uma ferramenta simples e de fácil aplicação calculada a partir da razão entre a massa corporal $(\mathrm{kg})$ e a estatura ao quadrado $\left(\mathrm{m}^{2}\right)$ (Guedes, 2006).

Apesar de ser um cálculo antigo, foi apenas na segunda metade do século XX que surgiu o interesse em investigar a associação do IMC com problemas cardiovasculares. Dentre os estudos incipientes, destaca-se o conduzido por Rabkin et al (1977), que acompanharam por mais de duas décadas e meia, 3.983 adultos jovens do sexo masculino. Os autores verificaram correlação positiva entre o IMC e o surgimento de isquemia e infarto agudo do miocárdio, insuficiência cardíaca congestiva e morte-súbita. Estudos mais recentes investigaram o poder preditivo deste índice para problemas cardiovasculares. Rezende et al (2006) investigaram a associação do IMC com fatores de risco cardiovascular de sujeitos com idades variadas (21 a 76 anos). Independentemente da idade, os autores observaram relação positiva do IMC com a glicemia, triglicérides e pressão arterial.

Ao examinar uma amostra representativa de tailandeses, Aekplakorn et al (2006) propuseram um ponto de corte do IMC para dislipidemia, diabetes do tipo 2 e hipertensão arterial de $23 \mathrm{~kg} / \mathrm{m}^{2}$ e $25 \mathrm{~kg} / \mathrm{m}^{2}$, para homens e mulheres, respectivamente. Recentemente, Gharakhanlou et al (2012) associaram a prevalência de sobrepeso e obesidade, medida pelo IMC, com fatores de risco cardiovascular de iranianos de ambos os sexos e diferentes faixas etárias. Nos homens $(\mathrm{n}=991)$ e nas mulheres $(\mathrm{n}=1.188)$, o IMC correlacionou-se de forma positiva com o colesterol total, triglicérides e LDL. O mesmo índice correlacionou-se de forma negativa com a lipoproteína de alta densidade (HDL). No mesmo ano, outro estudo com 2.867 taiwaneses de 
ambos os sexos (>18 anos) observou correlação positiva entre o IMC e o percentual de gordura corporal, medida por bioimpedância. Observou-se também correlação positiva entre o IMC e fatores de risco cardiometabólico (glicemia, triglicérides, colesterol total e pressão arterial). Ademais, os autores ressaltam que o IMC aumentado está associado a fatores de risco da SM, em especial nas mulheres (Chuang, Li et al., 2012).

É importante ressaltar que, apesar dos estudos supramencionados apresentarem grande aplicabilidade do IMC, este cálculo não leva em consideração a composição corporal de um indivíduo. Ou seja, um sujeito com excesso de massa magra pode ser classificado como sobrepesado ou até mesmo obeso (Guedes, 2006). Contudo, este índice está bem estabelecido como ferramenta importante na avaliação clínica da massa corporal de diversas populações, inclusive de idosos (Panel, 1998).

\subsubsection{Circunferência de Cintura e Relação Cintura Estatura}

A CC é uma medida que leva em consideração a gordura concentrada na região abdominal (Guedes, 2006), padrão androide. É importante observar a distribuição de gordura nesta região, pois está relacionada às complicações a saúde cardiovascular e metabólica (Thomas, Ho et al., 2004). Segundo Kuk et al (2006), o acúmulo excessivo de gordura intraperitoneal é considerado um fator de risco independente para o desenvolvimento de doenças cardiovasculares.

Ao observar a associação da CC e IMC com o risco de doenças cardiovasculares em 13.817 chineses ( $\geq 18$ anos) de ambos os sexos, Li et al (2013) demonstraram que há associação independente, destas variáveis antropométricas, com os fatores de risco observados, pressão arterial, dislipidemia e insulinemia. Para uma medida clínica mais robusta, os mesmos autores sugerem a utilização da CC paralelamente ao IMC. Em outro estudo, que classificou 28.886 sujeitos espanhóis (35 a 74 anos) de ambos os sexos, em obesidade geral e abdominal, por IMC e $\mathrm{CC}$, respectivamente, constatou-se que a CC elevada foi superior na predição de diabetes, hipertensão e dislipidemia. Os autores atribuíram os achados à capacidade da CC em identificar acúmulos excessivos de gordura na região abdominal, o que está relacionado às alterações negativas para a saúde cardiometabólica (Félix-Redondo, Grau et al., 2013). Recentemente, Dos Santos et al (2014) observaram o perfil lipídico, insulinemia, glicemia, PCR e pressão arterial de 
149 mulheres idosas brasileiras (>60 anos) e encontraram associação destes fatores de risco com a CC aumentada.

Outro índice da adiposidade corporal que leva em consideração a obesidade abdominal é a RCE (Hsieh e Yoshinaga, 1995). Ao associar a RCE, relação cintura quadril (RCQ) e IMC com pressão arterial, colesterol total e glicemia, em uma amostra composta por 1.077 japoneses (20 a 78 anos), Hsieh e Yoshinaga (1995) encontraram melhor poder preditivo para a RCE e os fatores de risco analisados. Em análise mais recente, Rodrigues et al (2010) compararam a associação de índices da adiposidade corporal (RCE, RCQ e IMC) e a associação com SM de 1.662 brasileiros (25 a 64 anos). Com base nos resultados obtidos, os autores sugerem que a RCE apresentou-se como o melhor indicador para hipertensão arterial e SM. Ademais, o estudo aponta um ponto de corte da RCE para a SM de 0,53 e 0,54, em homens e mulheres, respectivamente (Rodrigues, Baldo et al., 2010). Ou seja, possivelmente os limítrofes para a CC estejam compreendidos próximos a $50 \%$ da estatura de um sujeito.

Knowles et al (2011) observaram a associação do IMC, CC, RCQ e RCE como preditores de risco cardiometabólico de uma amostra composta por 1.518 adultos peruanos. Independentemente do índice da adiposidade corporal utilizado, os autores concluíram que a prevalência dos fatores de risco da SM é aumentada quando há aumento nestes índices. Vale ressaltar que houve análise estatística não paramétrica, pois a amostra foi distribuída em curva não normal, sendo assim, reduz-se a representatividade destes dados em uma população ou outra amostra semelhante. No ano seguinte, Wakabayashi (2012) relacionou índices de adiposidade com fatores de risco cardiovascular de uma amostra composta por 17.791 japoneses $(35$ a 70 anos). Identificou-se que a RCE elevada aumentou o risco relativo dos indivíduos apresentarem algum fator de risco cardiovascular. Ademais, o estudo ressalta que as associações entre obesidade e risco cardiometabólico são mais fortes em mulheres jovens quando comparadas aos homens da mesma idade, contudo esta diferença é reduzida em idades avançadas (Wakabayashi, 2012).

\subsection{3. Índice de Adiposidade Corporal}

Em alternativa ao IMC, Bergman et al (2011) propuseram um índice, que representasse a gordura corporal, denominado IAC. Este índice pode ser usado para refletir o percentual da 
massa gorda de adultos, de ambos os sexos e diferentes etnias, sem correções numéricas. O IAC foi validado a partir da análise da composição corporal, por meio do DEXA, de americanos de diferentes etnias. O cálculo leva em consideração a circunferência de quadril e a altura do indivíduo e reflete uma relação forte com a gordura corporal, medida pelo DEXA $(r=0,85)$. Segundo os autores, este índice é sugerido para análises clínicas em situações onde não há instrumentos de avaliação para a composição corporal. Contudo, a temática ainda é incipiente no que diz respeito ao relacionamento deste índice com fatores de risco cardiometabólico e funcionalidade de indivíduos com idade avançada.

\subsection{4. Índice de Conicidade}

O IC foi sugerido para avaliar a distribuição da gordura corporal de forma geral e na região central do corpo. Este índice considera o corpo humano em formato de dois cones com bases voltados para o centro e pode ser calculado a partir de uma equação proposta por Vadez et al (1993). Por exemplo, o resultado do IC representado por um valor "x" significa que a CC, levando em conta a estatura e massa corporal de um sujeito, é "x" maior que a sua circunferência, caso esta não apresentasse gordura abdominal (Pitanga e Lessa, 2005).

Ao observar a relação deste índice antropométrico em uma amostra composta por 276 ingleses (40 a 69 anos), o IC correlacionou-se positivamente com a pressão arterial, colesterol total e LDL de 276 ingleses (40 a 69 anos), e negativamente com o HDL desta mesma amostra (Yasmin, 2000). O estudo de Pitanga e Lessa (2005) comparou indicadores antropométricos (IMC, RCQ, IC e CC) com o risco coronariano elevado de 1.654 brasileiros (30 a 74 anos). Os autores concluíram que o IC e a RCQ foram os melhores índices para identificar o risco coronariano elevado. Adicionalmente, foi adotado um valor de corte para IC de 1,25 e 1,18 para homens e mulheres, respectivamente (Pitanga e Lessa, 2005). Recentemente, Shidfar et al (2012) observaram fatores de risco cardiovascular de 165 mulheres iranianas (56 anos), sendo que o IC correlacionou-se positivamente apenas com a pressão (PAS) e negativamente apenas com a glicemia. Contudo, o IC não apresentou correlação com PAD, colesterol total e subfrações de colesterol. Embora o IC tenha apresentado correlação apenas com 2 fatores de risco cardiovascular, outros índices analisados (IMC e CC) não apresentaram resultados superiores. Apesar das pesquisas supramencionadas, há uma carência de estudos que consolidem este índice como avaliação clínica importante de fatores de risco cardiovascular em populações específicas. 


\section{MATERIAIS E MÉTODOS}

\subsection{Delineamento do estudo}

Para comparar o poder preditivo dos índices de adiposidade corporal com a funcionalidade e o risco cardiometabólico, em mulheres idosas, adotou-se um modelo de estudo com corte transversal (Sampieri, Collado et al., 2006).

\subsection{Amostra}

Após cálculo amostral (descrito no item 5.11. Análise estatística), identificou-se um número amostral alvo de 144 mulheres idosas. Neste sentido, a amostra inicial do presente estudo foi composta por 150 mulheres, no entanto, houve perda amostral de uma participante, que por motivos pessoais não concluiu completamente as avaliações cardiometabólicas. Sendo assim, participaram do presente estudo 149 mulheres, com idade $\geq 60$ anos, residentes do Distrito Federal, Brasil. As participantes foram recrutadas por meio de divulgação divulgado por meio de cartazes e banners distribuídos em locais de acesso ao público alvo da investigação. Após a explicação detalhada dos procedimentos, as idosas que preencheram os critérios de inclusão foram convidadas a participar do estudo de forma voluntária. A presente investigação adotou em seu delineamento os seguintes critérios de exclusão: ser incapazes de caminhar sem assistência; possuir prótese unilateral ou bilateral de quadril; possuir prótese metálica; e apresentar anormalidade de condução ou perfusão cardíaca que contraindique a prática de atividades físicas. Como critério de inclusão, estipulou-se que as voluntárias deveriam ter idade acima de 60 anos.

\subsection{Cuidados éticos}

As participantes foram devidamente informadas sobre os objetivos das avaliações e os possíveis riscos e benefícios envolvidos no estudo. Após concordarem com os procedimentos, as voluntárias assinaram um Termo de Consentimento Livre e Esclarecido (TCLE) (ANEXO A). Os procedimentos propostos nesse projeto de pesquisa possuem aprovação do Comitê de Ética e Pesquisa da Faculdade de Ciências da Saúde (número do parecer: 01-13) da Universidade de Brasília - UnB (ANEXO B), de acordo com a Resolução no 466/12 do Conselho Nacional de 
Saúde (CNS) do Ministério da Saúde do Brasil, que regulamenta as pesquisas envolvendo seres humanos. Além dos esclarecimentos supracitados, as voluntárias apresentaram um atestado médico permitindo a prática de atividades físicas propostas durante as avaliações funcionais, testes de campo e exercício físico.

Todas as participantes receberam, de forma individualizada, os resultados dos testes funcionais, das avaliações laboratoriais e clínicas. Durante a entrega dos resultados, foi disponibilizado um momento para eventuais esclarecimentos. As voluntárias também foram informadas que as informações coletadas seriam, na ocasião, utilizadas para pesquisa científica, sendo apresentadas em congressos e publicadas em revistas científicas especializadas. Todos os esclarecimentos necessários foram realizados previamente a autorização das voluntárias no momento em que assinaram o TCLE, bem como, após os procedimentos durante a entrega dos dados. Ademais, foi preservada a identidade de todos os envolvidos neste processo, podendo estes desistirem da participação em qualquer momento.

\subsection{Avaliações antropométricas}

As avaliações antropométricas foram realizadas no Laboratório de Cineantropometria da Faculdade de Educação Física da Universidade de Brasília (FEF/UnB). Inicialmente, a massa corporal foi mensurada por meio de uma balança digital da marca Filizola, com capacidade máxima de 150 quilogramas e resolução de 50 gramas. Um estadiômetro de parede com resolução de 1 centímetro (CARDIOMED, Brasil) foi utilizado para mensurar a estatura das participantes. A partir dessas medidas, calculou-se o IMC por meio da seguinte fórmula:

$$
\operatorname{IMC}\left(\mathrm{kg} / \mathrm{m}^{2}\right)=\frac{\text { Massa Corporal }}{\text { Estatura }^{2}}
$$

A CC foi medida por meio de uma trena antropométrica da marca Sanny®, adotando-se a cicatriz umbilical como ponto de referência. Esta avaliação permitiu também o cálculo da RCE, de acordo com a seguinte fórmula:

$$
\mathrm{RCE}=\frac{\mathrm{CC}(\mathrm{m})}{\text { estatura }(\mathrm{m})}
$$


Em seguida, o IC foi calculado a partir das medidas de massa corporal, estatura e CC de acordo com a seguinte equação:

$$
\mathrm{IC}=\frac{\mathrm{CC}(\mathrm{m})}{0,109 \sqrt{(\text { Massa Corporal }(\mathrm{kg}) / \text { Estatura }(\mathrm{m}))}}
$$

$\mathrm{Na}$ equação acima, o numerador corresponde a $\mathrm{CC}$ em metros. No denominador, a constante 0,109 é resultante da raiz da razão entre $4 \pi$ (originado da dedução do perímetro do círculo de um cilindro) e a densidade média do ser humano de $1,050 \mathrm{~kg} / \mathrm{m}^{3}$. Portanto, o denominador corresponde ao cilindro produzido pela massa e estatura do sujeito. Sendo assim, pode-se interpretar o resultado da seguinte forma: se um sujeito tem o IC de 1,3, isto representa que a CC (corrigida pela estatura e massa corporal) é 1,3 vezes maior do que a circunferência que o mesmo teria caso não houvesse gordura abdominal.

Adicionalmente, a circunferência do quadril (CQ) foi medida no ponto de maior CQ, próximo ao trocanter maior. Esta avaliação permitiu o cálculo do IAC, que estima o percentual de gordura de adultos de ambos os sexos (Bergman, Stefanovski et al., 2011). O IAC foi calculado a partir da seguinte equação:

\section{$\mathrm{IAC}=\underline{\text { Circunferência do quadril }}$}

$\left(\right.$ Estatura $\left.^{1,5}\right)-18$

A composição corporal foi medida através do DEXA, equipamento da marca Lunnar, modelo DPX-IQ (Lunar Corporation, Madison, WI, USA). Para executar o procedimento, as voluntárias foram orientadas a retirar todos os metais (pulseiras, brincos, anéis, aliança, etc), em seguida, foram posicionadas em decúbito dorsal sobre a mesa do equipamento, de forma que ficassem totalmente centralizadas em relação às laterais da mesa. As voluntárias foram instruídas a se dispor com os joelhos estendidos. Uma fita de velcro posicionada acima dos maléolos foi utilizada para manter os membros inferiores próximos e dar suporte aos pés, de forma que ficassem em uma angulação de aproximadamente $45^{\circ}$ em relação ao plano vertical. Os membros superiores foram dispostos em extensão das articulações de ombro e cotovelo, em seguida posicionados ao longo do corpo, sem que houvesse contato com o tronco. Todas as mensurações 
foram realizadas individualmente pelo mesmo pesquisador, o qual apresentava, na ocasião, treinamento e experiência adequada para a realização destas avaliações. Após análise de toda a área corporal, o DEXA determinou a densidade mineral óssea e a densidade dos tecidos. Os tecidos foram subfracionados em Massa de Gordura (MG) e Massa Livre de Gordura (MLG).

\subsection{Nível de atividade física}

Para a caracterização do nível de atividade física das participantes, o Questionário Internacional de Atividade Física (IPAQ) versão curta (ANEXO C) foi aplicado individualmente. Trata-se de um instrumento validado para a população brasileira, que foi aplicado em comum acordo com a recomendação disponível na literatura (Pardini, Matsudo et al., 2001). Além de individual, o preenchimento do IPAQ contou com o auxílio de um pesquisador experiente para eventuais dúvidas e esclarecimentos. Os questionários foram identificados por um número de protocolo e as informações obtidas, bem como o anonimato, foram mantidas em sigilo visando

proteger as participantes de qualquer tipo de constrangimento. Adicionalmente, após o preenchimento do IPAQ, foram coletadas informações sobre o uso de medicamentos (substância, dosagem administrada e tempo de uso) para a pressão arterial, diabetes, dislipidemia e outros.

\subsection{Pressão arterial}

A medida da pressão arterial foi realizada no período da manhã, ainda em jejum, anteriormente as coletas sanguíneas. Isto permitiu a mensuração da pressão arterial sem a influência de alimentos, bem como efeitos residuais de atividades físicas. As participantes eram conduzidas até uma sala da própria universidade, com as luzes desligadas e com temperatura ambiente não controlada $\left(\cong 25-28^{\circ} \mathrm{C}\right.$ de acordo com o sítio eletrônico http://www.climatempo.com.br). As voluntárias foram orientadas a não falar durante a aferição, estar com a bexiga vazia e não ingerir bebidas alcoólicas até 24 horas antes da coleta (Cardiologia, 2010).

A determinação da PAS, PAD e PAM, foi realizada por um único avaliador, utilizando-se um medidor oscilométrico (Microlife 3AC1-1, Widnau, Suíça), previamente validado de acordo com os critérios da Sociedade Europeia de Hipertensão (Topouchian, El Assaad et al., 2005). 
Durante a aferição, as voluntárias permaneceram em repouso por 10 minutos, em posição sentada, mantendo os pés apoiados no solo e o dorso recostado na cadeira. Orientou-se a retirada das vestimentas do braço esquerdo, no qual foi colocado o manquito, a uma distância acima da fossa antecubital de 2,5 a $3 \mathrm{~cm}$. O braço esquerdo foi posicionado na altura do coração, utilizando-se o osso esterno como referência. O apoio deste braço foi possível por meio de um suporte específico, com o cotovelo levemente flexionado e a articulação rádioulnar supinada (palma da mão voltada para cima) (Chobanian, Bakris et al., 2003). Realizou-se então, duas medidas com cinco minutos de intervalo entre elas e a média aritmética das duas medidas foi considerada para as análises.

\subsection{Variáveis sanguíneas}

Uma amostra de sanguínea foi coletada para mensurar variáveis que constituem fatores de risco cardiovascular e metabólico, especificamente, colesterol e subfrações, triglicérides, glicemia e insulinemia. O modelo de avaliação da homeostase - resistência a insulina (HOMAIR) foi calculado de acordo com a seguinte fórmula: (glicemia em jejum (mmol/L) x insulina em jejum $(\mu \mathrm{UI} / \mathrm{ml})) / 22.5$ (Matthews, Hosker et al., 1985). O material biológico foi coletado por uma enfermeira experiente e mantido em resfriamento, em recipiente com gelo até ser transportado ao laboratório de análises sanguíneas. A coleta foi realizada em uma sala da FEF-UnB, previamente preparada, sempre no período da manhã, sendo as participantes orientadas a chegar ao local em jejum "overnight" de 12 horas. Todo o material utilizado foi individual e descartável, sendo retirado de sua embalagem original frente aos olhos das participantes e, após a utilização, desprezado em uma caixa descartex, da marca descarpack, com capacidade para 13 litros. Depois de cheia, esta caixa foi colocada em uma lixeira hospitalar.

O sangue venoso foi coletado em uma das veias da fossa antecubital na porção anterior do braço não dominante. Para tanto, as voluntárias foram posicionadas sentadas, com apoio do braço sobre um suporte regulável, aproximadamente na altura dos ombros. Realizou-se a antissepsia local utilizando um algodão embebido em álcool $70^{\circ}$ Gl. Após este preparo, uma agulha para coletas múltiplas foi introduzida sob o local, com a ajuda de um adaptador, para o encaixe do tubo de coleta a vácuo. Para as análises das concentrações de colesterol total, HDL, LDL, triglicérides e glicose sanguínea adotou-se o método colorimétrico enzimático, processado em um Autohumalyzer A5 (Human-2004). A insulina basal foi medida por um sistema de 
quimioluminescência automático ACS-180 (Ciba-Corning Diagnostic Corp, 1995, US) e a PCR foi medida por método turbidimétrico. Todos os procedimentos foram terceirizados pelo laboratório SABIN. O recurso para estas análises foi subsidiado por editais de apoio a pesquisa (Fundação de Apoio à Pesquisa do Distrito Federal: 193.000.555/2009; Edital Universal: 487622/2012-0).

\subsection{Classificação da síndrome metabólica}

Para a classificação de SM, utilizou-se a proposta do Terceiro Relatório do Programa Educacional Nacional de Colesterol (NCEP) - Painel de Tratamento de Adultos (ATP III) (Expert Panel on Detection, 2001). Esta proposta é baseada tanto em informações clínicas quanto laboratoriais, as quais são facilmente obtidos e amplamente utilizada pela literatura científica. Define-se SM a voluntária que apresentar pelo menos de 3 dos 5 fatores de risco descritos no Quadro 1. Em adição aos critérios, considera-se fator de risco o uso de medicamentos para o controle das seguintes variáveis: triglicérides, colesterol, pressão arterial e glicemia). 
Quadro 1. Identificação clínica de síndrome metabólica de mulheres.

\begin{tabular}{lc}
\hline Fator de risco & Nível de definição \\
\hline $\begin{array}{l}\text { Obesidade Abdominal } \\
\text { Circunferência de cintura }\end{array}$ & $>88 \mathrm{~cm}$ \\
\hline Triglicérides & $\geq 150 \mathrm{mg} / \mathrm{dL}$ \\
\hline Lipoproteína de alta densidade - HDL & $<40 \mathrm{mg} / \mathrm{dL}$ \\
\hline Pressão arterial (PAS/PAD) & $\geq 130 />85 \mathrm{~mm} \mathrm{Hg}$ \\
\hline Glicemia em jejum & $>110 \mathrm{mg} / \mathrm{dL}$ \\
\hline & Adaptado de NCEP - ATP III
\end{tabular}

\subsection{Avaliação da funcionalidade}

Para a avaliação da funcionalidade, aplicou-se uma bateria de testes que simulam as atividades da vida diária desta população. O procedimento foi conduzido de acordo com o protocolo proposto por Rikli e Jones, (1999). Previamente, foi oferecido gratuitamente às voluntárias, na própria FEF-UnB, uma mesa de café da manhã composta por frutas, pães, sucos e água. Respeitou-se um período pós-prandial de 2 horas para a o início dos testes, que foi iniciado com exercícios globais de aquecimento, com 5 minutos de duração. Em seguida, os testes foram conduzidos no pátio verde da FEF-UnB. Todas as voluntárias foram previamente orientadas para o uso de vestimenta adequada para a realização de atividades físicas. Por exemplo: blusa de algodão, calça de malha ou bermuda (cotton, algodão), tênis ou sapatilha de sola de borracha com meias confortáveis.

Descrição dos testes:

1) Teste de levantar e sentar da cadeira. Materiais: cadeira e um cronômetro. $\mathrm{O}$ objetivo do teste é avaliar a força e resistência muscular de membro inferior. Individualmente, o teste foi iniciado com a participante sentada em uma cadeira, que foi encostada em uma parede, por motivos de segurança. A voluntária foi posicionada com as plantas dos pés sobre o solo e braços cruzados a região peitoral, com as duas mãos sobre os ombros. Ao sinal do avaliador, a participante realizou repetidamente o movimento de levantar-se e sentar-se da cadeira de forma mais rápida quanto possível durante 30 segundos. Para este teste, consideraram-se apenas as repetições completas (i.e, retorno à posição inicial). 
2) Teste de caminhada de 6 minutos. Materiais: trena, giz, 10 cones e 10 cadeiras. $\mathrm{O}$ objetivo do teste é avaliar a capacidade aeróbia, caminhando uma distância máxima durante 6 minutos. O teste foi realizado com o número máximo de 10 participantes simultaneamente. Ao sinal do avaliador, as participantes caminharam o mais rápido possível (sem correr) durante 6 minutos em volta de um circuito específico. Durante a caminhada, as participantes que se sentiram cansadas puderam sentar-se nas cadeiras, o tempo que for necessário, e depois voltar a caminhar. Nos dois minutos finais, estímulos verbais foram oferecidos para as participantes. $\mathrm{O}$ circuito foi desenhado no chão, com giz branco, totalizando 45,7 m (50 jardas). Além das marcações, o circuito foi orientado por cones distribuídos de forma estratégica nos pontos extremos e ao longo do percurso.

3) Teste de Agilidade e Equilíbrio (levantar-se da cadeira, caminhar 2,44 metros, voltar e sentar-se na cadeira, 8-foot up-and-go). Materiais: cronômetro, giz e 1 cone. $\mathrm{O}$ objetivo do teste é avaliar a agilidade e equilíbrio dinâmico. Individualmente, as participantes iniciaram o teste em posição sentada, em uma cadeira, com a coluna ereta o mais próximo da borda do assento. Uma linha de demarcação foi utilizada sob o solo para o posicionamento correto dos pés. As participantes apoiaram as palmas das mãos sobre as coxas e ao sinal do avaliador, a participante levantou da cadeira, caminhou rapidamente, sem correr, ao redor de um cone e retornou à cadeira. Foram conduzidas 3 tentativas, com intervalo de recuperação de 1 minuto entre elas, sendo registrada a pontuação referente ao menor tempo percorrido para a realização do teste. Em todas as avaliações, a cadeira foi encostada na parede para evitar acidentes. O cone foi posicionado a uma distância de 2,44 metros da marcação feita para o posicionamento dos pés. Como medida de segurança, isolou-se um espaço de 1,22 metros após o cone.

Para classificar o desfecho de incapacidade funcional, utilizou-se os valores normativos previamente publicados por Rikli e Jones (2013), que sugeriram escores de referência para a população de idosos norte-americanos (Quadro 2). No presente estudo, foram classificadas com o desfecho de incapacidade funcional as idosas que apresentassem valores abaixo da referência em pelo menos dois dos três testes aplicados. 
Quadro 2. Critérios de referência para a manutenção da independência física de mulheres idosas.

\begin{tabular}{l|c|c|c|c|c|c|c}
\hline & \multicolumn{7}{c}{ Grupos por idade (anos) } \\
\cline { 2 - 8 } & $60-64$ & $65-69$ & $70-74$ & $75-79$ & $80-84$ & $85-89$ & $90-94$ \\
\hline $\begin{array}{l}\text { Força de Membro inferior } \\
\begin{array}{l}\text { Levantar e sentar de uma cadeira em } \\
\text { 30s; repetições) }\end{array}\end{array}$ & 15 & 15 & 14 & 13 & 12 & 11 & 9 \\
\hline $\begin{array}{l}\text { Capacidade aeróbia } \\
\text { (teste de 6 minutos; em segundos) }\end{array}$ & 571.5 & 553.2 & 530.4 & 502.9 & 466.3 & 420.6 & 365.7 \\
\hline $\begin{array}{l}\text { Agilidade/Equilíbrio dinâmico } \\
\text { (8-ft up-and-go; em segundos) }\end{array}$ & 5.0 & 5.3 & 5.6 & 6.0 & 6.5 & 7.1 & 8.0 \\
\hline
\end{tabular}

Adaptado de Rikli e Jones (2013)

\subsection{Organização das coletas}

As coletas foram realizadas em grupos de no máximo 20 idosas por dia. O calendário foi construído em comum acordo com a agenda das voluntárias e a disponibilidade do laboratório de análise sanguínea (SABIN). Todas as avaliações foram supervisionadas por 3 alunos de mestrado e 2 alunos de iniciação científica do Grupo de Estudos em Fisiologia e Saúde da Universidade de Brasília (GEFS-UnB). O projeto contou com a supervisão e orientação do professor Dr. Ricardo Moreno Lima. A figura 4 apresenta a organização logística das coletas. 


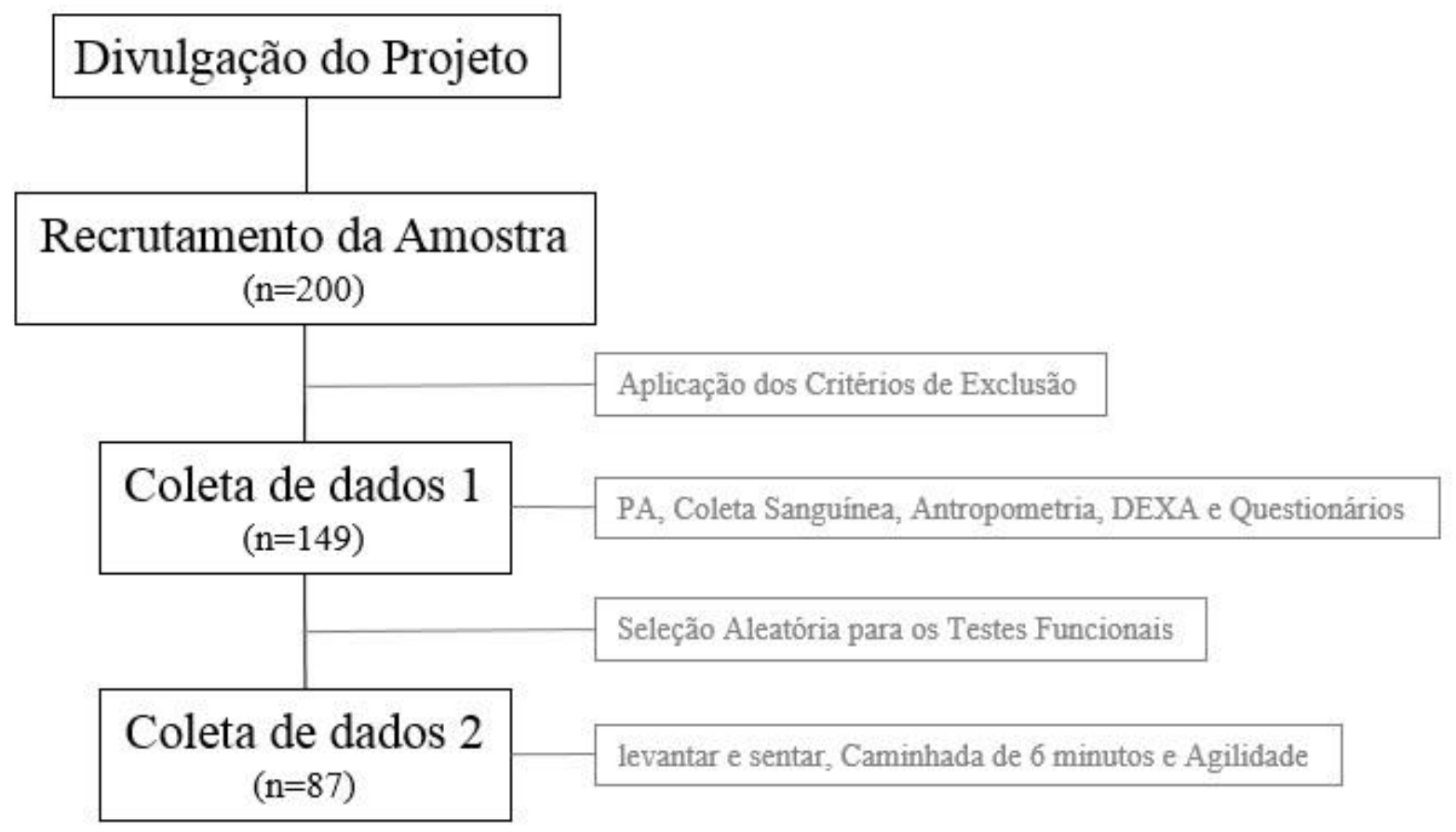

Figura 4. Fluxograma das atividades de divulgação do projeto, recrutamento da amostra e coleta de dados.

\subsection{Análise estatística}

Os dados foram apresentados por meio de estatística descritiva com os procedimentos de média e desvio padrão. Para representar a população de mulheres idosas do Distrito Federal (N $\cong 182.500$ ) (Miragaya, Peixoto et al., 2013), um cálculo amostral para populações conhecidas foi conduzido de acordo com a seguinte fórmula:

$$
\begin{aligned}
& \mathbf{n}=\left(\left(\mathbf{Z}_{\alpha / 2}\right)^{\mathbf{2}} \mathbf{N}(\mathbf{1}-\mathbf{P})\right) /\left(\mathbf{E}_{\mathbf{n}}^{2} \mathbf{P}(\mathbf{N}-\mathbf{1})+\left(\mathbf{Z}_{\mathbf{\alpha} / \mathbf{2}}\right)^{\mathbf{2}}(\mathbf{1}-\mathbf{P})\right) \\
& \mathrm{n}=\text { amostra } \\
& \alpha=\text { confiança atribuída/intervalo de confiança } \\
& \mathrm{N}=\text { população } \\
& \mathrm{P}=\text { prevalência estimada } \\
& \mathrm{E}=\text { erro atribuído }
\end{aligned}
$$

Neste cálculo, considerou-se $\alpha=95 \%, \mathrm{E}=5 \%$ e $\mathrm{P}=40 \%$. Atribuiu-se a prevalência de $40 \%$ com base nos valores encontrados na literatura nacional para prevalência de SM em amostras semelhantes. Inicialmente, identificou-se um número amostral de 369 sujeitos. Entretanto, por 
razões logísticas e financeiras este número não pode ser contemplado no presente estudo. Sendo assim, o cálculo amostral foi refeito, admitiu-se um erro atribuído aumentado em 3 pontos percentuais ( $\mathrm{E}=8 \%)$, identificou-se então, um número amostral de 144 voluntárias para representar a população de mulheres idosas do Distrito Federal.

Para verificar a distribuição dos dados, aplicou-se o teste de Kolmogorov-Smirnov. A associação entre os índices da adiposidade corporal e os fatores de risco cardiovascular e metabólico foi realizada por meio da correlação de Pearson. Calculou-se um ponto de corte para cada índice da adiposidade corporal por meio de Receiver Operating Characteristic Curve (curva ROC) em relação às variáveis de risco cardiometabólico e funcionalidade. A curva ROC é gerada a partir da sensibilidade (eixo y) em função da especificidade (eixo x), sendo que, a sensibilidade refere-se ao percentual de indivíduos que apresentaram os desfechos (i.e., síndrome metabólica e/ou incapacidade funcional) e que foram corretamente diagnosticados por meio do indicador (i.e., verdadeiro positivo). Já a especificidade, refere-se a descrição percentual dos indivíduos que não apresentaram o desfecho supracitados, ou seja, que foram diagnosticados por meio do indicador (i.e., verdadeiro negativo). Os pontos de corte foram obtidos a partir dos valores com sensibilidade e especificidade mais próximos entre si e a significância estatística de cada análise foi verificada pela área sob a curva ROC. Entende-se, neste contexto, que um indicador perfeito apresenta a área sob a curva ROC de 1,00, ao passo que uma linha diagonal representa a área sob a curva ROC de 50\%. Para um indicador apresentar uma habilidade discriminatória significativa, a área sob a curva ROC deve estar compreendida entre 1,00 e 0,50 e quanto maior a área, maior o poder discriminatório do indicador.

Após a classificação dos índices da adiposidade corporal, as médias dos grupos foram comparadas por meio do teste $t$ para amostras independentes. Além das comparações entre médias, a razão de possibilidades (Odds Ratio; OR) foi calculada para os fatores de risco cardiovascular e metabólico de acordo com cada classificação de adiposidade corporal. O grau de significância adotado foi de $p \leq 0,05$ e o Software utilizado para as análises foi o Statistical Package for the Social Sciences (SPSS 20.0) (Field, 2009). 


\section{RESULTADOS}

A Tabela 1 apresenta a descrição da amostra de acordo com as variáveis cardiometabólicas estudadas e os índices da adiposidade corporal utilizados. Ademais, as variáveis de percentual de gordura, CC, IMC, RCE, IC e IAC são apresentadas em um número amostral de 149 mulheres idosas.

Tabela 1. Características descritivas da amostra. Dados expressos em média e desvio padrão.

\begin{tabular}{|c|c|}
\hline \multicolumn{2}{|l|}{ Variável } \\
\hline \multicolumn{2}{|l|}{$n$} \\
\hline Idade (anos) & $67.17 \pm 6.12$ \\
\hline Tempo de Menopausa (anos) & $16.65 \pm 8.17$ \\
\hline Estatura (m) & $1.55 \pm 0.06$ \\
\hline Massa Corporal (kg) & $64.61 \pm 11.65$ \\
\hline $\mathrm{IMC}\left(\mathrm{kg} / \mathrm{m}^{2}\right)$ & $26.98 \pm 4.41$ \\
\hline Percentual de Gordura (\%) & $42.24 \pm 6.50$ \\
\hline $\mathrm{CC}(\mathrm{cm})$ & $88.06 \pm 11.27$ \\
\hline $\mathrm{RCE}(\mathrm{m} / \mathrm{m})$ & $0.57 \pm 0.74$ \\
\hline IC (UA) & $1.25 \pm 0.09$ \\
\hline IAC $(\%)$ & $34.69 \pm 5.37$ \\
\hline PAS (mm Hg) & $137.56 \pm 17.72$ \\
\hline PAD (mm Hg) & $78.14 \pm 9.25$ \\
\hline PAM (mm Hg) & $97.95 \pm 10.85$ \\
\hline PCR $(\mathrm{mg} / \mathrm{dL})$ & $0.42 \pm 0.59$ \\
\hline Colesterol Total (mg/dL) & $207.32 \pm 37.66$ \\
\hline HDL (mg/dL) & $56.49 \pm 10.43$ \\
\hline $\mathrm{LDL}(\mathrm{mg} / \mathrm{dL})$ & $123.55 \pm 33.30$ \\
\hline VLDL (mg/dL) & $27.03 \pm 11.87$ \\
\hline Triglicérides (mg/dL) & $137.17 \pm 63.72$ \\
\hline Insulina $(\mu \mathrm{UI} / \mathrm{mL})$ & $5.71 \pm 8.06$ \\
\hline HOMA IR $(\mu \mathrm{UI} / \mathrm{mL})$ & $1.44 \pm 2.19$ \\
\hline IMC $=$ Índice de Mas & Corporal; $\mathrm{CC}=$ \\
\hline Circunferência de Cintura; R & $=$ Relação Cintura \\
\hline Estatura; IC = Índice de Con & lade; IAC = Índice \\
\hline da Adiposidade Corporal; $\mathrm{P}$ & $=$ Pressão Arterial \\
\hline Sistólica; PAD = Pressão Arte & Diastólica; PCR = \\
\hline $\begin{array}{l}\text { Proteína C-reativa; HDL = } \\
\text { densidade; LDL = Lipoproteín }\end{array}$ & $\begin{array}{l}\text { oproteína de alta } \\
\text { le baixa densidade; }\end{array}$ \\
\hline VLDL = Lipoproteína de $\mathrm{d}$ & dade muito baixa; \\
\hline $\begin{array}{l}\text { HOMA IR = Modelo de ava } \\
\text { UA = Unidade Arbitrária. }\end{array}$ & ão da homeostase; \\
\hline
\end{tabular}


A Tabela 2 apresenta dados concernentes à caracterização do subgrupo selecionado para realizar a bateria de testes funcionais composto (Levantar e Sentar, Agilidade e Caminhada de 6 minutos).

Tabela 2. Características descritivas do subgrupo selecionado para a realização dos testes funcionais. Dados expressos em média e desvio padrão.

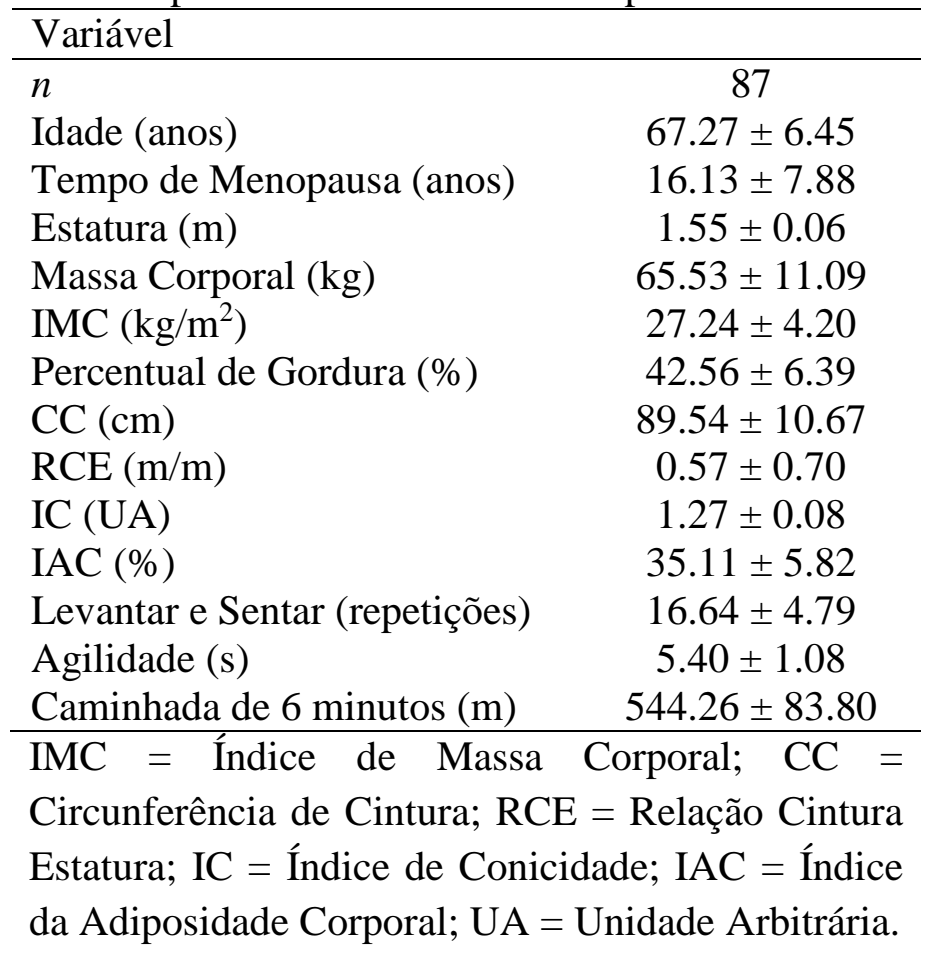

Como se pode observar na Tabela 3 , mais de $86 \%$ da amostra foi considerada fisicamente ativa ou muito ativa de acordo com o IPAQ versão curta. Das voluntárias observadas, apenas 2 relataram serem tabagistas e aproximadamente $18 \%$ fazem uso de reposição hormonal. Dentre as 149 voluntárias observadas, destacaram-se os valores percentuais para a prevalência de hipertensão arterial (60.4\%) e obesidade abdominal (48.3\%). Adicionalmente, foram classificadas com SM 29,5\% do número amostral observado. 
Tabela 3. Características descritivas da amostra de acordo com as variáveis categóricas. Dados apresentados em prevalência absoluta e relativa.

\begin{tabular}{lcc}
\hline Variável & Não & Sim \\
\hline$n=149$ & $118(79.0 \%)$ & $31(21.0 \%)$ \\
Muito Ativo (IPAQ) & $147(98 . \%)$ & $2(1.3 \%)$ \\
Tabagista & $121(81.2 \%)$ & $28(18.8 \%)$ \\
Reposição Hormonal & $131(87.9 \%)$ & $18(12.1 \%)$ \\
Diabetes Mellitus & $59(39.6 \%)$ & $90(60.4 \%)$ \\
Hipertensão & $115(77.2 \%)$ & $34(22.8 \%)$ \\
HDL (<50 mg/dL) & $101(67.8 \%)$ & $48(32.2 \%)$ \\
Triglicerídeos ( $\geq 150$ mg/dL) & $77(51.7 \%)$ & $72(48.3 \%)$ \\
Obesidade Abdominal & $105(70.5 \%)$ & $44(29.5 \%)$ \\
Síndrome Metabólica & &
\end{tabular}

IPAQ $=$ Questionário internacional de atividade física - traduzido. 
A Figura 4 (ver item 5.10. Organização das coletas) apresenta o fluxograma das atividades de campo desenvolvidas durante o estudo. Após a divulgação do projeto, 200 potenciais participantes foram contatadas, das quais cinquenta e uma apresentaram-se inaptas a participar do presente estudo. Sendo assim, para a coleta 1, que envolveu coleta sanguínea, mensuração da PA, antropometria, DEXA e questionários, foram recrutadas 149 voluntárias. Entretanto, na segunda coleta, referente aos testes funcionais, o número amostral foi reduzido por razões logísticas. Após a coleta 1, foram sorteadas, de forma aleatória, 100 mulheres idosas para a realização dos testes funcionais. Digno de nota, o procedimento supracitado foi adotado por questões operacionais primando pela qualidade das coletas. Reapresentaram-se para a bateria de testes funcionais 87 voluntárias.

O relacionamento entre os índices da adiposidade corporal e os testes funcionais são demonstrados na Tabela 4. Nesta tabela, é possível observar que as variáveis de CC e RCE apresentaram associação moderada, inversa e significativa, com o teste de levantar e sentar, enquanto que o IMC e o IC apresentaram padrão de associação similar, porém classificado como associação fraca para o mesmo teste. A agilidade correlacionou-se com o IMC, a CC, RCE e o IAC. Em seguida, o teste de caminhada apresentou correlação inversa e significativa, em nível moderado, com o IMC, o percentual de gordura, a CC, a RCE e o IAC.

Tabela 4. Correlação entre os índices da adiposidade corporal e os testes funcionais.

\begin{tabular}{lcccccc}
\hline Variável & $\mathrm{IMC}$ & $\% \mathrm{G}$ & $\mathrm{CC}$ & $\mathrm{IC}$ & $\mathrm{RCE}$ & $\mathrm{IAC}$ \\
\hline Levantar e Sentar (rep.) & $-0.258^{*}$ & -0.135 & $-0.345^{* *}$ & $-0.291^{* *}$ & $-0.311 * *$ & -0.112 \\
Agilidade (s) & $0.248^{*}$ & 0.118 & $0.255^{*}$ & 0.174 & $0.252^{*}$ & $0.296^{* *}$ \\
Caminhada (m) & $-0.403^{* *}$ & $-0.381^{* *}$ & $-0.365^{* *}$ & $-0.241^{*}$ & $-0.417 * *$ & $-0.388^{* *}$ \\
\hline
\end{tabular}

$\mathrm{IMC}=$ Índice de Massa Corporal; $\% \mathrm{G}=$ Percentual de Gordura; $\mathrm{CC}=$ Circunferência de cintura; IC = Índice de Conicidade; RCE = Relação Cintura Estatura; IAC = Índice de adiposidade corporal. $* \mathrm{p}<0.05 ; * *_{\mathrm{p}}<0.01$

$\mathrm{Na}$ Tabela 5, observa-se o relacionamento entre os índices da adiposidade corporal e as variáveis de risco cardiometabólico estudadas. Interessantemente, o percentual de gordura medido pelo DEXA apresentou associação apenas com duas variáveis estudadas. Em contrapartida, os demais índices apresentaram associações importantes com a maioria das variáveis estudadas, exceto com CT e LDL. Dentre as associações significativas, destacam-se as medidas que consideram a gordura abdominal, pois correlacionaram-se de forma importante com 
a CC a PCR e o HDL, com a RCE todas as medidas de Pressão Arterial e com o IC as medidas de VLDL e Triglicérides. Por fim, o IMC apresentou-se como o único índice correlacionado significativamente com a glicemia e apresentou maior associação com o HOMA-IR. 
Tabela 5. Correlação entre os índices da adiposidade corporal e as variáveis de risco cardiometabólico.

\begin{tabular}{|c|c|c|c|c|c|c|}
\hline Variável & IMC & $\% \mathrm{G}$ & $\mathrm{CC}$ & IC & RCE & IAC \\
\hline PAS (mm Hg) & $0.196 *$ & 0.012 & $0.239 * *$ & $0.253 * *$ & $0.299 * *$ & $0.222 * *$ \\
\hline PAD (mm Hg) & $0.211 * *$ & 0.002 & $0.235 * *$ & $0.208^{*}$ & $0.263 * *$ & $0.169 *$ \\
\hline PAM $(\mathrm{mm} \mathrm{Hg})$ & $0.227 * *$ & 0.008 & $0.264 * *$ & $0.256^{* *}$ & $0.312 * *$ & $0.217 * *$ \\
\hline Glicemia (mg/dL) & $0.231 * *$ & 0.158 & 0.156 & 0.003 & 0.137 & 0.151 \\
\hline PCR (mg/dL) & $0.333 * *$ & 0.160 & $0.334 * *$ & $0.223 * *$ & $0.330 * *$ & $0.271 * *$ \\
\hline CT (mg/dL) & 0.007 & -0.045 & 0.017 & 0.051 & 0.042 & 0.118 \\
\hline $\mathrm{HDL}(\mathrm{mg} / \mathrm{dL})$ & -0.122 & -0.055 & $-0.194^{*}$ & $-0.187^{*}$ & $-0.168 *$ & 0.082 \\
\hline $\mathrm{LDL}(\mathrm{mg} / \mathrm{dL})$ & -0.006 & -0.045 & -0.018 & -0.010 & -0.006 & 0.078 \\
\hline VLDL (mg/dL) & 0.139 & 0.048 & $0.261 * *$ & $0.343 * *$ & $0.290 * *$ & 0.109 \\
\hline Triglicérides (mg/dL) & 0.139 & 0.020 & $0.267 * *$ & $0.339 * *$ & $0.283 * *$ & 0.067 \\
\hline Insulina $(\mu \mathrm{UI} / \mathrm{mL})$ & $0.486^{* *}$ & $0.210 *$ & $0.443 * *$ & $0.229 * *$ & $0.432 * *$ & $0.315^{* *}$ \\
\hline HOMA IR & $0.473 * *$ & $0.221 * *$ & $0.422 * *$ & $0.206 *$ & $0.411 * *$ & $0.299 * *$ \\
\hline
\end{tabular}

IMC = Índice de Massa Corporal; \%G = Percentual de Gordura; MGT = Massa Gorda Total; $\mathrm{CC}=$ Circunferência de cintura; $\mathrm{IC}=$ Índice de Conicidade; RCE = Relação Cintura Estatura; IAC = Índice de adiposidade corporal; PAS = Pressão Arterial Sistólica; PAD = Pressão Arterial Diastólica; PAM = Pressão Arterial Média; PCR = Proteína C-reativa; $\mathrm{CT}=$ Colesterol Total; HDL = Lipoproteína de alta densidade; LDL = Lipoproteína de baixa densidade; VLDL = Lipoproteína de densidade muito baixa; HOMA IR = Modelo de Avaliação da homeostase. $* \mathrm{p}<0.05 ; * * \mathrm{p}<0.01$

A classificação de funcionalidade do subgrupo $(n=87)$ que realizou a bateria de testes funcionais está apresentada na Tabela 6. Na soma dos testes de capacidade funcional, a amostra apresentou-se funcionalmente capaz em 63.2\%. Contudo, ao observar os testes de forma individualizada, observa-se que Agilidade e Caminhada de 6 minutos dividiram a amostra em relação ao seu ponto de corte. Neste sentido, o teste de Levantar e Sentar foi determinante para que a funcionalidade total atingisse um percentual superior acima dos valores de referência para funcionalidade. 
Tabela 6. Classificação da capacidade funcional de acordo com os testes de Levantar e Sentar, Agilidade e Caminhada de 6 minutos. Dados apresentados por prevalência absoluta e relativa.

\begin{tabular}{lcc}
\hline \multirow{2}{*}{ Variável } & \multicolumn{2}{c}{ Funcionalidade } \\
\cline { 2 - 3 }$n=87$ & \multicolumn{1}{c}{ Baixa } & Moderada/Alta \\
Levantar e Sentar & $25(28.7 \%)$ & $62(71.3 \%)$ \\
Agilidade & $47(54.0 \%)$ & $40(46.0 \%)$ \\
Caminhada de 6 minutos & $44(50.6 \%)$ & $43(49.7 \%)$ \\
Capacidade Funcional & $32(36.8 \%)$ & $55(63.2 \%)$ \\
\hline
\end{tabular}

Capacidade Funcional: baixa (apresentou desempenho abaixo dos pontos de corte em pelo menos 2 dos 3 testes funcionais) e Moderada/Alta (apresentou desempenho acima dos pontos de corte em pelo menos 2 dos 3 testes funcionais). Valores de corte ajustados para cada faixaetária.

A Tabela 7 apresenta a comparação entre as variáveis estudadas de acordo com a classificação para SM e também para a Funcionalidade. Embora não tenha sido observada diferença significativa para idade, ao comparar os sujeitos com e sem SM, observa-se que os índices de adiposidade corporal, bem como, as variáveis de risco caridiometabólico, com exceção apenas para LDL e CT, diferenciaram-se de forma significativa e importante entre os grupos. Neste contexto, apenas o HDL, que representa a fração de colesterol bom, apresentou-se aumentado no grupo que não foi classificado com a SM. As demais variáveis demonstraram-se aumentadas para o grupo classificado com a mesma síndrome. Ainda na mesma tabela, há comparação entre os grupos que apresentaram funcionalidade abaixo e acima dos valores de referência. Nesta comparação, apenas as variáveis de Insulina e HOMA-IR demonstraram-se reduzidas de forma significativa no grupo com funcionalidade acima do ponto de corte adotado quando comparado ao grupo classificado como abaixo do mesmo referencial. Entretanto, houve uma tendência para diferença significativa, na comparação entre os grupos, para a $\mathrm{CC}(\mathrm{p}<0.07)$, 
RCE $(p<0.08)$ e PCR $(p<0.08)$. Ademais a idade não apresentou diferença significativa entre os grupos para ambas as classificações. 
Tabela 7. Comparação entre as variáveis cardiometabólicas e os Índices da Adiposidade corporal de acordo com as classificações de Síndrome Metabólica e Capacidade Funcional. Dados expressos em média e desvio padrão.

\begin{tabular}{|c|c|c|c|c|}
\hline \multirow{2}{*}{ Variável } & \multicolumn{2}{|c|}{ Síndrome Metabólica $(n=149)$} & \multicolumn{2}{|c|}{ Incapacidade Funcional $(n=87)$} \\
\hline & Não $(n=105)$ & $\operatorname{Sim}(n=44)$ & Não $(n=55)$ & $\operatorname{Sim}(n=32)$ \\
\hline Idade (anos) & $67.04 \pm 5.89$ & $67.50 \pm 6.71$ & $67.29 \pm 6.63$ & $67.38 \pm 5.85$ \\
\hline $\mathrm{IMC}\left(\mathrm{kg} / \mathrm{m}^{2}\right)$ & $25.84 \pm 4.03$ & $29.69 \pm 4.13^{* *}$ & $26.68 \pm 3.83$ & $28.06 \pm 4.62$ \\
\hline $\mathrm{CC}(\mathrm{cm})$ & $84.62 \pm 10.71$ & $96.28 \pm 7.85^{* *}$ & $87.63 \pm 9.71$ & $91.94 \pm 11.70 \dagger$ \\
\hline $\operatorname{IAC}(\%)$ & $33.91 \pm 4.61$ & $36.55 \pm 6.54 * *$ & $34.72 \pm 6.39$ & $35.36 \pm 4.88$ \\
\hline$\% \mathrm{G}$ & $41.44 \pm 6.89$ & $44.14 \pm 5.05^{*}$ & $41.81 \pm 6.44$ & $43.45 \pm 6.35$ \\
\hline $\mathrm{RCE}(\mathrm{m} / \mathrm{m})$ & $0.54 \pm 0.71$ & $0.61 \pm 0.53 * *$ & $0.56 \pm 0.68$ & $0.59 \pm 0.71$ \\
\hline $\mathrm{IC}(\mathrm{UA})$ & $1.23 \pm 0.08$ & $1.30 \pm 0.07 * *$ & $1.25 \pm 0.08$ & $1.28 \pm 0.08$ \\
\hline PAS (mm Hg) & $134.20 \pm 16.69$ & $145.60 \pm 17.68 * *$ & $135.59 \pm 18.03$ & $137.14 \pm 18.46$ \\
\hline PAD (mm Hg) & $77.04 \pm 8.74$ & $80.76 \pm 9.97 *$ & $78.02 \pm 9.63$ & $76.69 \pm 10.13$ \\
\hline PAM (mm Hg) & $96.09 \pm 10.28$ & $102.38 \pm 10.99 * *$ & $97.21 \pm 11.25$ & $96.84 \pm 11.90$ \\
\hline PCR (mg/dL) & $0.31 \pm 0.34$ & $0.69 \pm 0.91 * *$ & $0.40 \pm 0.48$ & $0.67 \pm 0.95$ \\
\hline Colesterol Total (mg/dL) & $205.14 \pm 34.56$ & $212.50 \pm 44.20$ & $210.67 \pm 42.60$ & $208.25 \pm 36.57$ \\
\hline $\mathrm{HDL}(\mathrm{mg} / \mathrm{dL})$ & $59.19 \pm 8.78$ & $50.05 \pm 11.31 * *$ & $57.51 \pm 11.37$ & $56.41 \pm 9.52$ \\
\hline LDL (mg/dL) & $123.40 \pm 31.79$ & $123.93 \pm 37.15$ & $125.43 \pm 35.98$ & $124.22 \pm 33.55$ \\
\hline $\operatorname{VLDL}(\mathrm{mg} / \mathrm{dL})$ & $22.55 \pm 7.27$ & $37.98 \pm 13.75^{* *}$ & $27.13 \pm 11.56$ & $27.63 \pm 12.98$ \\
\hline Triglicérides (mg/dL) & $112.85 \pm 36.51$ & $195.20 \pm 76.54 * *$ & $141.11 \pm 69.13$ & $138.28 \pm 64.78$ \\
\hline Insulina $(\mu \mathrm{UI} / \mathrm{mL})$ & $3.62 \pm 3.00$ & $10.69 \pm 12.88 * *$ & $4.51 \pm 3.83$ & $8.63 \pm 13.09 *$ \\
\hline HOMA IR $(\mu \mathrm{UI} / \mathrm{mL})$ & $0.81 \pm 0.72$ & $2.93 \pm 3.42 * *$ & $1.11 \pm 1.10$ & $2.25 \pm 3.25^{*}$ \\
\hline
\end{tabular}

IMC = Índice de Massa Corporal; CC = Circunferência de Cintura; IAC = Índice da Adiposidade Corporal; $\% \mathrm{G}=$ Percentual de Gordura; RCE = Relação Cintura Estatura; IC = Índice de Conicidade. Incapacidade funcional $=$ apresentou resultado inferior ao valor de referência em pelo menos 2 dos 3 testes funcionais aplicados. $*=p<0.05$ quando comparado a linha de base; $* *=p<0.01$ quando comparado a linha de base. 
As Tabelas 8 e 9 apresentam a área sob a curva ROC de cada índice da adiposidade corporal para a presença de incapacidade funcional e variáveis cardiometabólicas, respectivamente. Os índices de adiposidade corporal que apresentaram maior desempenho discriminatório foram CC e IMC. A CC apresentou maior área sob a curva ROC para a presença de SM (0.819; p<0.01) e classificação no teste de Sentar e Levantar (0.712; p<0.01). Interessantemente, a $\mathrm{CC}$ foi a única medida que apresentou diferença significativa entre a curva de referência (0.5) para a presença de incapacidade funcional $(0.618 ; \mathrm{p}<0.05)$. O IMC apresentou maior área sob a curva para a presença de diabetes $(0.660 ; \mathrm{p}<0.01)$ e de incapacidade nos testes de agilidade $(0.640 ; \mathrm{p}<0.05)$ e caminhada $(0.703 ; \mathrm{p}<0.05)$. Adicionalmente, a área sobre a curva para a presença de dislipidemia não foi estatisticamente significativa para nenhum dos índices de adiposidade corporal. 
Tabela 8. Área sob a curva ROC de cada índice da adiposidade corporal para os desfechos de desempenho funcional.

\begin{tabular}{lcccc}
\hline & Levantar e Sentar & Agilidade & Caminhada & Incapacidade Funcional \\
\hline Variável & & & & \\
CC & $0.712(0.605-0.804)^{* *}$ & $0.624(0.514-0.726)^{*}$ & $0.664(0.555-0.762)^{* *}$ & $0.618(0.507-0.720)^{*}$ \\
IMC & $0.650(0.540-0.749)^{*}$ & $0.640(0.530-0.740)^{*}$ & $0.703(0.595-0.796)^{*}$ & $0.589(0.478-0.693)$ \\
$\% G$ & $0.549(0.439-0.656)$ & $0.547(0.437-0.654)$ & $0.678(0.569-0.774)^{* *}$ & $0.568(0.457-0.674)$ \\
IC & $0.695(0.587-0.789)^{* *}$ & $0.598(0.487-0.702)$ & $0.559(0.488-0.703)$ & $0.605(0.494-0.708)$ \\
IAC & $0.519(0.409-0.627)$ & $0.578(0.468-0.684)$ & $0.674(0.566-0.771)^{* *}$ & $0.563(0.452-0.669)$ \\
RCE & $0.655(0.546-0.754)^{*}$ & $0.620(0.510-0.722)^{*}$ & $0.685(0.577-0.780)^{* *}$ & $0.594(0.483-0.698)$ \\
\hline
\end{tabular}

$*=\mathrm{p}<0.05$ (área 0.5$) ; * *=\mathrm{p}<0.01$ (área 0.5).

Tabela 9. Área sob a curva ROC de cada índice da adiposidade corporal para os desfechos de Hipertensão Arterial, Dislipidemia, Diabetes e Síndrome Metabólica.

\begin{tabular}{lcccc}
\hline & Hipertensão & Dislipidemia & Diabetes & Síndrome Metabólica \\
\hline Variável & & & & \\
CC & $0.627(0.544-0.705)^{* *}$ & $0.579(0.495-0.659)$ & $0.640(0.558-0.717)^{*}$ & $0.819(0.748-0.878)^{* *}$ \\
IMC & $0.656(0.573-0.731)^{* *}$ & $0.542(0.459-0.624)$ & $0.660(0.578-0.736)^{* *}$ & $0.757(0.680-0.824)^{* *}$ \\
$\% G$ & $0.590(0.506-0.670)^{*}$ & $0.516(0.432-0.598)$ & $0.522(0.439-0.604)$ & $0.633(0.550-0.710)^{* *}$ \\
IC & $0.571(0.487-0.652)$ & $0.581(0.497-0.661)$ & $0.565(0.481-0.646)$ & $0.749(0.672-0.816)^{* *}$ \\
IAC & $0.613(0.530-0.692)^{*}$ & $0.523(0.440-0.606)$ & $0.575(0.492-0.656)$ & $0.624(0.541-0.702)^{* *}$ \\
RCE & $0.638(0.555-0.715)^{* *}$ & $0.580(0.497-0.660)$ & $0.640(0.557-0.716)^{*}$ & $0.798(0.725-0.859)^{* *}$ \\
\hline
\end{tabular}

$*=\mathrm{p}<0.05$ (área 0.5);**= $\mathrm{p} \leq 0.01$ (área 0.5). 
As Figuras 5 e 6 apresentam o comportamento das curvas ROC de cada índice de adiposidade corporal e seu poder discriminatório (sensibilidade e especificidade) para a presença de Incapacidade Funcional e SM, respectivamente. A Figura 5 demonstra o comportamento similar entre as curvas ROC dos índices de adiposidade corporal para a presença de incapacidade funcional. Embora apenas a CC tenha apresentado uma tendência para área sob a curva significativa $(\mathrm{p}<0.06)$, não foram encontradas diferenças significativas entre as curvas quando comparadas entre si. Na comparação entre as curvas ROC dos índices de adiposidade para a presença de SM (Figura 6), neste caso, observa-se que o poder discriminatório é mais expressivo quando comparado ao anterior. Entretanto, não houveram diferenças nas comparações entre as seguintes curvas ROC: a) IC com o IMC (p=0.89), \%G (p<0.07), RCE (p<0.11); b) CC com RCE ( $<<0.14) ; c)$ RCE com IMC ( $<<0.20)$; e d) IAC com \% $(p<0.87)$. Ademais, as diferenças significativas foram observadas entre as seguintes curvas ROC: a) CC com \%G (p<0.001), IAC $(\mathrm{p}<0.001)$, IC (p<0.02), IMC (p<0.04); b) RCE com \%G (p<0.001), IAC (p<0.001); e c) IMC com \%G $(\mathrm{p}<0.001)$. 


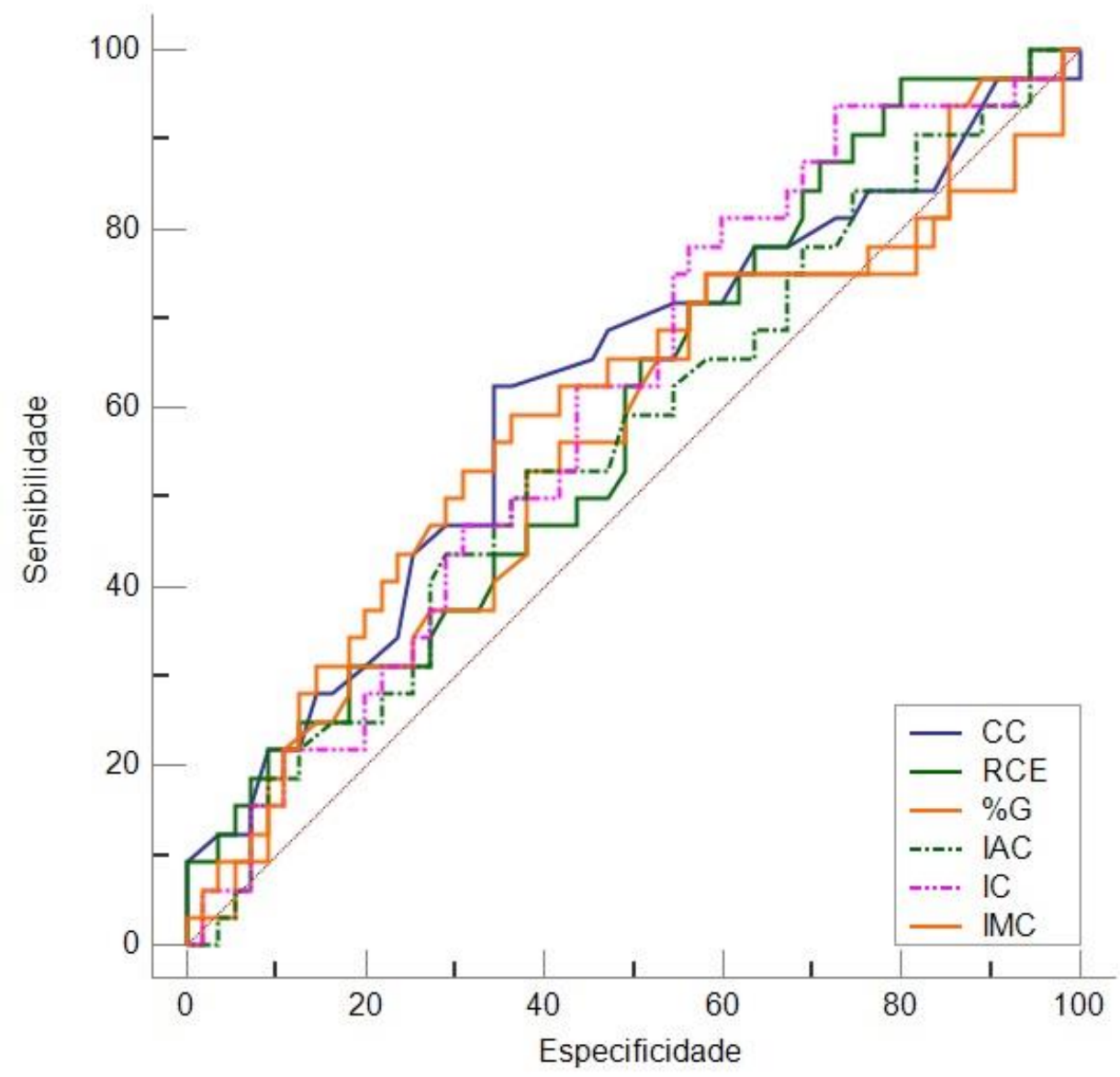

Figura 5. Comparação entre as curvas ROC dos índices de adiposidade corporal para a presença de incapacidade funcional. 


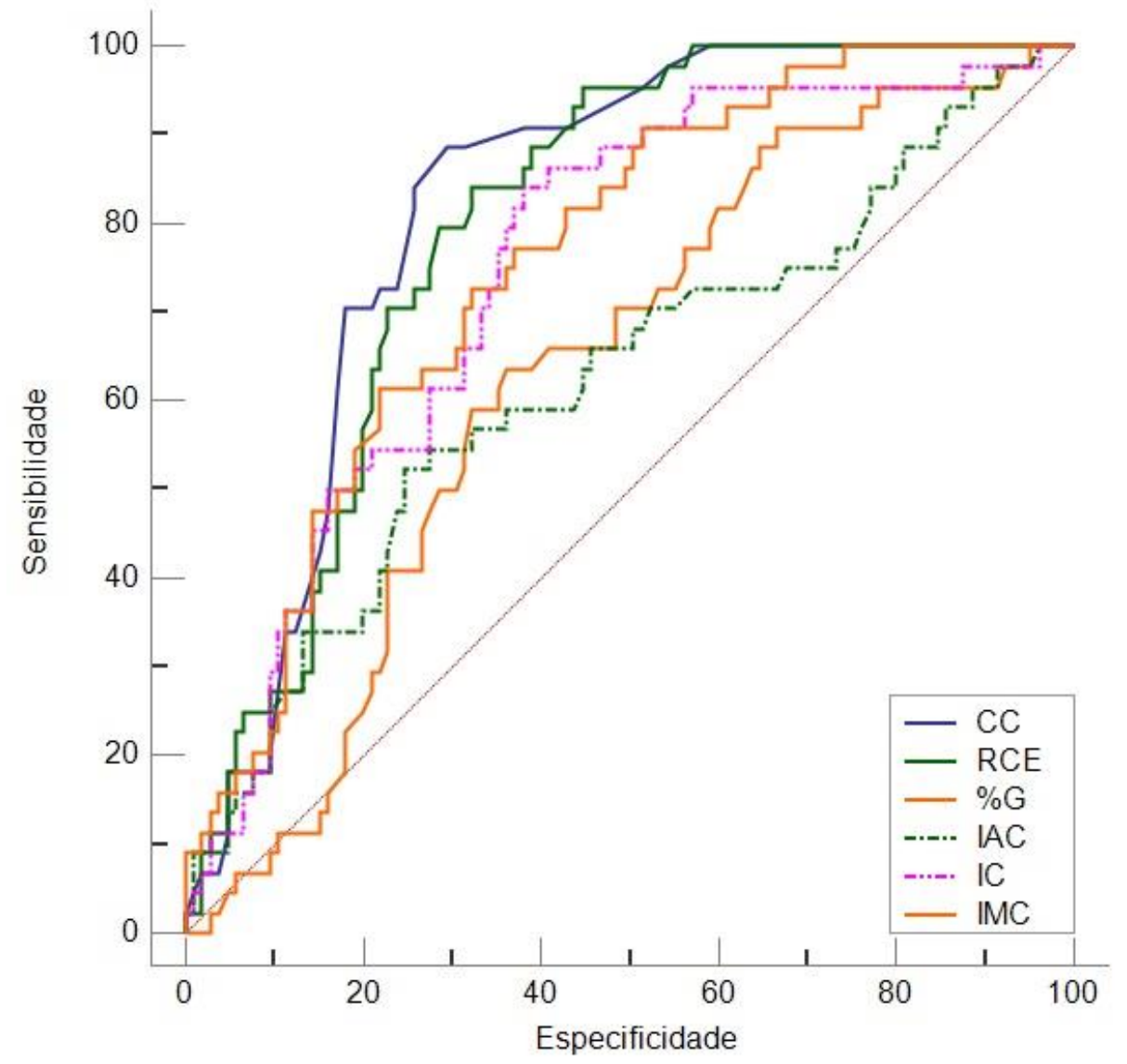

Figura 6. Comparação entre as curvas ROC dos índices de adiposidade corporal para a presença de Síndrome Metabólica. 
Os pontos de corte para cada índice da adiposidade corporal referente às variáveis de funcionalidade e cardiometabólica estão apresentados nas Tabelas 10 e 11, respectivamente. Nota-se que houveram pontos de corte distintos para o mesmo índice considerando variáveis diferentes, exceto para o IMC que apresentou valores repetidos para mais de uma variável (Tabela 11).

Tabela 10. Pontos de corte (sensibilidade; especificidade) referente a cada índice da adiposidade corporal para a presença de capacidade funcional reduzida.

\begin{tabular}{lcccc}
\hline & Agilidade & Levantar e Sentar & Caminhada & Incapacidade Funcional \\
\hline Índices de adiposidade & & & & \\
CC $(\mathrm{cm})$ & $87(55.3 ; 67.5)$ & $92.5(64.0 ; 75.8)$ & $89(61.4 ; 69.8)$ & $89.5(62.5 ; 65.5)$ \\
$\% \mathrm{G}$ & $37.4(34.0 ; 85.0)$ & $42.9(60.0 ; 58.1)$ & $46.3(38.6 ; 90.7)$ & $39.2(75.0 ; 41.8)$ \\
IMC $\left(\mathrm{kg} / \mathrm{m}^{2}\right)$ & $28.37(76.6 ; 47.5)$ & $26.93(68.0 ; 64.5)$ & $28.37(52.2 ; 83.7)$ & $26.93(59.4 ; 63.6)$ \\
IAC $(\%)$ & $40.0(87.2 ; 30.0)$ & $34.6(52.0 ; 59.7)$ & $36.4(50.0 ; 81.4)$ & $34.6(53.1 ; 61.8)$ \\
RCE $(\mathrm{m} / \mathrm{m})$ & $0.59(59.6 ; 62.5)$ & $0.52(100.0 ; 27.4)$ & $0.62(36.4 ; 90.7)$ & $0.51(96.9 ; 20.0)$ \\
IC $(\mathrm{UA})$ & $1.27(66.0 ; 55.0)$ & $1.27(76.0 ; 58.1)$ & $1.22(79.5 ; 44.2)$ & $1.23(78.1 ; 43.6)$ \\
\hline
\end{tabular}

$\mathrm{CC}=$ Circunferência de Cintura; $\% \mathrm{G}=$ Percentual de Gordura; IMC = Índice de Massa Corporal; IAC = Índice de Adiposidade Corporal; RCE = Relação Cintura Estatura; IC = Índice de Conicidade. 
Tabela 11. Pontos de corte (sensibilidade; especificidade) referente a cada índice da adiposidade corporal para a presença de risco cardiometabólico.

\begin{tabular}{lcccc}
\hline & Hipertensão & Diabetes & Dislipidemia & Síndrome Metabólica \\
\hline Índices de adiposidade & & & & \\
$\mathrm{CC}(\mathrm{cm})$ & $84(66.3 ; 60.8)$ & $89(65.0 ; 61.3)$ & $93(44.6 ; 75.0)$ & $88(88.6 ; 70.5)$ \\
$\% \mathrm{G}$ & $43(56.1 ; 64.7)$ & $38.2(88 ; 29)$ & $39.7(69.2 ; 41.7)$ & $43.7(63.6 ; 63.8)$ \\
$\mathrm{IMC}\left(\mathrm{kg} / \mathrm{m}^{2}\right)$ & $24.89(74.5 ; 58.8)$ & $28.29(60.0 ; 71.8)$ & $26.05(61.5 ; 51.2)$ & $26.85(72.7 ; 67.6)$ \\
$\mathrm{IAC}(\%)$ & $33.3(67.3 ; 58.8)$ & $38.12(36.0 ; 81.5)$ & $31.33(32.3 ; 79.8)$ & $36.34(52.3 ; 75.2)$ \\
$\mathrm{RCE}(\mathrm{m} / \mathrm{m})$ & $0.54(69.4 ; 56.9)$ & $0.55(80.0 ; 46.0)$ & $0.56(63.1 ; 57.1)$ & $0.57(84.1 ; 67.6)$ \\
IC $(\mathrm{UA})$ & $1.25(56.1 ; 64.7)$ & $1.25(68.0 ; 53.2)$ & $1.24(61.5 ; 56.0)$ & $1.24(84.1 ; 61.9)$ \\
\hline
\end{tabular}

$\mathrm{CC}=$ Circunferência de Cintura; \% $\%$ Percentual de Gordura; IMC = Índice de Massa Corporal; IAC = Índice de Adiposidade Corporal; RCE = Relação Cintura Estatura; IC = Índice de Conicidade. 
A Tabela 12 apresenta o Odds Ratio das classificações de adiposidade corporal, tanto acima quanto abaixo dos pontos de corte apresentados nas Tabelas 10 e 11, na presença de Hipertensão, Dislipidemia, Diabetes, SM e Incapacidade Funcional. Interessantemente, a CC foi o único índice utilizado que apresentou uma razão de possibilidades aumentada e significativa para todas as condições apresentadas na tabela (Tabela 12). Dentre os riscos cardiometabólicos apresentados, a CC apresentou a maior razão de possibilidades para a presença de dislipidemia e SM. Seguidamente, o IMC apresentou a maior razão de possibilidades para a presença de hipertensão e diabetes. Em relação à incapacidade funcional, a maior razão de possibilidades identificada foi para a RCE, seguido pela CC. Ademais, o percentual de gordura acima do corte estabelecido apresentou razão de possibilidades aumentada de forma significativa apenas para hipertensão e SM. 
Tabela 12. Odds Ratio (Intervalo de Confiança = 95\%) para o desfecho de Hipertensão, Dislipidemia, Diabetes, Síndrome Metabólica e Incapacidade Funcional para as classificações de adiposidade corporal conforme os pontos de corte determinados para cada índice de adiposidade corporal estudado.

\begin{tabular}{|c|c|c|c|c|c|}
\hline & Hipertensão & Dislipidemia & Diabetes & Síndrome Metabólica & Incapacidade Funcional \\
\hline \multicolumn{6}{|l|}{ Variável } \\
\hline \multicolumn{6}{|l|}{$\mathrm{CC}$} \\
\hline Acima do corte & $3.05(1.51-6.15)^{* *}$ & $2.42(1.21-4.84)^{* * *}$ & $2.81(1.15-6.88)^{*}$ & $18.62(6.71-51.69) * *$ & $3.16(1.28-7.82)^{* *}$ \\
\hline Acima do corte & $2.35(1.17-4.72)^{* *}$ & $1.61(0.81-3.18)$ & $3.00(0.85-10.65)$ & $3.09(1.48-6.42)^{* *}$ & $2.17(0.82-5.64)$ \\
\hline \multicolumn{6}{|l|}{ IMC } \\
\hline Acima do corte & $4.17(2.03-8.56)^{* *}$ & $1.60(0.83-3.09)$ & $3.81(1.57-9.29)^{* * *}$ & $5.57(2.55-12.14)^{* *}$ & $2.37(0.97-5.77) \dagger$ \\
\hline \multicolumn{6}{|l|}{ IAC } \\
\hline Acima do corte & $2.85(1.42-5.73)^{* *}$ & $1.90(0.61-5.96)$ & $2.47(0.97-6.28)^{*}$ & $3.33(1.59-6.97)^{* *}$ & $1.70(0.71-4.10)$ \\
\hline \multicolumn{6}{|l|}{ IC } \\
\hline Acima do corte & $2.35(1.17-4.73) * *$ & $2.03(1.05-3.93)^{*}$ & $2.34(0.94-5.82) \dagger$ & $8.59(3.50-21.10)^{* *}$ & $2.57(0.95-6.94) \dagger$ \\
\hline
\end{tabular}

Em destaque (negrito) o maior valor apresentado por risco Cardiometabólico e/ou Incapacidade Funcional.

$*=\mathrm{p}<0.05($ área 0.5); ** $=\mathrm{p} \leq 0.01$ (área 0.5); $\# \mathrm{p}=0.558($ área 0.5$) ; \dagger=\mathrm{p}<0.06$ (área 0.5). 


\section{DISCUSSÃO}

Diante dos principais achados do presente estudo, nota-se que há uma relação entre adiposidade corporal com aspectos cardiometabólicos, bem como com aspectos funcionais. Digno de nota, observou-se que os índices da adiposidade corporal que consideraram a gordura abdominal em seus cálculos, apresentaram esta relação de forma mais consistente em comparação aos demais índices. Adicionalmente, CC, IAC e RCE relacionaram-se de forma significativa com aspectos funcionais, avaliados pelos testes de Levantar e Sentar, Agilidade e Caminhada de 6 minutos, respectivamente. Por fim, determinou-se um ponto de corte para cada índice estudado, o que possibilitou identificar cada uma das condições de risco cardiometabólicos investigadas; e se observou que as idosas que estavam acima dos pontos de corte apresentaram maior chance para os desfechos negativos à saúde cardiometabólica e capacidade funcional.

\subsection{Caracterização da amostra}

De forma original, o presente estudo investigou a associação de Índices da adiposidade corporal com o risco cardiometabólico e funcional em uma amostra representativa de mulheres idosas residentes no Distrito Federal, Brasil. Dentre as voluntárias, identificou-se a prevalência de $29.5 \%$ para a SM. Estes dados aproximam-se dos achados de Park et al (2003), que observaram a prevalência de $27.2 \%$ para a SM, em estadunidenses adultas, de origem hispânica. Outro achado similar foi o de Miccoli et al (2005), em que ao investigaram mais de 2000 italianos adultos de ambos os sexos, e identificaram prevalência de 25\% para a SM em um subgrupo de sujeitos com idade avançada (>70 anos). Mais recentemente, Ramírez-Arriola et al (2011) identificaram a prevalência de 23\% para a mesma síndrome, em uma amostra composta por 61 mulheres idosas de nacionalidade mexicana. Conquanto os achados apresentem-se convergentes, nota-se que ainda há controvérsias em outras investigações. O estudo de Ford et al (2002), que embora tenham observado a prevalência de 22\% para a SM em uma amostra representativa de estadunidenses adultos, quando ajustado para a idade este percentual subiu para $43.5 \%$ nos sujeitos com mais de 60 anos. Do mesmo modo, Manzato et al (2008) identificaram a prevalência de $48.1 \%$ das mulheres (>60 anos), de uma amostra composta por italianas, para a SM. 
No Brasil, a temática também tem sido investigada e notadamente observa-se que a prevalência para a SM encontrada na literatura é superior em relação aos dados apresentados no presente estudo. Ao observar 1663 adultos de diversas idades, Salaroli et al (2007) identificaram a prevalência de $48.3 \%$ para a mesma síndrome nos sujeitos com idade entre 55 e 64 anos. Outros estudos, como o de Rigo et al (2009), Vieira et al (2014) e Saad et al (2014) encontraram prevalências superiores a 45\% no Rio Grande do Sul, em Goiás e no Rio de Janeiro, respectivamente. Embora estudos prévios já tenham realizado o levantamento da prevalência de SM em mulheres idosas, não foram encontrados estudos desta natureza que representassem os idosos do Distrito Federal. Além disso, a utilização de diferentes métodos durante a identificação da SM, bem como a falta de controle de variáveis importantes, como o nível de atividade física e uso de repositores hormonais, pode influenciar tais disparidades encontradas na literatura.

Além da SM, o presente estudo identificou a prevalência de 36.8\% para a incapacidade funcional de mulheres idosas, de acordo com a bateria de testes Senior Fit Test proposta por Rikli e Jones (2013). Nesta mesma direção, um estudo de corte transversal em amostra representativa do município de Pelotas ( $\mathrm{n}=598$ ), Rio Grande do Sul, 29.5\% das mulheres, com idade superior a 60 anos, apresentaram incapacidade funcional para atividades básicas e/ou instrumentais da vida diária, avaliadas pela escala de Katz e Lawton, respectivamente (Del Duca, Silva et al., 2009). Contudo, Dos Santos et al (2013) observaram números divergentes ao investigarem a incapacidade funcional de 404 mulheres idosas residentes de municípios do estado de Minas Gerais. Por meio de auto relato, os autores encontraram prevalência de $19.1 \%$ e 52.7\% para incapacidade nas atividades básicas da vida diária e atividades instrumentais da vida diária, respectivamente (Dos Santos, Tribess et al., 2013). Entende-se que o perfil referente às amostras dos estudos supramencionados pode influenciar nesta margem percentual, por exemplo, com o avançar da idade, espera-se um aumento de prevalência na incapacidade funcional (Rikli e Jones, 2013). Possivelmente, outras variáveis como: o uso de repositores hormonais, alimentação inadequada, tabagismo e nível de atividade física podem influenciar negativamente estes scores. 


\subsection{Pontos de Corte}

O presente estudo adotou valores de referência disponíveis na literatura para classificar a adiposidade corporal das voluntárias. Embora o IMC, a CC, a RCE e o IC apresentem pontos de corte para o risco cardiovascular de populações específicas, não foram encontrados pontos de corte para o risco de incapacidade funcional e risco cardiometabólico de mulheres idosas para a classificação destes índices. Além disso, tanto o \%G medido pelo DEXA quanto o IAC carecem de investigações mais aprofundadas em relação a um valor de classificação para ambas as variáveis.

Os parâmetros utilizados para classificar o IMC das participantes foi a proposta da OMS (1995), que considera três principais categorias (normal, sobrepeso e obesidade). A partir do cálculo da massa corporal pela estatura ao quadrado, considera-se um IMC normal quando este valor é $>18$ e $<25 \mathrm{~kg} / \mathrm{m}^{2}$; caso o valor seja $>25$ e $<30 \mathrm{~kg} / \mathrm{m}^{2}$, o sujeito é classificado como sobrepesado; e por fim, o IMC $\geq 30 \mathrm{~kg} / \mathrm{m}^{2}$ representa obesidade. Digno de nota, observa-se adaptações destes parâmetros para a classificação do IMC de indivíduos idosos. Por exemplo, segundo a Organização Pan-americana de Saúde (Opas, 2001), as classificações de IMC devem ser corrigidas para $>23$ e $\leq 28 \mathrm{~kg} / \mathrm{m}^{2},>28$ e $\leq 30 \mathrm{~kg} / \mathrm{m}^{2}$, e $>30 \mathrm{~kg} / \mathrm{m}^{2}$, para eutrófico, sobrepesado e obeso, respectivamente. Outra classificação disponível na literatura é a do Ministério da Saúde do Brasil (Sisvan, 2004), que considera normal um IMC $\geq 22$ e $\leq 27 \mathrm{~kg} / \mathrm{m}^{2}$; e sobrepeso um IMC $>27 \mathrm{~kg} / \mathrm{m}^{2}$. Embora as sugestões supramencionadas sejam direcionadas a população idosa, optou-se pelos valores de referência propostos pela OMS, pois estes apresentam maior consistência em número de investigações, bem como ampla utilização tanto em ambiente científico quanto clínico.

Os pontos de corte identificados para o IMC e a presença de risco cardiometabólico variaram entre 24.89 e $28.29 \mathrm{~kg} / \mathrm{m}^{2}$. Dentre as variáveis que compuseram o risco cardiometabólico, destaca-se o ponto de corte identificado para a SM $\left(26.85 \mathrm{~kg} / \mathrm{m}^{2}\right)$, sendo que as voluntárias com IMC superior ao parâmetro encontrado, apresentaram uma razão de possibilidades significativamente aumentada $(\mathrm{OR}=5.57)$ para a $\mathrm{SM}$. No caso dos testes funcionais, o ponto de corte variou entre 26.93 e $28.37 \mathrm{~kg} / \mathrm{m}^{2}$. Contudo, ao analisar o risco de incapacidade funcional, o valor de IMC proposto foi de $26.93 \mathrm{~kg} / \mathrm{m}^{2}(\mathrm{OR}=2.37 ; \mathrm{p}<0.06)$. Os 
achados do presente estudo corroboram a proposta de classificação utilizada pela OMS (2000), considerando-se $26 \mathrm{~kg} / \mathrm{m}^{2}$ como um ponto crítico tanto para a saúde cardiometabólica quanto para a incapacidade funcional. Entretanto, deve-se salientar que existe risco para valores aproximados de $24 \mathrm{~kg} / \mathrm{m}^{2}$. Por exemplo, o presente estudo identificou um ponto de corte de 24.9 $\mathrm{kg} / \mathrm{m}^{2}$ para hipertensão arterial, corroborando os achados de Midha et al (2014), que ao investigarem a mesma variável em uma amostra composta por 445 mulheres indianas $(34.8+$ 11.6) identificaram o mesmo ponto de corte referente ao IMC para identificar hipertensão arterial. Outrossim, cumpre salientar que Zaher et al (2009) encontraram um ponto de 25.8 $\mathrm{kg} / \mathrm{m} 2$ para hipertensão arterial em uma amostra composta por mulheres asiáticas de diversas etnias.

Os pontos de corte identificados de CC para as variáveis de risco cardiometabólico variaram entre 84 e $93 \mathrm{~cm}$. Interessantemente, estes valores estão próximos aos encontrados pelo mesmo índice e as variáveis de funcionalidade, os quais variaram entre 87 e $92.5 \mathrm{~cm}$. Em adição, o ponto de corte identificado de CC para SM e Incapacidade funcional foram 88 e $89.5 \mathrm{~cm}$, respectivamente. Os achados do presente estudo aproximam-se do valor de referência previamente adotado de $88 \mathrm{~cm}$, para mulheres (Han, Van Leer et al., 1995), entretanto, demonstraram-se superiores ao valor encontrado por Mora-García et al (2014), os quais identificaram pontos de corte de CC equivalente a $85 \mathrm{~cm}$ para identificar SM em uma amostra composta por 434 mulheres colombianas. Neste sentido, deve-se considerar qualquer variação neste ponto de corte, pois estudos prévios demonstraram que este parâmetro antropométrico varia de acordo com o risco avaliado, bem como com a população estudada (Alberti, Eckel et al., 2009; Zaher, Zambari et al., 2009; Midha, Krishna et al., 2014; Mora-García, Gómez-Camargo et al., 2014).

Embora as principais entidades relacionadas à saúde cardiometabólica disponibilizem parâmetros para classificar a obesidade abdominal de diversas populações a partir da CC, estes valores oscilam entre 80 e $90 \mathrm{~cm}$, em mulheres adultas de diversas etnias (Alberti, Eckel et al., 2009). Sendo assim, estudos que determinem parâmetros regionalizados são necessários e encorajados para a classificação de obesidade central e como consequência, a classificação de SM de populações específicas (Alberti, Eckel et al., 2009). 
O excesso de massa corporal, como um todo, tem sido reportado como influenciador negativo da funcionalidade de indivíduos com idade avançada. É bem estabelecido que a obesidade avaliada pelo IMC e/ou CC, está associada à mobilidade reduzida de indivíduos idosos (Hubert, Bloch et al., 1993; Ensrud, Nevitt et al., 1994; Galanos, Pieper et al., 1994; Launer, Harris et al., 1994; Jenkins, 2004). Angleman et al (2006) demonstraram que a distribuição da gordura corporal parece ser um importante indicador da mobilidade, valorizando a avaliação da CC em relação ao IMC, por ser diretamente relacionada a gordura visceral. Na mesma direção, e mais recentemente, Lisko et al (2014) identificaram associação de CC com performance física e incapacidade de realizar atividades da vida diária, em amostra composta por 416 mulheres nonagenárias de origem nórdica. Notavelmente, os autores sugerem que a medida de CC apresentou-se mais consistente do que o IMC, corroborando os achados do presente estudo. Em adição, um estudo conduzido por Muramoto et al (2014) investigou a influência da obesidade central sobre a síndrome locomotiva, um termo criado pela Associação Japonesa de Ortopedia para designar pessoas de meia idade ou idosos em alto risco de necessitar de cuidados de enfermagem por conta de problemas com órgãos locomotivos. O estudo de Muramoto et al (2014) revelou que a obesidade central, avaliada por CC, foi significativamente associada com a síndrome locomotiva em amostra composta por 217 mulheres ( $\geq 60$ anos) de etnia japonesa.

Ainda utilizando a CC, no entanto adicionada a sua relação pela estatura, observou-se que os pontos de corte de RCE para as variáveis de risco cardiometabólico variaram entre 54.19 e $57.43 \%$ (da CC em relação à estatura). Notavelmente, observa-se que a RCE encontrada para identificar o risco cardiometabólico, aproximou-se dos achados de Rodrigues et al (2010) cujo determinaram ponto de corte equivalente a $0.54 \mathrm{CC} /$ Estatura para identificar o risco cardiovascular de mulheres brasileiras, todavia, o parâmetro de referência proposto no presente estudo para a identificação de SM foi superior ( $\mathrm{RCE}=0.57 \mathrm{CC} /$ Estatura) aos valores previamente declarados por Rodrigues et al (2010). Destaca-se a proximidade dos achados do presente estudo com os valores encontrados por Roriz et al (2014), que determinaram ponto de corte de RCE (=0.58 CC/Estatura) para identificar obesidade abdominal (i.e., área de tecido adiposo visceral $\geq$ $130 \mathrm{~cm}^{2}$ ) medido por tomografia computadorizada, em uma amostra composta por mulheres idosas brasileiras. 
De forma convergente aos achados do presente estudo, Mora-García et al (2014) identificaram ponto de corte de RCE para a SM equivalente a 56\% (da CC em relação à estatura) em uma amostra composta por mulheres colombianas. Entretanto, e mais recentemente, ao investigar o risco cardiometabólico de uma população composta por mulheres adultas de nacionalidade Chinesa, Zeng et al (2014), observaram variação entre 0.48 e 0.50 CC/Estatura para identificar Diabetes, Hipertensão e dislipidemia. Conquanto Zeng et al (2014) tenham relatado valores abaixo dos achados do presente estudo, entende-se a etnia como uma diferença importante entre as amostras e ou populações observadas. Em relação à incapacidade funcional, o presente estudo identificou RCE limítrofe para 51\% da CC em relação à estatura, contudo não foram encontrados estudos que determinassem um ponto de corte para RCE e funcionalidade de mulheres adultas ou idosas.

Além da CC e da RCE, outro índice estudado que considerou a gordura abdominal em seu cálculo, foi o IC. O IC foi sugerido para avaliar a distribuição da gordura corporal de forma geral e na região central do corpo. Este índice considera o corpo humano em formato de dois cones com bases voltados para o centro e pode ser calculado a partir de uma equação proposta por Vadez et al (1993). Recentemente, Roriz et al (2014) observaram a associação do IC com a gordura visceral de mulheres idosas brasileiras. Além disso, os mesmos autores determinaram um ponto de corte deste índice equivalente a 1.30 UA para identificar obesidade abdominal (i.e., área de tecido adiposo visceral $\geq 130 \mathrm{~cm}^{2}$ ) medida por tomografia computadorizada (Roriz, Passos et al., 2014). Embora o IC apresente-se como um índice capaz de avaliar a obesidade abdominal, os achados do presente estudo não amparam a aplicação do parâmetro proposto por Roriz et al (2014), sendo que o ponto de corte identificado deste índice, para discriminar as variáveis de risco cardiometabólico, variou entre 1.24 e 1.25 UA.

Os achados do presente estudo corroboram o estudo de Almeida et al (2009), entretanto contestam a aplicação de pontos de corte para o mesmo índice, já propostos na literatura (Pitanga e Lessa, 2005; Nadeem, Naveed et al., 2013; Roriz, Passos et al., 2014; Tonding, Silva et al., 2014). Ao avaliar o desempenho do IC sobre o risco coronariano elevado de 270 mulheres (42.69 \pm 8.73 anos) residentes da região nordeste do Brasil, Almeida et al (2009) identificaram que o ponto de corte de IC que melhor discriminou o risco supracitado foi equivalente a 1.25 UA. Estes 
achados contrapõem o estudo de Pitanga e Lessa (2005), que determinaram pontos de corte menor (IC $\geq 1.18 \mathrm{UA}$ ) para identificar o risco coronariano elevado, em uma amostra composta por 577 mulheres $(45.73 \pm 11.64$ anos $)$ residentes da mesma região do país. Interessantemente, Lessa e Pitanga (2005) também encontraram o ponto de corte equivalente a 1.25 UA, contudo para indivíduos do sexo masculino.

Em relação a desordens metabólicas, Nadeem et al (2013) determinaram pontos de corte de índices antropométricos para identificar a resistência à insulina de uma amostra composta por 209 (136 homens; 73 mulheres) paquistaneses (51.5 \pm 1.16 anos). Em ambos os gêneros, identificou-se parâmetros superiores aos achados do presente estudo, sendo que o ponto de corte de IC para discriminar resistência à insulina foi de 1.32 e 1.39 para homens e mulheres, respectivamente (Nadeem, Naveed et al., 2013). Nesta mesma direção, Tonding et al (2014) avaliaram a associação entre este marcador de adiposidade e o alto risco de doença coronariana de 420 pacientes $(61.9 \pm 9.5$ anos $)$ com diabetes mellitus do tipo 2, e identificaram que os sujeitos com o IC $\geq 1.35$ UA apresentaram maior risco para a saúde cardiovascular.

Em relação a funcionalidade, o ponto de corte identificado no presente estudo para o IC e o desempenho nos testes funcionais ficou entre 1.22 e 1.27 UA, sendo que, para o conjunto dessas variáveis (i.e., incapacidade funcional) o valor de corte encontrado foi de 1.23 UA.

Outro índice utilizado com a finalidade de qualificar a composição corporal, foi o IAC. Este índice é uma proposta conduzida por Bergman et al (2011) em alternativa ao IMC, contudo pode ser usado para refletir a massa gorda relativa de adultos de ambos os sexos. Trata-se de um índice validado a partir de análise da composição corporal feita pelo DEXA, sendo que o cálculo leva em consideração a circunferência de quadril e a estatura do indivíduo, e reflete uma relação forte com a gordura corporal $(r=0,85)$. Embora existam publicações recentes sobre a temática, $o$ conhecimento sobre a aplicação deste índice ainda é incipiente.

Observa-se que os pontos de corte do IAC para discriminar o risco cardiometabólico variaram entre 31.33 e $38.12 \%$, sendo que o ponto que melhor discriminou a SM foi equivalente a 36.34\%. Estes dados aproximam-se dos achados de Gupta e Kapoor (2014), que identificaram ponto de corte para o IAC equivalente a $37.7 \%$ para discriminar o risco cardiovascular de 292 
mulheres de uma casta indiana específica (Aggarwal Baniyas), com idade superior a 30 anos (38.7 \pm 4.9$)$. Em adição, os mesmos autores ressaltam que o IAC pode ser utilizado em conjunto ao IMC, como um índice capaz de rastrear desfechos negativos à saúde cardiovascular de populações numerosas, embora sua validação ainda careça de ser demonstrada em outras populações, antes de tomar este índice com um marcador de risco cardiovascular (Gupta e Kapoor, 2014).

O presente estudo contou também com a avaliação da composição corporal por meio do DEXA, que é considerado padrão ouro para avaliar a composição corporal de seres humanos (Visser, Fuerst et al., 1999; Chen, Wang et al., 2007). Embora a literatura aponte para uma relação forte entre o IAC e o percentual de gordura medido pelo DEXA, os achados do presente estudo identificaram pontos de corte divergentes para discriminar o risco cardiometabólico entre ambos os índices. Ressalta-se a originalidade destes dados, pois não foi identificado um parâmetro consensual para discriminar as variáveis analisadas por meio desta avaliação de composição corporal.

O ponto de corte referente ao \%G medido pelo DEXA variou entre 38.2 e $43.7 \%$ para discriminar as variáveis de risco cardiometabólico, sendo que o maior valor percentual discriminou à SM. Notavelmente, mesmo em avaliações de padrão ouro, observa-se que há divergência na literatura em relação a um percentual de gordura que discrimine a obesidade de amostras semelhantes (Goh, Tain et al., 2004; Jackson, Ellis et al., 2006; Kagawa, Uenishi et al., 2006; Pongchaiyakul, Nguyen et al., 2006; Yang, Lv et al., 2006; De Lorenzo, Bianchi et al., 2013), o que reforça a importância de parâmetros específicos para diferentes populações. Os parâmetros de percentual de gordura medido pelo DEXA encontrados na literatura para discriminar a obesidade variaram desde aproximadamente 30\% (Jackson, Ellis et al., 2006; Kagawa, Uenishi et al., 2006; Yang, Lv et al., 2006), passando por 35\% (Goh, Tain et al., 2004; Pongchaiyakul, Nguyen et al., 2006; De Lorenzo, Bianchi et al., 2013), sendo que os mais próximos aos valores encontrados no presente estudo foram de aproximadamente 38\% (Blew, Sardinha et al., 2002; Chen, Ho et al., 2006; Evans, Rowe et al., 2006). Já o ponto de corte que melhor discriminou as variáveis funcionais aproximou-se dos valores cardiometabólicos, com margem de 37.4 a 46.4\%. Ademais, não foram encontrados estudos com esta abordagem. 


\subsection{Comparação entre os métodos}

\subsubsection{Risco Cardiometabólico}

Ao observar a associação dos índices da adiposidade corporal com o risco cardiometabólico, foi possível observar que as avaliações antropométricas apresentaram resultados mais consistentes quando comparadas a avaliação de composição corporal realizada pelo DEXA. Adicionalmente, destacaram-se as avaliações antropométricas que consideraram a gordura abdominal em seus cálculos. Nesta mesma direção, ao comparar o poder preditivo destes índices, observou-se que para identificar a SM, a CC apresentou área sob a curva $(\mathrm{ROC}=0.819)$ maior quando comparada ao \% G (p<0.001), ao IAC (p<0.01), ao IC (p<0.02) e ao IMC (p<0.04). Outrossim, a RCE apresentou área sob a curva $(\mathrm{ROC}=0.798)$ superior quando comparado ao \% $\mathrm{G}$ e ao IAC ( $\mathrm{p}<0.01)$, e a área sob a curva do IMC $(\mathrm{ROC}=0.757)$ foi maior do que a do \%G $(\mathrm{p}<0.01)$.

O presente estudo também comparou as variáveis cardiometabólicas e os índices da adiposidade corporal entre os sujeitos classificados com o desfecho de SM e os que não apresentaram esse conjunto de anormalidades cardiometabólica. Exceto para idade, LDL e colesterol total que não apresentaram diferença estatística entre os grupos, o grupo de voluntárias classificadas com a SM apresentou resultados inferiores para as demais variáveis quando comparadas ao grupo de referência (sem desordem cardiometabólica), o que corrobora achados prévios (Menke, Muntner et al., 2007; Knowles, Paiva et al., 2011; Zhang, Deng et al., 2013) e elucida o aumento da razão de possibilidades (Odds Ratio) encontrado para o mesmo desfecho metabólico.

Os achados de Knowles et al (2011) propõe associação importante de índices da adiposidade corporal (IMC, CC, RCQ, RCE e índice da adiposidade visceral) como preditores de risco cardiometabólico de uma amostra composta por 1518 adultos peruanos. Na ocasião, os autores concluíram que independentemente do índice antropométrico utilizado, a prevalência dos fatores de risco da SM é aumentada quando há aumento nestes índices. Embora a utilização dos índices de adiposidade seja interessante, sua validade tem sido questionada por não medirem diretamente a quantidade de tecido gordo. Além disso, estes índices antropométricos não diferenciam frações de componentes corporais (Müller, Lagerpusch et al., 2012), o que dificulta 
avaliar sujeitos com características físicas distintas. Contudo, na última década, alguns estudos se dedicaram em analisar e comparar algumas destas variáveis e seu poder preditivo de risco cardiometabólico (Menke, Muntner et al., 2007; Knowles, Paiva et al., 2011; Zhang, Deng et al., 2013).

O estudo de Pitanga e Lessa (2005) comparou indicadores antropométricos (IMC, RCQ, IC e CC) com o risco coronariano elevado de 1654 brasileiros de ambos os sexos (30 a 74 anos). Embora, na ocasião, o desfecho do estudo tenha apresentado o IC e a RCQ como melhores índices para identificar o risco coronariano elevado, os autores ressaltam a importância de medidas que avaliem a adiposidade abdominal na identificação deste tipo de risco, corroborando o principal achado do presente estudo. Entretanto, a temática ainda se faz controversa, pois há uma carência de estudos que consolidem o IC e a RCQ como índices superiores na identificação de risco cardiovascular. Mais recentemente, Shidfar et al (2012) observaram fatores de risco cardiovascular de 165 mulheres iranianas (56 anos), sendo que o IC correlacionou-se positivamente apenas com a PAS e negativamente apenas com a glicemia. Contudo, o IC não apresentou correlação com PAD, colesterol total e subfrações de colesterol. Embora o IC tenha apresentado associação importante apenas com 2 fatores de risco cardiovascular, outros índices analisados como o IMC e a CC, não apresentaram resultados superiores. A partir da escassez de estudos que consolidem o IC como avaliação clínica importante de fatores de risco cardiovascular, sobretudo em populações específicas, torna-se inviável confrontar os resultados do presente estudo com a literatura vigente.

Menke et al (2007) observaram e compararam a associação de cinco medidas de adiposidade com fatores de risco de doenças cardiovasculares (hipertensão, diabetes, PCR, HDL, HOMA, triglicérides e LDL), em estudo populacional composto por 12608 estadunidenses com idade $\geq 20$ anos. Os autores concluíram que a CC foi o preditor mais consistente para discriminar fatores de risco de doença cardiovascular quando comparado a IMC, dobras cutâneas, gordura corporal total e/ou percentual de gordura medido por bioimpedância. Notavelmente, observa-se que dentre as medidas de adiposidade utilizadas por Menke et al (2007), a CC foi a única que avaliou, mesmo que de forma duplamente indireta, a gordura visceral, corroborando os achados do presente estudo. 
Embora a gordura abdominal seja a principal explicação para o forte desempenho da CC no estudo supracitado, Knowles et al (2011) investigaram um índice específico para a gordura visceral (índice da adiposidade ou visceral), o qual não apresentou desempenho superior na discriminação de fatores de risco da SM e PCR quando comparado aos demais índices observados (CC, RCE, RCQ e IMC). Os achados de Knowles et al (2011) assemelham-se aos apresentados neste estudo. Assim sendo, dentre as mulheres observadas ( $\mathrm{n}=952)$ no estudo, a CC e a RCE foram os melhores preditores para o descontrole da glicemia em jejum ( $\mathrm{ROC}=0.72 \mathrm{e}$ 0.72, respectivamente); a RCQ apresentou o melhor desempenho para triglicérides aumentado $(\mathrm{ROC}=0.65)$; já para a PA elevada, a RCE apresentou a maior área sob a curva ROC $(=0.70)$; e por fim, para o HDL reduzido, o IMC foi o preditor mais forte dentre os observados $(\mathrm{ROC}=$ 0.62) (Knowles, Paiva et al., 2011). Além disso, a medida de adiposidade que espelhou a gordura visceral utilizada pelos autores (IMC e CC elevados) apresentou razão de possibilidades aumentada para glicemia em jejum elevada $(O R=4.34 ; \mathrm{p}<0.00)$, PA elevada $(O R=3.40 ; \mathrm{p}<0.00)$, baixo HDL $(\mathrm{OR}=2.64 ; \mathrm{p}<0.00)$ e triglicérides elevado $(\mathrm{OR}=6.47 ; \mathrm{p}<0.00)$ nas mulheres observadas. Por outro lado, o IMC e a CC aumentados não apresentaram razão de possibilidades aumentada para a PCR $(\mathrm{OR}=1.20 ; \mathrm{p}<0.102)$ (Knowles, Paiva et al., 2011).

Posteriormente, Wai et al (2012) avaliaram a associação de diferentes medidas de adiposidade (IMC, CC, RCE e RCQ) com fatores de risco para doenças cardiovasculares em trabalhadores etíopes de ambos os sexos. Dentre as 728 mulheres analisadas, a CC apresentou associação significativa $(\mathrm{p} \leq 0.001)$ e mais consistente com triglicérides $(\mathrm{r}=0.460)$, glicemia em jejum ( $\mathrm{r}=0.279)$ e PAS ( $\mathrm{r}=0.410)$. Já o HDL e PAD associaram-se de forma significativa e mais consistentes com o IMC ( $\mathrm{r}=-0.124 ; \mathrm{p} \leq 0.01)$ e com a RCE $(\mathrm{r}=0.417 ; \mathrm{p} \leq 0.01)$, respectivamente (Wai, Dhami et al., 2012). Diferentemente dos achados apresentados no presente estudo, que apontaram associações mais consistentes para triglicérides e IC ( $\mathrm{r}=0.339$; p<0.01); glicemia em jejum e IMC (r=0.231; p<0.01); PAS e PAD com a RCE (respectivamente o valor de $\mathrm{r}=0.299$; $\mathrm{p}<0.01$; e r=0.263; $\mathrm{p}<0.05)$; e HDL com CC $(\mathrm{r}=-0.194 ; \mathrm{p}<0.05)$.

Em um delineamento semelhante ao do presente estudo, Zhang et al (2013) compararam alguns índices antropométricos na identificação de distúrbios cardiometabólicos de 2780 mulheres adultas (37-74 anos de idade) de etnia asiática, sendo que, os índices da adiposidade 
utilizados na ocasião, foram: IMC, CC, RCQ, RCE e percentual de gordura medido por bioimpedância. Na mesma direção aos achados do presente estudo, os autores concluíram que as medidas antropométricas que consideraram a obesidade abdominal em seus cálculos apresentaram desempenho superior para identificar distúrbios metabólicos, destacando-se, na ocasião, a RCE. Adicionalmente, o mesmo estudo indica o uso do IMC como medida alternativa de obesidade para identificar a hipertensão arterial (Zhang, Deng et al., 2013). Embora o presente estudo demonstre associação de pressão arterial (sistólica, diastólica e média) mais consistente com o índice RCE ( $\mathrm{r}=0.263$ - 0.312; $\mathrm{p}<0.01$ ), observou-se que os sujeitos classificados como obesos pelo IMC contiveram maior razão de possibilidades $(\mathrm{OR}=4.17)$ para o desfecho de hipertensão, corroborando a proposta de Zhang et al (2013).

Recentemente, Zhang et al (2014) avaliaram o poder preditivo do IAC, IMC e CC para discriminar o \%G (medido pelo DEXA) e para discriminar fatores de risco associados com a obesidade em uma população de chineses de ambos os sexos (1707 mulheres e 680 homens). Zhang et al (2014) identificaram o IAC como um índice consideravelmente mais fraco em todas as condições de risco estudadas (SM e espessura da artéria comum aórtica) quando comparados ao IMC e a CC, corroborando os achados do presente estudo. Ademais, os autores apontam que a associação do IAC com o \%G é dependente do sexo, sendo alta quando a análise foi conduzida em amostra mista, porém baixa quando analisadas separadamente (Zhang, Liu et al., 2014). Os achados do presente estudo também são sustentados pela proposta de Bennasar-Veny et al (2013), que após avaliar a associação do IAC com IMC, CC, RCQ, RCE e fatores de risco cardiometabólico em amostra composta por 21040 mulheres caucasianas $(39.35 \pm 10.05$ anos $)$ identificaram a CC e a RCE como índices superiores aos demais para a avaliação de risco cardiovascular, tanto em ambiente clínico quanto em ambiente laboratorial.

No presente estudo, o IAC apresentou correlação significativa com o percentual de gordura medido pelo DEXA ( $\mathrm{r}=0.583 ; \mathrm{p} \leq 0.01$; dados não apresentados), porém menor do que o relacionamento da gordura corporal medida pelo DEXA com a CC $(r=0.651 ; \mathrm{p}<0.01$; dados não apresentados), RCE (r=0.611; p<0.01; dados não apresentados) e/ou IMC ( $\mathrm{r}=0.778 ; \mathrm{p}<0.01$; dados não apresentados). Trata-se de um índice que considera a circunferência de quadril em seu cálculo, mais precisamente no numerador da equação. Sendo este, um possível viés para a 
estimativa do risco cardiometabólico, pois é sabido que uma circunferência de quadril larga é protetora contra fatores de risco metabólico (Esmaillzadeh, Mirmiran et al., 2006), tornando-se inviável a utilização clínica deste índice em mulheres idosas, uma vez que estas, sabidamente possuem padrão ginóide para acúmulo de gordura corporal. Em relação ao desempenho dos demais índices antropométricos observados, ainda que, o IMC seja o índice mais utilizado para classificar obesidade, bem como, um forte preditor para todas as causas de mortalidade estando fora de sua faixa de normalidade (i.e., $<22.5 \mathrm{ou}>25 \mathrm{~kg} / \mathrm{m}^{2}$ ) (Collaboration, 2009), sua utilização para predizer o risco cardiometabólico pode ser influenciada por diferenças na adiposidade corporal de acordo com a etnia, a distribuição de adiposidade e idade dos sujeitos avaliados (Camhi, Bray et al., 2011). Neste sentido, faz-se necessário propostas que minimizem fatores de confusão na predição de fatores de risco cardiometabólico. Outrossim, entende-se que o desempenho superior dos índices que consideraram a adiposidade abdominal em seus cálculos, foi devido a capacidade desta medida em espelhar a obesidade central. Neste sentido, não se justifica a utilização de cálculos (IC, IMC ou IAC), sendo que uma simples medida de CC ou sua relação pela estatura pode fornecer informações importantes para a predição de risco cardiometabólico.

\subsubsection{Capacidade funcional}

O presente estudo demonstrou um relacionamento mais consistente entre os índices antropométricos e os testes de capacidade funcional, quando comparados à avaliação feita pelo DEXA. Sobretudo, os índices que consideraram a obesidade abdominal em seus cálculos, neste caso, a CC e a RCE apresentaram desempenho superior nos testes de Levantar e Sentar (r=0.345; $\mathrm{p}<0.01)$ e Caminhada de 6 minutos $(\mathrm{r}=-0.417 ; \mathrm{p}<0.01)$, respectivamente. No teste de Agilidade, o índice que apresentou associação mais consistente foi o IAC (r=0.296; p<0.05) seguido pelos dois índices supramencionados. Contudo, ao observar as voluntárias classificadas com adiposidade corporal elevada, a razão de possibilidades para o desfecho de Incapacidade funcional apresentou-se aumentada apenas para a CC (OR=3.16; IC:1.28-7.82; $\mathrm{p} \leq 0.01)$ e RCE $(\mathrm{OR}=7.75$; IC:0.95-63.17; $\mathrm{p}<0.05)$. Adicionalmente, a $\mathrm{CC}$ foi a única medida que apresentou poder discriminatório para o desfecho de Incapacidade Funcional (ROC=0.618; IC:0.507-0.720; $\mathrm{p}=0.056)$, dentre os índices estudados. 
As medidas antropométricas tornam-se indicadores importantes para a capacidade funcional durante o processo de envelhecimento, uma vez que o excesso de massa corporal tem sido reportado como influenciador negativo da funcionalidade de indivíduos com idade avançada. Neste cenário, a obesidade, quando avaliada pelo IMC, apresenta associação com a mobilidade reduzida de indivíduos idosos (Hubert, Bloch et al., 1993; Ensrud, Nevitt et al., 1994; Galanos, Pieper et al., 1994; Launer, Harris et al., 1994; Jenkins, 2004). Adicionalmente, observa-se que a distribuição da gordura corporal é um indicador determinante para a função de populações idosas (Angleman, Harris et al., 2006).

De forma pioneira, um estudo populacional conduzido por Angleman et al (2006), avaliou o risco de incapacidade em idade avançada (pré-aposentadoria) associado a cinco medidas antropométricas diferentes (Massa corporal, IMC, CC, circunferência do quadril e RCQ). Dentre as mulheres avaliadas ( $\mathrm{N}=1030 ; 55$ - 74 anos) identificou-se que a distribuição da gordura corporal parece ser um importante indicador da mobilidade, valorizando a avaliação da CC em relação as demais medidas, por ser diretamente relacionada à gordura visceral. Notavelmente, a CC aumentada apresentou uma razão de possibilidades (Odds Ratio) maior para dificuldades em atividades da vida diária e atividades instrumentais da vida diária, quando comparado ao grupo de referência (i.e., menor CC). Embora o presente estudo reforce os achados supracitados, ressalta-se que foram conduzidas avaliações distintas para qualificar a funcionalidade, sendo que as atividades da vida diária foram simuladas a partir de uma bateria de testes de campo, diferentemente da proposta conduzida por Angleman et al (2006) que qualificaram as atividades da vida diária, bem como, as atividades instrumentais da vida diária a partir de questionários e auto relatos. Adicionalmente, Angleman et al (2006) também avaliaram a velocidade da marcha (em distância de 8 pés) que foi consistentemente associada a todas as cinco medidas antropométricas utilizadas sugerindo avaliações de campo conforme conduzido no presente estudo.

Mais recentemente, Lisko et al (2014) examinaram se a obesidade (medida por IMC e/ou CC) está associada com a inaptidão em atividades da vida diária em nonagenários finlandeses ( $\mathrm{n}=569 ; 416$ mulheres). A incapacidade funcional foi medida por dois instrumentos, o teste de Levantar de uma Cadeira (5 repetições consecutivas) e o índice de Barthel que avalia o potencial 
funcional a partir de informações sobre as atividades da vida diária de indivíduos com idade avançada. Corroborando os achados previamente apresentados, Lisko et al (2014) identificaram que os sujeitos com maior CC apresentaram pior performance física. Ademais, os mesmos sujeitos apresentaram escores de funcionalidade piores nas avaliações de atividades da vida diária, sendo a CC uma medida de obesidade mais consistente. Em suma, a CC foi inversamente associada com performance física e atividades da vida diária de mulheres nonagenárias. Outrossim, estes dados são sustentados em nonagenários asiáticos. Pesquisadores chineses investigaram a relação entre $\mathrm{CC}$ e atividades da vida diária e atividades instrumentais da vida diária de 505 mulheres chinesas (Yang, Jiang et al., 2014). O desfecho do estudo de Yang et al (2014) apontou um risco aumentado de incapacidade funcional e instrumental da vida diária em idosas com maior CC, quando comparadas ao grupo de referência (menor CC).

Nesta mesma direção, Dong et al (2015) investigaram se medidas antropométricas (IMC e CC), variáveis de composição corporal (bioimpedância e dobra cutânea tricipital) e força (preensão manual) foram associadas a função física e independência em atividades da vida diária em mulheres octogenárias de nacionalidade sueca. Os autores subdividiram a amostra em 3 grupos de acordo com a classificação de IMC, normal $(n=30)$, sobrepesadas $(n=29)$ e obesas $(\mathrm{n}=24)$. De forma convergente aos achados do presente estudo, a função física medida por questionário (SF36 $\mathrm{PF}$ ) foi menor no grupo de mulheres obesas quando comparado ao grupo normal, contudo, não houve diferença significativa entre as médias do grupo de mulheres obesas e sobrepesadas ( $\mathrm{p}=0.08$ ) (Dong, Marcusson et al., 2015). Estes achados reforçam a necessidade de identificação de pontos de corte para populações específicas, o que foi observado para o presente estudo, uma vez que o ponto de corte de IMC variou entre 27 e $28 \mathrm{~kg} / \mathrm{m}^{2}$ para os desfechos de funcionalidade. Já as medidas de atividade da vida diária e atividades instrumentais da vida diária, não apresentaram diferenças entre as classificações do IMC (Dong, Marcusson et al., 2015). O mesmo estudo apresentou a CC única medida independente para atividades instrumentais da vida diária, o que não foi observado para as medidas de composição corporal, o que contribui para os achados expostos pelo presente estudo. Ademais, os autores sugerem a utilização da CC e de medidas de força relativa para identificar baixa funcionalidade, bem como perda de independência em atividades da vida diária de pessoas obesas com idade avançada (Dong, Marcusson et al., 2015). 
Recentemente, Murphy et al (2014) avaliaram de forma longitudinal e abrangente a adiposidade e o risco de limitação da mobilidade e baixa performance em amostra inicialmente composta por 3011 estadunidenses de ambos os sexos, com idade avançada (70-79 anos). Na ocasião, foram conduzidas avaliações de IMC, tecido adiposo visceral, tecido adiposo subcutâneo e tecido adiposo intermuscular a partir de tomografia computadorizada (abdômen e coxa), sendo que a mobilidade foi avaliada por auto relato a cada 6 meses durante acompanhamento de 13 anos. Considerou-se baixa mobilidade dois reportes consecutivos de dificuldades para caminhar $1 / 4$ de milha $(0.4 \mathrm{~km})$ ou subir 10 degraus. Além disso, a performance foi avaliada por meio da velocidade da marcha (6 metros) durante acompanhamento de 9 anos. Interessantemente, o perfil dos participantes que desenvolveram limitações em mobilidade foram: predominantemente mulheres, com idade mais avançada, baixa instrução (escolaridade), tabagistas ou ex-tabagistas, mais pesados, mais obesos e tendo mais condições de comorbidades. Adicionalmente, a média do acompanhamento para a mobilidade foi de aproximadamente 6 anos, sendo que 2243 participantes (129 a cada 1000) desenvolveram limitações em mobilidade. Os autores concluem que o IMC, bem como, a área de depósito de tecido adiposo são associados com o risco de limitação de mobilidade e baixa performance. Em adição, a área de adiposidade pode transmitir risco para além do IMC para depósitos de adipócitos em locais específicos considerando os tecidos adiposos: visceral, intermuscular e subcutâneo).

Ainda que os estudos supracitados demonstrem associação entre algumas medidas antropométricas e funcionalidade, destaca-se que a maior parte destas avaliações foram conduzidas por meio de auto relatos e questionários. Diferentemente da abordagem proposta pelo presente estudo, que originalmente comparou medidas antropométricas e identificou o seu poder preditivo perante uma bateria de testes de campo que avaliam a funcionalidade de indivíduos idosos previamente validados, a partir de seus valores de referência (Rikli e Jones, 2013). Digno de nota, utilizou-se uma adaptação a proposta inicial para classificar o desfecho de incapacidade funcional de acordo com a realidade das voluntárias. Nesta mesma direção, identificou-se alguns estudos que propuseram abordagens com testes funcionais de campo para entender a associação dos fenótipos de obesidade com alguns testes que avaliam a funcionalidade. $\mathrm{O}$ estudo de Okoro et al (Okoro, Zhong et al., 2006) examinou a relação entre os componentes da SM e a velocidade 
da marcha de estadunidenses com idade $\geq 50$ anos. Os autores concluíram que dentre as mulheres, a velocidade da marcha é inversamente associada com a obesidade abdominal, o que reforça o uso da medida na avaliação da funcionalidade corroborando os achados do presente estudo.

O estudo de Vieira et al (2013) comparou parâmetros de desordem metabólica com flexibilidade, força e potência muscular com a capacidade funcional de idosas ( $\mathrm{n}=28$ ) brasileiras, com e sem SM. Apesar de não observarem diferenças para \%G, medidas de PA, teste de levantar e sentar e medidas de força absoluta, as voluntárias classificadas no grupo sem a SM apresentaram menor IMC, CC, RCE e massa gorda total. Ademais, as voluntárias classificadas com a SM apresentaram pior performance no teste de agilidade (TUG), menor flexibilidade, menor distância percorrida em caminhada de 6 minutos, pior potência de membros inferiores e força relativa quando comparadas ao grupo sem a SM. Estes dados foram parcialmente confirmados a partir dos achados do presente estudo. Contudo a associação de SM com funcionalidade ainda é controversa, pois exceto para flexibilidade, o estudo de Chang et al (2015) não encontrou diferenças entre testes funcionais e classificação de SM de taiwaneses com idade avançada.

Por fim, entende-se que os fenótipos relacionados à obesidade estão relacionados com piores escores de funcionalidade de sujeitos com idade avançada. Contudo, trata-se de uma condição multifatorial, que pode ser influenciada por diversos fatores, como: nível de atividade física, etnia, tabagismo, consumo de álcool, escolaridade, dentre outros.

\subsection{Mecanismos responsáveis pela associação entre adiposidade e risco cardiometabólico}

Conforme descrito anteriormente, o processo de envelhecimento está associado a alterações importantes na composição corporal, principalmente de indivíduos com idade mais avançada. Resumidamente, após a terceira década de vida, há redução progressiva da massa livre de gordura e concomitante aumento da massa gorda. Este decréscimo de tecido magro é superior a 40\% entre 30 e 70 anos de idade (Baumgartner, Stauber et al., 1995; Muller, Elahi et al., 1996; Gallagher, Visser et al., 1997). Neste processo, observa-se também alteração no padrão de distribuição da gordura corporal, sendo que há um aumento relativo de gordura intra-abdominal 
quando comparado aos demais locais de deposição de gordura (i.e., gordura subcutânea e/ou gordura corporal total), sendo que o aumento desta gordura, em pessoas idosas, está associado com a resistência à insulina (Cree, Newcomer et al., 2004).

Em geral, existem algumas sugestões sobre quais mecanismos determinam a associação de medidas de adiposidade e os fatores de risco cardiovasculares. Dentre as hipóteses, a mais aceita para esta associação propõe um efeito direto de depósito de tecido adiposo omental e mesentérico sobre a resistência à insulina, metabolismo de lipoproteína e pressão arterial. Neste cenário, a gordura intra-abdominal apresenta sua drenagem por meio de veia porta (hepática), diferentemente da gordura subcutânea (Menke, Muntner et al., 2007; Canoy, 2008). Resumidamente, os produtos metabólicos dos depósitos de tecido adiposo omental e mesentérico são liberados na veia porta (hepática), que abastece diretamente o fígado. A lipólise de triglicérides do tecido adiposo omental e mesentérico libera ácidos graxos livres que podem induzir resistência à insulina hepática e abastecer substrato para síntese de lipoproteínas e armazenamento de lipídios no fígado. O aumento da secreção de LDL por consequência conduz para um aumento da atividade lipase hepática e baixa dos níveis de HDL. Por fim, o influxo de ácidos graxos livre no fígado reduz a extração de insulina hepática desse modo inibindo a supressão de glicose produzida e levando a maiores níveis de glicose plasmática (Menke, Muntner et al., 2007). Adicionalmente, algumas proteínas específicas e hormônios produzidos pelo tecido adiposo omental e mesentérico, tais como adipocinas inflamatórias, angiotensinogênio e cortisol, podem também contribuir para doenças cardiomentabólicas.

Contudo, ainda não está totalmente esclarecido se o armazenamento de uma quantidade excessiva (absoluta ou relativa) de triacilglicerol em depósitos de gordura abdominal seja diretamente responsável pelo aumento do risco de doenças, se tal deposição é simplesmente associada com outros processos que causam esse risco aumentado, ou se é a combinação de ambas as situações. Em adição, valores de CC fornecem uma medida tanto de tecido adiposo subcutâneo bem como tecido adiposo intra-abdominal. Portanto, a relação entre CC e risco cardiometabólico não determina se o risco é associado com a gordura subcutânea abdominal ou intra-abdominal (Klein, Allison et al., 2007). 
O mecanismo responsável pela relação entre a distribuição excessiva de gordura abdominal e doenças cardiometabólicas não está plenamente esclarecido, embora existam outras hipóteses postuladas. Sinha et al. (2002) sugeriram que uma habilidade limitada de depósito de gordura subcutânea para armazenar excesso de energia tem como resultado um extravasamento de energia química para o tecido adiposo intra-abdominal e locais ectópicos, como fígado e músculo esquelético. Nesse sentido, esse acúmulo excessivo de gordura ectópica teria como desfecho a disfunção metabólica nesses órgãos. De fato, como foi comentado anteriormente, a gordura intra-hepática elevada está associada com dislipidemia e resistência à insulina hepática, e a gordura intra-mio-celular aumentada é associada com resistência à insulina músculo esquelética (Sinha, Dufour et al., 2002). Neste paradigma, o tecido adiposo intra-abdominal é primariamente um marcador da magnitude do "transbordamento" de ácidos graxos de depósitos subcutâneos. Portanto, a CC aumentada pode ser um marcador discernível de um dano sistêmico em regulação de armazenamento de energia, no qual um aumento do tecido adiposo intraabdominal reflete uma capacidade reduzida para estocar energia em outros locais (Sinha, Dufour et al., 2002).

Uma outra hipótese é que os genes que predispõe para deposição preferencial de gordura em armazenamento na região abdominal causam de forma independente doenças cardiometabólicas. Estas hipóteses não são mutualmente exclusivas e é possível que todas, e outros mecanismos ainda desconhecidos estejam envolvidos em uma associação entre gordura abdominal e consequências metabólicas adversas (Klein, Allison et al., 2007).

\subsection{Mecanismos responsáveis pela associação entre adiposidade e funcionalidade}

Embora a obesidade seja um fator de risco razoavelmente estabelecido para a incapacidade, sobretudo em sujeitos com idade avançada, sabe-se pouco sobre os seus mecanismos potenciais. A obesidade é um fator de risco para muitas doenças (i.e., diabetes, doenças coronarianas e etc.) que por sua vez podem contribuir, mesmo que de forma indireta, para a incapacidade (Murphy, Reinders et al., 2014). Estudo prévios sugeriram que uma sobrecarga física direta (tensão sobre o sistema esquelético) (Koster, Ding et al., 2011), infiltração de gordura em órgãos como o fígado e músculo (Visser, Goodpaster et al., 2005) 
inflamação (Alemán, Esparza et al., 2011), e perda de condicionamento geral (Stenholm, Alley et al., 2009) pode contribuir para a relação obesidade e incapacidade.

O sobrepeso e a obesidade podem levar ao desgaste articular, capacidade de exercício reduzida e alta taxa de doenças crônicas, então resultando em incapacidade física. $\mathrm{O}$ aparecimento do sobrepeso ou obesidade em jovens e idade adulta média pode resultar em menores níveis de atividade física, contribuindo para o decréscimo em força muscular e capacidade cardiovascular e maiores declínios em função física devido à longa duração do excesso de massa corporal (i.e., sobrecarga extra) e o surgimento mais precoce de doença crônica (Houston, Ding et al., 2009). Outrossim, entende-se que a sobrecarga extra constante advinda da gordura corporal excessiva contribui para a manutenção de uma vida sedentária, tendo como desfecho menor desempenho físico conforme observado no presente estudo.

\subsection{Aplicações práticas}

A partir dos resultados apresentados, o presente estudo identificou associação de índices da obesidade corporal com fatores de risco cardiometabólico e capacidade funcional de mulheres idosas. Conforme já mencionado, foi possível identificar que os índices que consideram a distribuição de gordura para a região abdominal destacaram-se de forma mais consistente do que os demais. Isto se faz relevante tanto no âmbito científico quanto no âmbito clínico, pois a obesidade é um problema de saúde pública crescente, que merece atenção para o seu controle. Atualmente, nos Estados Unidos, o custo do tratamento de redução de peso é estimado para 117 bilhões de dólares por ano (Stein e Colditz, 2004). O controle do sobrepeso e da obesidade são considerados uma iniciativa de saúde pública importante e diversos estudos tem demonstrado os efeitos benéficos de redução de peso e gordura em pessoas acima do peso (Donnelly, Blair et al., 2009). Neste sentido, entende-se que as ferramentas de identificação e classificação da obesidade

possuem um papel importante em qualquer política de acompanhamento e/ou controle de sobrepeso e obesidade.

Embora existam diversas formas de se identificar e classificar a adiposidade corporal, a temática ainda é controversa. Atualmente, o índice mais utilizado para a classificação da obesidade é o IMC, contudo esta ferramenta tem sido criticada por apresentar algumas limitações importantes. Por exemplo, o IMC não possibilita a distinção de gordura para os demais tecidos 
corporais, além disso não há como identificar distribuição dos diversos tecidos para diferentes regiões do corpo. Neste cenário, ressalta-se a importância de outras propostas de identificação da obesidade em diversas populações. Conforme já discutido no presente estudo, a CC apresenta de forma satisfatória, um poder discriminatório para diversas condições de saúde cardiometabólica e de funcionalidade. Ainda que a medida de CC não identifique a contribuição de gordura subcutânea e intra-abdominal para a região avaliada (circunferência abdominal), observa-se que o seu poder discriminatório é relevante para as condições investigadas no presente estudo. Ademais, destaca-se que a CC é uma medida de baixo custo e fácil acesso, uma vez que, para discernir gordura subcutânea, gordura intra-abdominal e demais tecidos na região central do corpo, são necessários exames de imagem específicos, como ressonância magnética e tomografia computadorizada. Contudo o valor destas técnicas na prática clínica ainda carece de investigação científica (Klein, Allison et al., 2007).

Outro resultado que contribui de forma importante e original tanto para a prática clínica quanto para futuras investigações científicas, foi a identificação de pontos de corte específicos das medidas de adiposidade para discriminar as condições de risco cardiometabólicas e funcionais. Até o presente momento, após revisão de literatura, não foram encontradas propostas similares, sobretudo para mulheres idosas brasileiras. Conforme já comentado em discussão, as características da população (exemplo: etnia, idade, sexo, nível de atividade física) influenciam de forma importante a determinação dos pontos de corte para os desfechos supramencionados. Neste cenário, para a população Brasileira, especialmente mulheres idosas com o perfil exposto no presente estudo, os pontos de corte utilizados têm sido fundamentados em estudos estrangeiros. Sendo assim, a especificidade das medidas proposta pelo presente estudo, aumenta a validade ecológica destes pontos de corte. Ademais, índices como o IAC e IC carecem de investigações de qualquer natureza.

Por fim, entende-se que dentre os índices de adiposidade corporal observados, a CC destacou-se não só pelo seu poder discriminatório, mas sim pela simplicidade desta medida que pode ser realizada por qualquer indivíduo. Notavelmente, a precisão desta é considerada alta para qualquer ponto de referência. Além disso, mesmo a auto medida pode ser altamente reprodutível, embora este procedimento resulte em uma CC baixo-estimada quando comparada a mesma avaliação realizada por sujeitos treinados (Klein, Allison et al., 2007). Interessantemente, 
ressalta-se que além de fácil aplicação, estes índices consideram o tecido adiposo tanto subcutâneo quanto intra-abdominal depositado na região central do organismo, que por sua vez tem forte associação indicares de saúde (Klein, Allison et al., 2007).

\subsection{Limitações do Estudo}

As limitações do presente estudo são reconhecidas. Em primeiro lugar, o número amostral de estudos desta natureza costuma ser superior ao utilizado. Entretanto, o cálculo amostral utilizado indica que este número amostral utilizado é representativo para mulheres idosas residentes no Distrito Federal. Ademais, o presente delineamento contou com a avaliação da composição corporal feita pelo DEXA e com exames laboratoriais que dificultaram um número amostral maior. O estudo contou com dois momentos de coleta, a parte cardiometabólica e a parte funcional, sendo que, esta segunda contou com um número amostral reduzido por razões logísticas e abstenções. Por fim, ressalta-se que a natureza transversal deste estudo não possibilita estabelecer relação de causa e efeito, impossibilitando identificar o impacto do risco cardiometabólico aumentado e da capacidade funcional reduzida sobre a saúde das voluntárias. Neste sentido, sugerem-se estudos que acompanhem um número amostral maior de forma longitudinal para se identificar o risco em longo prazo destas variáveis estudadas. 


\section{CONCLUSÃO}

Com base nos dados apresentados, identificou-se um relacionamento importante entre os índices de adiposidade corporal com os riscos cardiometabólico e funcional. Contudo, esta relação apresentou-se mais consistente para os índices que levaram em consideração a gordura abdominal em seus cálculos. Além disso, foram sugeridos pontos de corte para cada índice de adiposidade corporal, a partir de sua sensibilidade e especificidade, para predizer fatores de risco cardiometabólicos e de incapacidade funcional de mulheres idosas residentes no Distrito Federal. Neste sentido, a CC, a RCE e o IC apresentaram maior razão de possibilidades para os desfechos relacionados a síndrome metabólica. Outrossim, os índices de funcionalidade apresentaram comportamento semelhante. Ademais, ressalta-se a alta aplicabilidade desses resultados, uma vez que os índices de adiposidade corporal que apresentaram associações mais consistentes com os desfechos para a saúde metabólica e funcional caracterizam-se por sua fácil aplicação e baixo custo. 


\section{REFERÊNCIAS BIBLIOGRÁFICAS}

AEKPLAKORN, W.; KOSULWAT, V.; SURIYAWONGPAISAL, P. Obesity indices and cardiovascular risk factors in Thai adults. International journal of obesity, v. 30, n. 12, p. 1782-1790, 2006. ISSN 0307-0565.

AFFIUNE, A. Envelhecimento cardiovascular. Tratado de geriatria e gerontologia. Rio de Janeiro: Guanabara Koogan, 2002.

ALBERTI, K. et al. Harmonizing the Metabolic Syndrome A Joint Interim Statement of the International Diabetes Federation Task Force on Epidemiology and Prevention; National Heart, Lung, and Blood Institute; American Heart Association; World Heart Federation; International Atherosclerosis Society; and International Association for the Study of Obesity. Circulation, v. 120, n. 16, p. 1640-1645, 2009. ISSN 0009-7322.

ALEMÁN, H. et al. Longitudinal evidence on the association between interleukin-6 and Creactive protein with the loss of total appendicular skeletal muscle in free-living older men and women. Age and ageing, v. 40, n. 4, p. 469-475, 2011. ISSN 0002-0729.

ALEXANDER, C.; LANDSMAN, P.; GRUNDY, S. M. The influence of age and body mass index on the metabolic syndrome and its components. Diabetes, Obesity and Metabolism, v. 10, n. 3, p. 246-250, 2008. ISSN 1463-1326.

ALMEIDA, R. T. D.; ALMEIDA, M. M. G. D.; ARAÚJO, T. M. Obesidade abdominal e risco cardiovascular: desempenho de indicadores antropométricos em mulheres. Arq Bras Cardiol, v. 92, n. 5, p. 375-80, 2009.

ANGLEMAN, S.; HARRIS, T.; MELZER, D. The role of waist circumference in predicting disability in periretirement age adults. International journal of obesity, v. 30, n. 2, p. 364373, 2006. ISSN 0307-0565.

APOVIAN, C. M. et al. Body mass index and physical function in older women. Obes Res, v. 10, n. 8, p. 740-747, 2002. ISSN 1550-8528.

ASSOCIATION, A. D. Standards of medical care in diabetes-2010. Diabetes care, v. 33, $\mathbf{n}$. Supplement 1, p. S11-S61, 2010. ISSN 0149-5992.

BALKAU, B. et al. International Day for the Evaluation of Abdominal Obesity (IDEA) A Study of Waist Circumference, Cardiovascular Disease, and Diabetes Mellitus in 168000 Primary Care Patients in 63 Countries. Circulation, v. 116, n. 17, p. 1942-1951, 2007. ISSN 0009-7322.

BAUMGARTNER, R. N. et al. Epidemiology of sarcopenia among the elderly in New Mexico. Am J Epidemiol, v. 147, n. 8, p. 755-63, Apr 15 1998. ISSN 0002-9262 (Print) 0002-9262 (Linking). Disponível em: < http://www.ncbi.nlm.nih.gov/pubmed/9554417 >. 
BAUMGARTNER, R. N. et al. Cross-sectional age differences in body composition in persons 60+ years of age. The Journals of Gerontology Series A: Biological Sciences and Medical Sciences, v. 50, n. 6, p. M307-M316, 1995. ISSN 1079-5006.

BEAUFRERE, B.; MORIO, B. Fat and protein redistribution with aging: metabolic considerations. Eur J Clin Nutr, v. 54, p. S48-53, 2000. ISSN 0954-3007.

BENNASAR-VENY, M. et al. Body adiposity index and cardiovascular health risk factors in Caucasians: a comparison with the body mass index and others. PloS one, v. 8, n. 5, p. e63999, 2013. ISSN 1932-6203.

BERGMAN, R. N. et al. A better index of body adiposity. Obesity, v. 19, n. 5, p. 1083-1089, 2011. ISSN 1930-739X.

BIRREN, J. E.; SCHROOTS, J. J. History, concepts, and theory in the psychology of aging. 1996. ISSN 0121012603.

BLAUM, C. S. et al. The association between obesity and the frailty syndrome in older women: the Women's Health and Aging Studies. J Am Geriatr Soc, v. 53, n. 6, p. 927-934, 2005. ISSN 1532-5415.

BLEW, R. M. et al. Assessing the validity of body mass index standards in early postmenopausal women. Obes Res, v. 10, n. 8, p. 799-808, 2002. ISSN 1550-8528.

CABRERA, M. A.; JACOB FILHO, W. Obesidade em idosos: prevalência, distribuição e associação com hábitos e co-morbidades. Arquivos Brasileiros de Endocrinologia \& Metabologia, v. 45, n. 5, p. 494-501, 2001. ISSN 0004-2730.

CAMHI, S. M. et al. The relationship of waist circumference and BMI to visceral, subcutaneous, and total body fat: sex and race differences. Obesity, v. 19, n. 2, p. 402-408, 2011. ISSN 1930-739X.

CANNING, K. L. et al. Relationship between obesity and obesity-related morbidities weakens with aging. The Journals of Gerontology Series A: Biological Sciences and Medical Sciences, v. 69, n. 1, p. 87-92, 2014. ISSN 1079-5006.

CANOY, D. Distribution of body fat and risk of coronary heart disease in men and women. Current opinion in cardiology, v. 23, n. 6, p. 591-598, 2008. ISSN 0268-4705.

CARDIOLOGIA, S. B. D. Departamento de Hipertensão arterial. VI Diretrizes Brasileiras de Hipertensão arterial. Rev bras hipertens, v. 17, n. 1, p. 4-60, 2010.

CETIN, D. C.; NASR, G. Obesity in the elderly: More complicated than you think. Cleveland Clinic journal of medicine, v. 81, n. 1, p. 51-61, 2014. ISSN 0891-1150. 
CHANG, K.-V. et al. Reduced Flexibility Associated with Metabolic Syndrome in Community-Dwelling Elders. PloS one, v. 10, n. 1, 2015.

CHEN, Y. et al. Validity of body mass index and waist circumference in the classification of obesity as compared to percent body fat in Chinese middle-aged women. International journal of obesity, v. 30, n. 6, p. 918-925, 2006. ISSN 0307-0565.

CHEN, Z. et al. Dual-energy X-ray absorptiometry is a valid tool for assessing skeletal muscle mass in older women. The Journal of nutrition, v. 137, n. 12, p. 2775-2780, 2007. ISSN 0022-3166.

CHOBANIAN, A. V. et al. The seventh report of the joint national committee on prevention, detection, evaluation, and treatment of high blood pressure: the JNC 7 report. Jama, v. 289, n. 19, p. 2560-2571, 2003. ISSN 0098-7484.

CHUANG, H. H. et al. Correlation between body composition and risk factors for cardiovascular disease and metabolic syndrome. Biofactors, v. 38, n. 4, p. 284-291, 2012. ISSN 1872-8081.

CHUGHTAI, H. L. et al. Intraperitoneal fat is associated with thickening of the thoracic aorta in individuals at high risk for cardiovascular events. Obesity, v. 19, n. 9, p. 1784-1790, 2011. ISSN 1930-739X.

CIGNARELLA, A.; KRATZ, M.; BOLEGO, C. Emerging role of estrogen in the control of cardiometabolic disease. Trends in pharmacological sciences, v. 31, n. 4, p. 183-189, 2010. ISSN 0165-6147.

COLLABORATION, P. S. Body-mass index and cause-specific mortality in 900000 adults: collaborative analyses of 57 prospective studies. The Lancet, v. 373, n. 9669, p. 1083-1096, 2009. ISSN 0140-6736.

CONNELLY, D. M. et al. Motor unit firing rates and contractile properties in tibialis anterior of young and old men. Journal of Applied Physiology, v. 87, n. 2, p. 843-852, 1999. ISSN 8750-7587.

CORONA, G. et al. Hypogonadism, ED, metabolic syndrome and obesity: a pathological link supporting cardiovascular diseases. International journal of andrology, v. 32, n. 6, p. 587-598, 2009. ISSN 1365-2605.

COSTA, E. et al. Semiologia do idoso. Semiologia médica, v. 4, p. 165-197, 2001.

CREE, M. G. et al. Intramuscular and liver triglycerides are increased in the elderly. Journal of Clinical Endocrinology \& Metabolism, v. 89, n. 8, p. 3864-3871, 2004. ISSN 0021-972X. 
DAVISON, K. K. et al. Percentage of body fat and body mass index are associated with mobility limitations in people aged 70 and older from NHANES III. J Am Geriatr Soc, v. 50, n. 11, p. 1802-1809, 2002. ISSN 1532-5415.

DE LORENZO, A. et al. Adiposity rather than BMI determines metabolic risk. International journal of cardiology, v. 166, n. 1, p. 111-117, 2013. ISSN 0167-5273.

DEL DUCA, G. F.; SILVA, M. C. D.; HALLAL, P. C. Incapacidade funcional para atividades básicas e instrumentais da vida diária em idosos. Rev saúde publica, v. 43, n. 5, p. 796-805, 2009.

DONG, H.-J. et al. Obese very old women have low relative handgrip strength, poor physical function, and difficulties in daily living. J Nutr Health Aging, v. 19, n. 1, p. 20-25, 2015. ISSN 1279-7707.

DONNELLY, J. et al. Appropriate Physical Activity Intervention Strategies for Weight Loss and Prevention of Weight Regain for Adults (vol 41, pg 459, 2009). Medicine and Science in Sports and Exercise, v. 41, n. 7, p. 1532-1532, 2009. ISSN 0195-9131.

DOS SANTOS, E. P. et al. Sarcopenia and sarcopenic obesity classifications and cardiometabolic risks in older women. Archives of gerontology and geriatrics, v. 59, n. 1, p. 56-61, 2014. ISSN 0167-4943.

DOS SANTOS, R. G. et al. Força de membros inferiores como indicador de incapacidade funcional em idosos. 2013.

EKNOYAN, G. Adolphe Quetelet (1796-1874) — the average man and indices of obesity. Nephrology Dialysis Transplantation, v. 23, n. 1, p. 47-51, 2008. ISSN 0931-0509.

ELIA, M.; RITZ, P.; STUBBS, R. Total energy expenditure in the elderly. Eur J Clin Nutr, v. 54, p. S92-103, 2000. ISSN 0954-3007.

ENSRUD, K. E. et al. Correlates of impaired function in older women. J Am Geriatr Soc, 1994. ISSN 1532-5415.

ESMAILLZADEH, A. et al. Larger hip circumference independently contributed to reduced metabolic risks in Tehranian adult women. International journal of cardiology, v. 108, n. 3, p. 338-345, 2006. ISSN 0167-5273.

EVANS, E. et al. Is the current BMI obesity classification appropriate for black and white postmenopausal women? International journal of obesity, v. 30, n. 5, p. 837-843, 2006. ISSN 0307-0565. 
EXPERT PANEL ON DETECTION, E. Executive summary of the third report of the National Cholesterol Education Program (NCEP) expert panel on Detection, Evaluation, and Treatment of high blood cholesterol in adults (Adult Treatment Panel III). Jama, v. 285, n. 19, p. 2486, 2001. ISSN 0098-7484.

FARINATTI, P. D. T. Teorias biológicas do envelhecimento: do genético ao estocástico. Rev. bras. med. esporte, v. 8, n. 4, p. 129-138, 2002. ISSN 1517-8692.

FÉLIX-REDONDO, F. J. et al. Prevalence of obesity and associated cardiovascular risk: the DARIOS study. BMC public health, v. 13, n. 1, p. 542, 2013. ISSN 1471-2458.

FELSON, D. T. et al. Obesity and knee osteoarthritisThe Framingham Study. Annals of internal medicine, v. 109, n. 1, p. 18-24, 1988. ISSN 0003-4819.

FERNANDES, R. A. et al. Prevalência de dislipidemia em indivíduos fisicamente ativos durante a infância, adolescência e idade adulta. Arq Bras Cardiol, v. 97, n. 4, p. 317-23, 2011.

FIELD, A. Descobrindo a estatística usando o SPSS. Bookman, 2009. ISBN 8536320184.

FLEGAL, K. M. et al. Overweight and obesity in the United States: prevalence and trends, 1960-1994. International Journal of Obesity \& Related Metabolic Disorders, v. 22, n. 1, 1998. ISSN 0307-0565.

FLEGAL, K. M. et al. Prevalence and trends in obesity among US adults, 1999-2000. Jama, v. 288, n. 14, p. 1723-1727, 2002. ISSN 0098-7484.

FLYNN, M. et al. Total body potassium in aging humans: a longitudinal study. Am J Clin Nutr, v. 50, n. 4, p. 713-717, 1989. ISSN 0002-9165.

FOGELHOLM, M. et al. Predictors of Weight Change in Middle-aged and Old Men. Obes Res, v. 8, n. 5, p. 367-373, 2000. ISSN 1550-8528.

FORD, E. S.; GILES, W. H.; DIETZ, W. H. Prevalence of the metabolic syndrome among US adults: findings from the third National Health and Nutrition Examination Survey. Jama, v. 287, n. 3, p. 356-359, 2002. ISSN 0098-7484.

FREITAS, E. V. D. et al. Tratado de geriatria e gerontologia. In: (Ed.). Tratado de geriatria e gerontologia. 3. Rio de Janeiro: Guanabara Koogan, 2011.

FRONTERA, W. R. et al. Aging of skeletal muscle: a 12-yr longitudinal study. Journal of Applied Physiology, v. 88, n. 4, p. 1321-1326, 2000. ISSN 8750-7587. 
GALANOS, A. N. et al. Nutrition and function: is there a relationship between body mass index and the functional capabilities of community-dwelling elderly? J Am Geriatr Soc, 1994. ISSN 1532-5415.

GALLAGHER, D. et al. Appendicular skeletal muscle mass: effects of age, gender, and ethnicity. Journal of Applied Physiology, v. 83, n. 1, p. 229-239, 1997. ISSN 8750-7587.

GELBER, A. C. et al. Body mass index in young men and the risk of subsequent knee and hip osteoarthritis. The American journal of medicine, v. 107, n. 6, p. 542-548, 1999. ISSN $0002-9343$.

GHARAKHANLOU, R. et al. Medidas antropométricas como preditoras de fatores de risco cardiovascular na população urbana do Irã. Arq Bras Cardiol, v. 98, n. 2, p. 126-135, 2012.

GIGANTE, D. P. et al. Prevalência de obesidade em adultos e seus fatores de risco. Rev Saúde Pública, v. 31, n. 3, p. 236-46, 1997.

GIGANTE, D. P.; MOURA, E. C.; SARDINHA, L. M. V. Prevalência de excesso de peso e obesidade e fatores associados, Brasil, 2006. Rev Saúde Pública, v. 43, n. Supl 2, p. 83-9, 2009.

GOH, V. H. et al. Are BMI and other anthropometric measures appropriate as indices for obesity? A study in an Asian population. Journal of lipid research, v. 45, n. 10, p. 18921898, 2004. ISSN 0022-2275.

GRINKER, J. A. et al. Body habitus changes among adult males from the normative aging study: relations to aging, smoking history and alcohol intake. Obes Res, v. 3, n. 5, p. 435446, 1995. ISSN 1550-8528.

GUEDES, D. P. Recursos antropométricos para análise da composição corporal. Rev Bras Educ Fís Esp, v. 20, n. 5, p. 115-9, 2006.

GUPTA, S.; KAPOOR, S. Body adiposity index: its relevance and validity in assessing body fatness of adults. ISRN obesity, v. 2014, 2014.

HAARBO, J. et al. Relation of body fat distribution to serum lipids and lipoproteins in elderly women. Atherosclerosis, v. 80, n. 1, p. 57-62, 1989. ISSN 0021-9150.

HALL, J. E. Guyton \& Hall Fundamentos de Fisiologia. Elsevier Brasil, 2012. ISBN 8535255893.

HAN, T.; TAJAR, A.; LEAN, M. Obesity and weight management in the elderly. British medical bulletin, v. 97, n. 1, p. 169-196, 2011. ISSN 0007-1420. 
HAN, T. et al. Waist circumference action levels in the identification of cardiovascular risk factors: prevalence study in a random sample. Bmj, v. 311, n. 7017, p. 1401-1405, 1995. ISSN 0959-8138.

HAWLEY, J. A.; HOUMARD, J. A. Introduction-preventing insulin resistance through exercise: a cellular approach. Medicine and Science in Sports and Exercise, v. 36, n. 7, p. 1187-1190, 2004. ISSN 0195-9131.

HEDLEY, A. A. et al. Prevalence of overweight and obesity among US children, adolescents, and adults, 1999-2002. Jama, v. 291, n. 23, p. 2847-2850, 2004. ISSN 00987484.

HERGENROEDER, A. L. et al. The influence of body mass index on self-report and performance-based measures of physical function in adult women. Cardiopulmonary physical therapy journal, v. 22, n. 3, p. 11, 2011.

HIRANI, V. Generalised and abdominal adiposity are important risk factors for chronic disease in older people: results from a nationally representative survey. $J$ Nutr Health Aging, v. 15, n. 6, p. 469-478, 2011. ISSN 1279-7707.

HOUSTON, D. K. et al. Overweight and Obesity Over the Adult Life Course and Incident Mobility Limitation in Older Adults The Health, Aging and Body Composition Study. Am J Epidemiol, v. 169, n. 8, p. 927-936, 2009. ISSN 0002-9262.

HSIEH, S.; YOSHINAGA, H. Abdominal fat distribution and coronary heart disease risk factors in men-waist/height ratio as a simple and useful predictor. International journal of obesity and related metabolic disorders: journal of the International Association for the Study of Obesity, v. 19, n. 8, p. 585-589, 1995. ISSN 0307-0565.

HUBERT, H. B.; BLOCH, D. A.; FRIES, J. F. Risk factors for physical disability in an aging cohort: the NHANES I Epidemiologic Followup Study. The Journal of rheumatology, v. 20, n. 3, p. 480-488, 1993. ISSN 0315-162X.

HUBERT, H. B. et al. Obesity as an independent risk factor for cardiovascular disease: a 26-year follow-up of participants in the Framingham Heart Study. Circulation, v. 67, n. 5, p. 968-977, 1983. ISSN 0009-7322.

IWAO, S. et al. Effect of aging on the relationship between multiple risk factors and waist circumference. J Am Geriatr Soc, v. 48, n. 7, p. 788-794, 2000. ISSN 0002-8614.

JACKSON, A. S. et al. Accuracy of BMI to Detect Percent Fat Obesity in Men and Women, Ages 17 to 39 y: The TIGER Study: 1882: Board\# 33 8: 30 AM-9: 30 AM. Medicine \& Science in Sports \& Exercise, v. 38, n. 5, p. S311, 2006. ISSN 0195-9131. 
JECKEL-NETO, E. A. et al. Teorias biológicas do envelhecimento. Vianna EFM, Py L, Neri AL, Cançado FAX, Gorzoni ML, Rocha SM, organizadores. Tratado de geriatria e gerontologia. Rio de Janeiro: Guanabara Koogan, p. 13-19, 2002.

JENKINS, K. R. Obesity's effects on the onset of functional impairment among older adults. The Gerontologist, v. 44, n. 2, p. 206-216, 2004. ISSN 0016-9013.

JENSEN, G. L.; FRIEDMANN, J. M. Obesity Is Associated with Functional Decline in Community-Dwelling Rural Older Persons. J Am Geriatr Soc, v. 50, n. 5, p. 918-923, 2002. ISSN 1532-5415.

JETTE, A. M.; CLEARY, P. D. Functional disability assessment. Physical Therapy, v. 67, n. 12, p. 1854-1859, 1987. ISSN 0031-9023.

JORDAN, J. M. et al. Self-reported functional status in osteoarthritis of the knee in a rural southern community: the role of sociodemographic factors, obesity, and knee pain. Arthritis \& Rheumatism, v. 9, n. 4, p. 273-278, 1996. ISSN 1529-0131.

KAGAWA, M. et al. Is the BMI cut-off level for Japanese females for obesity set too high?A consideration from a body composition perspective. Asia Pacific journal of clinical nutrition, v. 15, n. 4, p. 502-507, 2006. ISSN 0964-7058.

KANNEL, W. B.; GORDON, T.; CASTELLI, W. P. Obesity, lipids, and glucose intolerance. The Framingham Study. Am J Clin Nutr, v. 32, n. 6, p. 1238-1245, 1979. ISSN $0002-9165$.

KARSCH, U. M. Idosos dependentes: famílias e cuidadores Dependent seniors: families and caregivers. Cad. saúde pública, v. 19, n. 3, p. 861-866, 2003.

KAUFMANN, T. L. et al. Manual de reabilitação geriátrica. 2001. ISBN 8527706490.

KLEIN, S. et al. Waist circumference and cardiometabolic risk: a consensus statement from shaping America's health: Association for Weight Management and Obesity Prevention; NAASO, the Obesity Society; the American Society for Nutrition; and the American Diabetes Association. Obesity, v. 15, n. 5, p. 1061-1067, 2007. ISSN 1930-739X.

KNOWLES, K. et al. Waist circumference, body mass index, and other measures of adiposity in predicting cardiovascular disease risk factors among Peruvian adults. International journal of Hypertension, v. 2011, 2011.

KOSTER, A. et al. Does the amount of fat mass predict age-related loss of lean mass, muscle strength, and muscle quality in older adults? The Journals of Gerontology Series A: Biological Sciences and Medical Sciences, v. 66, n. 8, p. 888-895, 2011. ISSN 1079-5006. 
KOWAL, P. et al. Data resource profile: the World Health Organization Study on global AGEing and adult health (SAGE). International journal of epidemiology, v. 41, n. 6, p. 1639-1649, 2012. ISSN 0300-5771.

KROOK, A.; WALLBERG-HENRIKSSON, H.; ZIERATH, J. R. Sending the signal: molecular mechanisms regulating glucose uptake. Medicine and Science in Sports and Exercise, v. 36, n. 7, p. 1212-1217, 2004. ISSN 0195-9131.

KUCZMARSKI, R. J. et al. Increasing prevalence of overweight among US adults: the National Health and Nutrition Examination Surveys, 1960 to 1991. Jama, v. 272, n. 3, p. 205-211, 1994. ISSN 0098-7484.

KUK, J. L. et al. Visceral Fat Is an Independent Predictor of All-cause Mortality in Men. Obesity, v. 14, n. 2, p. 336-341, 2006. ISSN 1930-739X.

KUSKOWSKA-WOLK, A.; RÖSSNER, S. Body mass distribution of a representative adult population in Sweden. Diabetes Res Clin Pract, v. 10, p. S37-S41, 1990. ISSN 01688227.

LAUNER, L. J. et al. Body mass index, weight change, and risk of mobility disability in middle-aged and older women: the epidemiologic follow-up study of NHANES I. Jama, v. 271, n. 14, p. 1093-1098, 1994. ISSN 0098-7484.

LEBRÃO, M. L. O envelhecimento no Brasil: aspectos da transição demográfica e epidemiológica. Saúde Coletiva, v. 4, n. 17, p. 135-40, 2007.

LI, W.-C. et al. Waist-to-height ratio, waist circumference, and body mass index as indices of cardiometabolic risk among 36,642 Taiwanese adults. European journal of nutrition, v. 52, n. 1, p. 57-65, 2013. ISSN 1436-6207.

LIMA-COSTA, M. F.; VERAS, R. Saúde pública e envelhecimento. Cadernos de Saúde Pública, v. 19, n. 3, p. 700-701, 2003. ISSN 0102-311X.

LIMA, J. C. C. et al. Validação da medida de proteína C-reativa de alta sensibilidade (PCR-as) por quimioluminescência para estimativa de risco cardiovascular em indivíduos ambulatoriais: análise comparativa com nefelometria. J Bras Patol Med Lab, v. 41, n. 1, p. 15-9, 2005.

LINDLE, R. et al. Age and gender comparisons of muscle strength in 654 women and men aged 20-93 yr. Journal of Applied Physiology, v. 83, n. 5, p. 1581-1587, 1997. ISSN 87507587.

LISKO, I. et al. Association of Body Mass Index and Waist Circumference With Physical Functioning: The Vitality 90+ Study. The Journals of Gerontology Series A: Biological Sciences and Medical Sciences, p. glu202, 2014. ISSN 1079-5006. 
LITVOC, J.; BRITO, F. C. D. Envelhecimento prevenção e promoção da saúde. Atheneu, 2004. ISBN 8573796693.

MACHADO, A. B. M.; CAMPOS, G. B. Neuroanatomia funcional. Atheneu São Paulo, 1993.

MANCINI, M. et al. Tratado de Obesidade. Itapevi: AC Farmacêutica, 2010.

MANSON, J. E. et al. Body weight and mortality among women. New England Journal of Medicine, v. 333, n. 11, p. 677-685, 1995. ISSN 0028-4793.

MANZATO, E. et al. Metabolic syndrome and cardiovascular disease in the elderly: the Progetto Veneto Anziani (Pro. VA) Study. Aging Clin Exp Res, v. 20, n. 1, p. 47-52, 2008. ISSN 1594-0667.

MATTHEWS, D. et al. Homeostasis model assessment: insulin resistance and $\beta$-cell function from fasting plasma glucose and insulin concentrations in man. Diabetologia, $v$. 28, n. 7, p. 412-419, 1985. ISSN 0012-186X.

MCARDLE, W. D.; KATCH, F., I., \& KATCH V., L. Fisiologia do exercício, energia, nutrição e desempenho humano, v. 4, 2008.

MENKE, A. et al. Measures of adiposity and cardiovascular disease risk factors. Obesity, v. 15, n. 3, p. 785-795, 2007. ISSN 1930-739X.

MICCOLI, R. et al. Prevalence of the metabolic syndrome among Italian adults according to ATP III definition. Nutrition, metabolism and cardiovascular diseases, v. 15, n. 4, p. 250254, 2005. ISSN 0939-4753.

MIDHA, T. et al. Cut-off of body mass index and waist circumference to predict hypertension in Indian adults. World Journal of Clinical Cases: WJCC, v. 2, n. 7, p. 272, 2014.

MIRAgAYA, J. et al. Perfil dos idosos no distrito federal, segundo as regiões administrativas. Companhia de planejamento do distrito federal - CODEPLAN, 2013.

MOKDAD, A. H. et al. The continuing epidemics of obesity and diabetes in the United States. Jama, v. 286, n. 10, p. 1195-1200, 2001. ISSN 0098-7484.

MOKDAD, A. H. et al. The spread of the obesity epidemic in the United States, 1991-1998. Jama, v. 282, n. 16, p. 1519-1522, 1999. ISSN 0098-7484. 
MONTEIRO, C. A.; CONDE, W. L. Tendência secular da desnutrição e da obesidade na infância na cidade de São Paulo (1974-1996). Rev Saúde Pública, v. 34, n. 6 Supl, p. 52-61, 2000 .

MORA-GARCÍA, G. J. et al. Anthropometric parameters' cut-off points and predictive value for metabolic syndrome in women from Cartagena, Colombia. salud pública de méxico, v. 56, n. 2, p. 146-153, 2014. ISSN 0036-3634.

MOTA, M. P.; FIGUEIREDO, P. A.; DUARTE, J. A. Teorias biológicas do envelhecimento. Revista Portuguesa de Ciências do Desporto, v. 4, n. 1, p. 81-110, 2004.

MULLER, D. C. et al. The effect of age on insulin resistance and secretion: a review. Seminars in nephrology, 1996. p.289.

MÜLLER, M. et al. Beyond the body mass index: tracking body composition in the pathogenesis of obesity and the metabolic syndrome. Obesity Reviews, v. 13, n. S2, p. 6-13, 2012. ISSN 1467-789X.

MURAMOTO, A. et al. Waist circumference is associated with locomotive syndrome in elderly females. Journal of Orthopaedic Science, v. 19, n. 4, p. 612-619, 2014. ISSN 09492658.

MURPHY, R. A. et al. Associations of BMI and adipose tissue area and density with incident mobility limitation and poor performance in older adults. Am J Clin Nutr, p. ajcn. 080796, 2014. ISSN 0002-9165.

NADEEM, A. et al. Cut-off values of anthropometric indices to determine insulin resistance in Pakistani adults. Age (years), v. 51, n. 12.1, p. 51.16-10.62, 2013.

NEGRÃO, C. E.; BARRETTO, A. C. P. Cardiologia do exercício: do atleta ao cardiopata. Editora Manole, 2005. ISBN 8520421083.

NETTER, F. H. Netter-Atlas de Anatomia Humana. Elsevier Brasil, 2008. ISBN 8535221484.

NEWMAN, A. B. et al. Sarcopenia: alternative definitions and associations with lower extremity function. J Am Geriatr Soc, v. 51, n. 11, p. 1602-9, Nov 2003. ISSN 0002-8614 (Print)

0002-8614 (Linking). Disponível em: < http://www.ncbi.nlm.nih.gov/pubmed/14687390 >.

OKORO, C. A. et al. Association between the metabolic syndrome and its components and gait speed among US adults aged 50 years and older: a cross-sectional analysis. BMC public health, v. 6, n. 1, p. 282, 2006. ISSN 1471-2458. 
OPAS, W. XXXVI Reunión del Comité Asesor de Investigaciones en Salud. Encuesta multicentrica: salud, bien estar e envejecimiento (SABE) em América Latina y el Caribe. Washington, 2001.

ORGANIZATION, W. H. Obesity: Prevention and managing the global epidemic: Report of a WHO consultation. WHO technical report series, v. 894, 2000.

The world health report 2002: reducing risks, promoting healthy life. World Health Organization, 2002. ISBN 9241562072.

Good health adds life to years: Global brief for World Health Day 2012. 2012.

ORY, M. G. et al. Frailty and injuries in later life: the FICSIT trials. J Am Geriatr Soc, v. 41, n. 3, p. 283-296, 1993. ISSN 0002-8614.

PANEL, N. O. E. I. E. Clinical guidelines on the identification, evaluation, and treatment of overweight and obesity in adults. 1998.

PARDINI, R. et al. Questinário internacional de atividade f1sica(IPAQ): estudo de validade e reprodutibilidade no Brasil / International physical activity questionnaire (IPAQ): study of validity and reability in Brazil. Rev. bras. ativ. fís. saúde, v. 6(2), p. 05-18, 2001.

PARK, Y.-W. et al. The metabolic syndrome: prevalence and associated risk factor findings in the US population from the Third National Health and Nutrition Examination Survey, 1988-1994. Archives of internal medicine, v. 163, n. 4, p. 427-436, 2003. ISSN 00039926.

PASCHOAL, S. M. P. Epidemiologia do envelhecimento. In: (Ed.). Gerontologia: a velhice eo envelhecimento em visão globalizada: Atheneu, 2002. p.26-43.

PENN, D. et al. High BMI and waist circumference are associated with a high prevalence of comorbidities in older Americans Act programs in Georgia senior centers. JNHA-The Journal of Nutrition, Health and Aging, v. 13, n. 9, p. 827-832, 2009. ISSN 1279-7707.

PERIAGO, M. R. Longevity and the quality of life: a new challenge for public health in the Americas. Revista Panamericana de Salud Pública, v. 17, n. 5-6, p. 295-296, 2005. ISSN 1020-4989.

PI-SUNYER, X. The medical risks of obesity. Postgraduate medicine, v. 121, n. 6, p. 21, 2009.

PITANGA, F. J. G.; LESSA, I. Indicadores antropométricos de obesidade como instrumento de triagem para risco coronariano elevado em adultos na cidade de SalvadorBahia. Arq Bras Cardiol, v. 85, n. 1, p. 26-31, 2005. 
PONGCHAIYAKUL, C. et al. Defining obesity by body mass index in the Thai population: an epidemiologic study. Asia Pacific journal of clinical nutrition, v. 15, n. 3, p. 293, 2006. ISSN 0964-7058.

PRADO, C. et al. Sarcopenic obesity: a critical appraisal of the current evidence. Clinical Nutrition, v. 31, n. 5, p. 583-601, 2012. ISSN 0261-5614.

PRADO, C. M. et al. Prevalence and clinical implications of sarcopenic obesity in patients with solid tumours of the respiratory and gastrointestinal tracts: a population-based study. Lancet Oncol, v. 9, n. 7, p. 629-35, Jul 2008. ISSN 1474-5488 (Electronic) 1470-2045 (Linking). Disponível em: < http://www.ncbi.nlm.nih.gov/pubmed/18539529 >.

RABKIN, S. W.; MATHEWSON, F. A.; HSU, P.-H. Relation of body weight to development of ischemic heart disease in a cohort of young North American men after a 26 year observation period: the Manitoba Study. The American journal of cardiology, v. 39, $n$. 3, p. 452-458, 1977. ISSN 0002-9149.

RAMÍREZ-ARRIOLA, M. C. et al. Correlación de los componentes del síndrome metabólico en mujeres mexicanas mayores de 60 años. Padecimientos reumáticos, v. 79, $n$. 1, p. 18-23, 2011.

REAVEN, G. M. Role of insulin resistance in human disease. Diabetes, v. 37, n. 12, p. 1595 1607, 1988. ISSN 0012-1797.

REZENDE, F. A. C. et al. Índice de massa corporal e circunferência abdominal: associação com fatores de risco cardiovascular. Arq Bras Cardiol, v. 87, n. 6, p. 728-34, 2006.

RIGO, J. C. et al. Prevalência de síndrome metabólica em idosos de uma comunidade: comparação entre três métodos diagnósticos. Arq Bras Cardiol, v. 93, n. 2, p. 85-91, 2009.

RIKLI, R. E.; JONES, C. J. Development and validation of a functional fitness test for community-residing older adults. Journal of aging and physical activity, v. 7, p. 129-161, 1999. ISSN 1063-8652.

Development and validation of criterion-referenced clinically relevant fitness standards for maintaining physical independence in later years. The Gerontologist, v. 53, n. 2, p. 255-267, 2013. ISSN 0016-9013.

RISSANEN, A.; HELIÖVAARA, M.; AROMAA, A. Overweight and anthropometric changes in adulthood: a prospective study of 17,000 Finns. International journal of obesity, v. 12, n. 5, p. 391-401, 1987. ISSN 0307-0565. 
RODRIGUES, S. L.; BALDO, M. P.; MILL, J. G. Associação entre a razão cinturaestatura e hipertensão e síndrome metabólica: estudo de base populacional. Arq Bras Cardiol, v. 95, n. 2, p. 186-191, 2010.

RORIZ, A. K. C. et al. Evaluation of the Accuracy of Anthropometric Clinical Indicators of Visceral Fat in Adults and Elderly. PloS one, v. 9, n. 7, p. e103499, 2014. ISSN 19326203.

ROSENBERG, I. H. Epidemiologic and methodologic problems in determining nutritional status of older persons. Proceedings of a conference. Albuquerque, New Mexico, October 19-21, 1988. Am J Clin Nutr, v. 50, n. 5 Suppl, p. 1121-235, Nov 1989. ISSN 0002-9165 (Print)

0002-9165 (Linking). Disponível em: < http://www.ncbi.nlm.nih.gov/pubmed/2816807 $>$.

ROUBENOFF, R.; CASTANEDA, C. Sarcopenia-understanding the dynamics of aging muscle. Jama, v. 286, n. 10, p. 1230-1231, 2001. ISSN 0098-7484.

SAAD, M. A. N. et al. Prevalência de síndrome metabólica em idosos e concordância entre quatro critérios diagnósticos. Arq. Bras. Cardiol, v. 102, n. 3, p. 263-269, 2014.

SALAROLI, L. B. et al. Prevalência de síndrome metabólica em estudo de base populacional, Vitória, ES-Brasil. Arq. bras. endocrinol. metab, v. 51, n. 7, p. 1143-1152, 2007. ISSN 0004-2730.

SAMPIERI, R. H. et al. Metodologia de pesquisa. 2006. ISBN 8586804932.

SARKISIAN, C. A. et al. Modifiable risk factors predict functional decline among older women: a prospectively validated clinical prediction tool. The Study of Osteoporotic Fractures Research Group. J Am Geriatr Soc, v. 48, n. 2, p. 170-178, 2000. ISSN 00028614.

SHEPHARD, R. J. Envelhecimento, atividade física e saúde. Phorte, 2003. ISBN 8586702714 .

SHIDFAR, F. et al. Association of waist circumference, body mass index and conicity index with cardiovascular risk factors in postmenopausal women: cardiovascular topic. Cardiovascular journal of Africa, v. 23, n. 8, p. 442-445, 2012. ISSN 1680-0745.

SHIELDS, M.; TJEPKEMA, M. Trends in adult obesity. Health reports/Statistics Canada, Canadian Centre for Health Information= Rapports sur la sante/Statistique Canada, Centre canadien d'information sur la sante, v. 17, n. 3, p. 53-59, 2006. ISSN 0840-6529.

SINHA, R. et al. Assessment of skeletal muscle triglyceride content by $1 \mathrm{H}$ nuclear magnetic resonance spectroscopy in lean and obese adolescents relationships to insulin 
sensitivity, total body fat, and central adiposity. Diabetes, v. 51, n. 4, p. 1022-1027, 2002. ISSN 0012-1797.

SISVAN, S. D. V. A. E. N. orientações básicas para a coleta, processamento, análise de dados e informação em serviços de saúde. Brasília: Ministério da Saúde, 2004.

SPIRDUSO, W. W. Dimensões físicas do envelhcimento. Editora Manole Ltda, 2005. ISBN 8520413412.

StANDARDiZATION, W. E. C. O. B.; ORgAniZATION, W. H. Physical status: the use and interpretation of anthropometry: report of a WHO Expert Committee. World Health Organization, 1995. ISBN 9241208546.

STEIN, C. J.; COLDITZ, G. A. The epidemic of obesity. The Journal of Clinical Endocrinology \& Metabolism, v. 89, n. 6, p. 2522-2525, 2004. ISSN 0021-972X.

STENHOLM, S. et al. The effect of obesity combined with low muscle strength on decline in mobility in older persons: results from the InCHIANTI study. International journal of obesity, v. 33, n. 6, p. 635-644, 2009. ISSN 0307-0565.

THOMAS, G. N. et al. Impact of obesity and body fat distribution on cardiovascular risk factors in Hong Kong Chinese. Obes Res, v. 12, n. 11, p. 1805-1813, 2004. ISSN 1550-8528.

TONDING, S. F. et al. Adiposity markers and risk of coronary heart disease in patients with type 2 diabetes mellitus. Nutrition journal, v. 13, n. 1, p. 124, 2014. ISSN 1475-2891.

TOPOUCHIAN, J. A. et al. Validation of two devices for self-measurement of brachial blood pressure according to the International Protocol of the European Society of Hypertension: the SEINEX SE-9400 and the Microlife BP 3AC1-1. Blood pressure monitoring, v. 10, n. 6, p. 325-331, 2005. ISSN 1359-5237.

TURCATO, E. et al. Waist circumference and abdominal sagittal diameter as surrogates of body fat distribution in the elderly: their relation with cardiovascular risk factors. International Journal of Obesity \& Related Metabolic Disorders, v. 24, n. 8, 2000. ISSN 0307-0565.

VALDEZ, R. et al. A new index of abdominal adiposity as an indicator of risk for cardiovascular disease. A cross-population study. International journal of obesity, v. 17, $\mathbf{n}$. 2, p. 77-82, 1993. ISSN 0307-0565.

VELLOSO, M.; DI LORENZO, V. A. P. Fisioterapia aplicada aos idosos portadores de disfunções cardiovasculares. In: (Ed.). Fisioterapia geriátrica: a prática da assistência ao idoso: Manole, 2004. p.329-362. ISBN 8520413986. 
VIEIRA, D. C. L. et al. Decreased functional capacity and muscle strength in elderly women with metabolic syndrome. Clinical interventions in aging, v. 8, p. 1377, 2013.

VIEIRA, E. A. et al. Razão triglicérides/HDL-C e proteína C reativa de alta sensibilidade na avaliação do risco cardiovascular. J Bras Patol Med Lab, v. 47, n. 2, p. 113-8, 2011.

VIEIRA, E. C.; PeiXoto, M. D. R. G.; SILVeIRA, E. A. D. Prevalence and factors associated with Metabolic Syndrome in elderly users of the Unified Health System. Revista Brasileira de Epidemiologia, v. 17, n. 4, p. 805-817, 2014. ISSN 1415-790X.

VILLAREAL, D. T. et al. Obesity in older adults: technical review and position statement of the American Society for Nutrition and NAASO, The Obesity Society. Obes Res, v. 13, n. 11, p. 1849-1863, 2005. ISSN 1550-8528.

VILLAREAL, D. T. et al. Physical frailty and body composition in obese elderly men and women. Obes Res, v. 12, n. 6, p. 913-20, Jun 2004. ISSN 1071-7323 (Print) 1071-7323 (Linking). Disponível em: < http://www.ncbi.nlm.nih.gov/pubmed/15229329 $>$.

VISSER, M. et al. Validity of fan-beam dual-energy X-ray absorptiometry for measuring fat-free mass and leg muscle mass. Journal of Applied Physiology, v. 87, n. 4, p. 1513-1520, 1999. ISSN 8750-7587.

VISSER, M. et al. Muscle mass, muscle strength, and muscle fat infiltration as predictors of incident mobility limitations in well-functioning older persons. The Journals of Gerontology Series A: Biological Sciences and Medical Sciences, v. 60, n. 3, p. 324-333, 2005. ISSN 1079-5006.

VISSER, M. et al. High body fatness, but not low fat-free mass, predicts disability in older men and women: the Cardiovascular Health Study. Am J Clin Nutr, v. 68, n. 3, p. 584-590, 1998. ISSN 0002-9165.

VYSSOULIS, G. et al. Effect of age on interdependence and hierarchy of cardiovascular risk factors in hypertensive patients. The American journal of cardiology, v. 108, n. 2, p. 240-245, 2011. ISSN 0002-9149.

WAI, W. S. et al. Comparison of measures of adiposity in identifying cardiovascular disease risk among Ethiopian adults. Obesity, v. 20, n. 9, p. 1887-1895, 2012. ISSN 1930739X.

WAKABAYASHI, I. Age-dependent influence of gender on the association between obesity and a cluster of cardiometabolic risk factors. Gender medicine, v. 9, n. 4, p. 267-277, 2012. ISSN 1550-8579.

WATERS, D. L.; BAUMGARTNER, R. N. Sarcopenia and obesity. Clin Geriatr Med, v. 27, n. 3, p. 401-21, Aug 2011. ISSN 1557-8623 (Electronic) 
0749-0690 (Linking). Disponível em: < http://www.ncbi.nlm.nih.gov/pubmed/21824555 $>$.

YANG, F. et al. Receiver-operating characteristic analyses of body mass index, waist circumference and waist-to-hip ratio for obesity: Screening in young adults in central south of China. Clinical Nutrition, v. 25, n. 6, p. 1030-1039, 2006. ISSN 0261-5614.

YANG, M. et al. Association between waist circumference and self-reported disability among Chinese adults aged 90 years and older. Geriatrics \& gerontology international, 2014. ISSN 1447-0594.

YASMIN, C. Adiposity indices and their relationship with some risk factors of coronary heart disease in middle-aged Cambridge men and women. Annals of human biology, v. 27, n. 3, p. 239-248, 2000. ISSN 0301-4460.

ZAHER, Z. et al. Optimal cut-off levels to define obesity: body mass index and waist circumference, and their relationship to cardiovascular disease, dyslipidaemia, hypertension and diabetes in Malaysia. Asia Pac J Clin Nutr, v. 18, n. 2, p. 209-216, 2009.

ZAMBONI, M. et al. Health consequences of obesity in the elderly: a review of four unresolved questions. International journal of obesity, v. 29, n. 9, p. 1011-1029, 2005. ISSN 0307-0565.

ZENG, Q. et al. Optimal cut-off values of BMI, waist circumference and waist: height ratio for defining obesity in Chinese adults. British Journal of Nutrition, v. 112, n. 10, p. 1735-1744, 2014. ISSN 1475-2662.

ZHANG, Z.-Q. et al. Comparison of various anthropometric and body fat indices in identifying cardiometabolic disturbances in chinese men and women. PloS one, v. 8, n. 8, p. e70893, 2013. ISSN 1932-6203.

ZHANG, Z. Q. et al. The validity of the body adiposity index in predicting percentage body fat and cardiovascular risk factors among Chinese. Clinical endocrinology, v. 81, n. 3, p. 356-362, 2014. ISSN 1365-2265.

ZIZZA, C. A. et al. Obesity Affects Nursing-Care Facility Admission among Whites but Not Blacks. Obes Res, v. 10, n. 8, p. 816-823, 2002. ISSN 1550-8528. 


\title{
10. ANEXOS
}

\subsection{Anexo A - Termo de Consentimento Livre e Esclarecido TERMO DE CONSENTIMENTO LIVRE E ESCLARECIDO}

\author{
Universidade de Brasília - UnB \\ Faculdade de Educação Física - FEF
}

Pesquisador Responsável: André Bonadias Gadelha

A senhora está sendo convidada a participar de uma pesquisa envolvendo coleta sanguínea, avaliações funcionais e antropométricas. O estudo será realizado em uma amostra composta por mulheres com idade $\geq 60$ anos, que não possuam limitações físicas que impossibilitem a execução da atividade proposta. Neste estudo, será avaliada a capacidade funcional, bem como alguns dos fatores de risco cardiovascular e metabólico, por análises clínica e laboratorial, respectivamente. Além das avaliações supramencionadas, iremos realizar coletas de dados antropométricos e compara-los, entre si, no que diz respeito ao poder preditivo de cada indicador antropométrico para a saúde funcional e cardiometabólica de 150 voluntárias. Este tipo de estudo é importante para entendermos a aplicabilidade destas avaliações na predição da capacidade funcional e risco cardiometabólico da população idosa.

Esse projeto foi submetido ao Comitê de Ética em Pesquisa da Faculdade de Ciências da Saúde da UnB ( $n^{\text {o: }}$ 01/13). Todas as informações fornecidas serão mantidas em sigilo e somente os pesquisadores envolvidos no projeto terão acesso a elas. Adicionalmente, os pesquisadores estarão à disposição para orientar e esclarecer qualquer dúvida durante a pesquisa. Você não é obrigada a responder questões que lhe tragam constrangimentos.

Os resultados desta pesquisa serão divulgados em revistas científicas da área e Congressos Internacionais, Nacionais e Regionais sobre envelhecimento e saúde. Os dados da pesquisa, materiais utilizados e qualquer informação adicional ficarão sob a responsabilidade do pesquisador Prof. André Bonadias Gadelha. Há duas vias deste documento: 1 para o pesquisador e 1 para a participante. Caso necessário os telefones de contato são: Prof. André Bonadias Gadelha - (61)8490-8490 ou Comitê de Ética em Pesquisa da Faculdade de Ciências da Saúde da UnB (61)3107-1947.

"Li as informações acima, recebi as explicações sobre a pesquisa e desejo participar voluntariamente sabendo que posso retirar meu consentimento e interromper minha participação a qualquer momento, sem penalidades. Uma cópia deste documento me será dada."

\section{Participante Voluntário}

Data: / /
André Bonadias Gadelha

Data: / / 


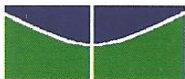 \\ Universidade de Brasília \\ Faculdade de Ciências da Saúde \\ Comitê de Ética em Pesquisa - CEP/FS}

\section{PROCESSO DE ANÁLISE DE PROJETO DE PESQUISA}

\section{Registro do Projeto no CEP: 001/13}

Título do Projeto: "Estudo compreensivo dos efeitos crônicos do treinamento resistido em mulheres idosas."

Pesquisador Responsável: Ricardo Moreno Lima

Data de Entrada: 06/12/2012

Com base na Resolução 196/96, do CNS/MS, que regulamenta a ética em pesquisa com seres humanos, o Comitê de Ética em Pesquisa com Seres Humanos da Faculdade de Ciências da Saúde da Universidade de Brasília, após análise dos aspectos éticos e do contexto técnico-científico, resolveu APROVAR o projeto 001/13 com o título: "Estudo compreensivo dos efeitos crônicos do treinamento resistido em mulheres idosas.”, analisado na 1 a Reunião Ordinária, realizada no dia 29 de janeiro de 2013.

O pesquisador responsável fica, desde já, notificado da obrigatoriedade da apresentação de um relatório semestral e relatório final sucinto e objetivo sobre o desenvolvimento do Projeto, no prazo de 1 (um) ano a contar da presente data (item VII.13 da Resolução 196/96).

Brasília, 22 de fevereiro de 2013.

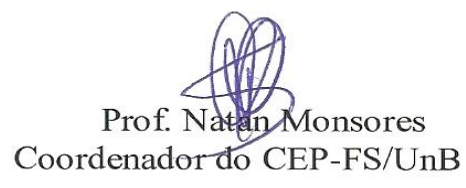




\subsection{Anexo C-Questionário internacional de atividade física (IPAQ - versão curta).}

Nome:

Data:

/

Idade :

Sexo: $F() M()$

Nós estamos interessados em saber que tipos de atividade física as pessoas fazem como parte do seu dia a dia. Este projeto faz parte de um grande estudo que está sendo feito em diferentes países ao redor do mundo. Suas respostas nos ajudarão a entender que tão ativos nós somos em relação à pessoas de outros países. As perguntas estão relacionadas ao tempo que você gasta fazendo atividade física na ÚLTIMA semana. As perguntas incluem as atividades que você faz no trabalho, para ir de um lugar a outro, por lazer, por esporte, por exercício ou como parte das suas atividades em casa ou no jardim. Suas respostas são MUITO importantes. Por favor responda cada questão mesmo que considere que não seja ativo. Obrigado pela sua participação!

Para responder as questões lembre que:

[? atividades físicas VIGOROSAS são aquelas que precisam de um grande esforço físico e que fazem respirar MUITO mais forte que o normal.

?] atividades físicas MODERADAS são aquelas que precisam de algum esforço físico e que fazem respirar UM POUCO mais forte que o normal.

Para responder as perguntas pense somente nas atividades que você realiza por pelo menos 10 minutos contínuos de cada vez.

1a Em quantos dias da última semana você CAMINHOU por pelo menos 10 minutos contínuos em casa ou no trabalho, como forma de transporte para ir de um lugar para outro, por lazer, por prazer ou como forma de exercício?

dias____ por SEMANA ( ) Nenhum 
1b Nos dias em que você caminhou por pelo menos 10 minutos contínuos quanto tempo no total você gastou caminhando por dia?

horas:___ Minutos:

2a. Em quantos dias da última semana, você realizou atividades MODERADAS por pelo menos 10 minutos contínuos, como por exemplo pedalar leve na bicicleta, nadar, dançar, fazer ginástica aeróbica leve, jogar vôlei recreativo, carregar pesos leves, fazer serviços domésticos na casa, no quintal ou no jardim como varrer, aspirar, cuidar do jardim, ou qualquer atividade que fez aumentar moderadamente sua respiração ou batimentos do coração (POR FAVOR NÃO INCLUA CAMINHADA)

dias____ por SEMANA ( ) Nenhum

2b. Nos dias em que você fez essas atividades moderadas por pelo menos 10 minutos contínuos, quanto tempo no total você gastou fazendo essas atividades por dia?

horas:___ Minutos:

3a Em quantos dias da última semana, você realizou atividades VIGOROSAS por pelo menos 10 minutos contínuos, como por exemplo correr, fazer ginástica aeróbica, jogar futebol, pedalar rápido na bicicleta, jogar basquete, fazer serviços domésticos pesados em casa, no quintal ou cavoucar no jardim, carregar pesos elevados ou qualquer atividade que fez aumentar MUITO sua respiração ou batimentos do coração.

dias____ por SEMANA ( ) Nenhum

3b Nos dias em que você fez essas atividades vigorosas por pelo menos 10 minutos contínuos quanto tempo no total você gastou fazendo essas atividades por dia? 
horas: Minutos:

Estas últimas questões são sobre o tempo que você permanece sentado todo dia, no trabalho, na escola ou faculdade, em casa e durante seu tempo livre. Isto inclui o tempo sentado estudando, sentado enquanto descansa, fazendo lição de casa visitando um amigo, lendo, sentado ou deitado assistindo TV. Não inclua o tempo gasto sentando durante o transporte em ônibus, trem, metrô ou carro.

4a. Quanto tempo no total você gasta sentado durante um dia de semana?

horas minutos

4b. Quanto tempo no total você gasta sentado durante em um dia de final de semana?

horas minutos

\title{
PERGUNTA SOMENTE PARA O ESTADO DE SÃO PAULO
}

5. Você já ouviu falar do Programa Agita São Paulo? ( ) Sim ( ) Não

6.. Você sabe o objetivo do Programa? ( ) Sim ( ) Não

\author{
CENTRO COORDENADOR DO IPAQ NO BRASIL-CELAFISCS \\ INFORMAÇÕES ANÁLISE, CLASSIFICAÇÃO E COMPARAÇÃO DE RESULTADOS NO BRASIL \\ Tel-Fax: - 011-42298980 ou 42299643. E-mail: celafiscs@celafiscs.com.br \\ Home Page: www.celafiscs.com.br IPAQ Internacional: www.ipaq.ki.se
}




\subsection{Anexo D - Produção científica/Artigo científico}

10.4.1. Strength, muscle quality and markers of cardiometabolic risk in older women

GAUCHE, R. ; GAdELHA, A. B. ; PAIVA, F. M. L. ; OlIVEIRA, P. F. A. ; LIMA, R. M. Revista Brasileira de Cineantropometria \& Desempenho Humano (Online), v. 17, p. 186, 2015.

\section{Strength, muscle quality and markers of cardiometabolic risk in older women}

\section{Força, qualidade muscular e marcadores de risco cardiometabólico em mulheres idosas}

\author{
Rafael Gauche \\ Andre Bonadias Gadelha: \\ Flavio Macedo Lahud Palva \\ Fedro Ferretra Alves de Olivelra \\ Ricardo Moreno Lima
}

\begin{abstract}
The aging process is associated with a decline in physiological functions including a reduction in muscle quality, as well as changes in cardiometabolic risk factors. Thus, the aim of this study was to verify if a correlation exists between muscle strength and quality and cardiometabolic risk markers in older women. Thirty older women ( $66.13 \pm 5.26$ years, $67.33 \pm 12.45 \mathrm{~kg}, 1.54 \pm 0.07 \mathrm{~m}$, body mass index: $28.20 \pm 4.72$ ) were submitted to the evaluation of muscle thickness and strength and blood analysis of cardiometabolic risk markers (glucose, basal insulin, C-reactive protein, total cholesterol, HDL-cholesterol, LDL-cholesterol, VLDL-cholesterol, triglycerides, and HOMA-IR). No significant correlations were found between muscle phenotypes and markers of cardiometabolic risk, even after adjustment for confounding factors. The present study indicates that muscle strength or quality is not correlated with markers of cardiometabolic risk.
\end{abstract}

Key words: Elderly; Muscle strength; Risk factors.

Resumo - O processo de envelhecimento está associado a um declinio nas funçdes fisiológicas, refletindo em reduçôes na qualidade muscular, bem como em alteraçoes de marcadores de risco cardiometabólico. Nesse sentido, o objetivo do estudo foi verificar a associacto entre qualidade muscular e marcadores de risco cardiometaboblico em mulheres idosas. Trinta mulheres idosas $(66,13 \pm 5,26$ anos, $67,33 \pm 12,45 \mathrm{~kg}, 1,54 \pm 0,07 \mathrm{~m}, 28,20 \pm 4,72$ IMC) foram submetidas à avaliaça da espessura e força musculares do quadriceps, e a análise sanguinea de marcadores de risco cardiometabólico (glicemia, insulina basal, proteina C-reativa, colesterol total, HDL-colesterol, LDL-colesterol, VLDL-colesterol, triglicerideos, e indice HOMA-IR). Näo foram encontradas correlacodes significativas entre os fenótipos musculares e os marcadores de risco cardiometabólico estudados, mesmo com controle para fatores de confusäo. A presente pesquisa indica näo haver correlą̧äo entre forca e qualidade muscular com os marcadores de risco cardiometabólico estudados. Palavras-chave: Fatores de risco; Força muscular; Idoso.
1 Universidade de Brasilis, Faculdade de Educaçáo Fisica. Brasilia, Distrito Federal, Brasil.

Received: 09 May 2014 Accepted: 17 October 2014

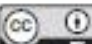

Licence Creative Comnom 


\subsection{Anexo E - Produção científica/Artigo científico}

10.5.1. Session rating of perceived exertion following resistance exercise with blood flow restriction.

VIEIRA, AMILTON ; GADELHA, ANDRÉ B. ; FERREIRA-JUNIOR, JOÃO B. ; VIEIRA, CARLOS A. ; DE MELO KEENE VON KOENIG SOARES, EDGARD ; CADORE, EDUARDO L. ; WAGNER, DALE R. ; BOTTARO, MARTIM. Clinical Physiology and Functional Imaging (Print) ${ }^{\mathrm{JCR}}, 2014$.

\section{Session rating of perceived exertion following resistance exercise with blood flow restriction}

Amilton Vieira ${ }^{1}$, André B. Gadelha', Joāo B. Ferreira-Junior ${ }^{1}$, Carlos A. Vieira ${ }^{1}$, Edgard de Melo Keene von Koenig Soares ${ }^{1}$, Eduardo L. Cadore ${ }^{2}$, Dale R. Wagner ${ }^{3}$ and Martim Bottaro ${ }^{1}$

${ }^{1}$ College of Physical Eduation, University of Brestlia (UnB), Bresilia, Federal, ${ }^{2}$ Callege of Physial Educatian, Federal University of Rio Grande do Sul (UFRGS), Porto Alegre, Rio Grande do Sul, Brexil and ${ }^{3}$ Health, Physical Eduation, and Recroation Department, Utah State University, Logan, UT, USA

\section{Summary}

Correspondence

Amilton Vieira, Rua Itapura, 136, Jardim Paulista, 14090-082 Ribeirão Preto, SP Brazil

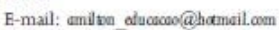

Accepted for publication

Recelved 17 Oablet 2013;

acexted 20 Decemilet 2013

Key words

trigh intessity, internal lood; ischoemia; bow intrity; resistance training
Session ratings of perceived exertion (SRPE) provide a valid and reliable indicator of resistance exercise session intensity. However, there is a lack of studies on the effects of resistance exercise with blood flow restriction (BFR) on SRPE. Thus, the aim of this study is to compare the effects of resistance exercise at high intensity versus low intensity with BFR on internal training load measured by SRPE. Thirteen young $(22.2 \pm 3.8$ years) resistance-trained men (training experience $3.2 \pm 2.4$ years) participated in the study protocol. After determining one maximum repetition (1-RM), the subjects were assigned to two groups in a counterbalanced design (i) high-intensity exercise (HIE, performed one training session at $80 \%$ of $1-\mathrm{RM}$ ) and (ii) low intensity with BFR (BFR, performed an exercise session at $50 \%$ of $1-\mathrm{RM}$ with BFR). During each session, subjects performed three sets of unilateral elbow flexion leading to concentric failure with a 1 -min rest interval between sets. A cuff around the arm, inflated at $110 \mathrm{mmHg}$, was used continuously for BFR. The SRPE was reported $30 \mathrm{~min}$ after the end of the session. The low intensity with BFR showed lower total work $(197.13 \pm 63.49$ versus $300.92 \pm 71.81 \mathrm{~kg} ; \mathrm{P}=0.002)$ and higher SRPE ( 9 versus $6 ; \mathrm{P}=0.007)$ than high-intensity resistance exercise. The present results indicate that BFR is an important factor to increase internal training load. Future studies should investigate the physiological stress imposed by different training methods rather than just quantify the external training load such as intensity or volume.

\section{Introduction}

Monitoring exercise internal training load during resistance training is an essential constituent to a favourable outcome in a periodized model (Foster et al., 2001). Therefore, strength and conditioning professionals have been using training volume and training intensity (load) to control external and internal load during resistance exercise. However, the use of resistance training volume and intensity may be inadequate to estimate the internal load and the physiological stress imposed by the resistance exercise session. Alternatively, studies have shown that the session rating of perceived exertion (SRPE) is a valid and reliable measure of internal training load during resistance exercise (Day at al., 2004; Herman a d., 2006). SRPE is a retrospective assessment taken at 30 -min postexercise and represents a single global rating of the perceived intensity for the entire exercise session (Foster et al., 2001).

\begin{abstract}
Several studies that used the SRPE during resistance exercise reported that intensity has a greater effect than volume on internal training load (Gearhart et al., 2002; Day at al., 2004; Sweet a d., 2004). These researchers found that more repetitions with a lighter load are perceived as easier than performing few repetitions against a heavier load. However, Pritchett et al. (Pritchett et d., 2009) showed that, when exercise sets are performed to failure (maximum repetitions), low intensity with higher volume induces higher SRPE than high-intensity exercise with lower volume. These controversies may be related to a number of factors such as training leading to failure or not, rest interval duration, training status and other exercise variables. In addition, resistance exercise represents a complex milieu of perceptual signals including muscle mass recruited, metabolic acidosis, and loading, all of which interact with the type of resistance exercise protocol and may have an influence on SRPE. Thus, it seems that more important than
\end{abstract}




\title{
10.6. Anexo F-Produção científica/Artigo científico
}

10.6.1. Associação entre força, sarcopenia e obesidade sarcopénica com o desempenho funcional de idosas.

GADELHA, A. B. ; DUTRA, M. T. ; OLIVEIRA, R. J. ; SAFONS, M. P. ; LIMA, R. M. Motricidade (Santa Maria da Feira), v. 10, p. 31-39, 2014.

Motricidade

2014, vol. 10 , n. 3 , pp. $31-39$ (c) Ediçōes Desafio Singular

http://dx.doi.org/10.6063/motricidade.10(3).2775

\section{Associação entre força, sarcopenia e obesidade sarcopénica com o desempenho funcional de idosas}

\author{
Association among strength, sarcopenia and sarcopenic obesity with \\ functional performance in older women
}

André Bonadias Gadelha, ${ }^{1^{*}}$ Maurílio Tiradentes Dutra, ${ }^{1}$ Ricardo Jacó de Oliveira, ${ }^{1}$ Marisete Peralta Safons, ${ }^{1}$ Ricardo Moreno Lima ${ }^{1^{*}}$

Sarcopenia e obesidade sarcopénica (OS) são condiçōes geriátricas que apresentam consequências negativas em idosos, entretanto, a associação com a capacidade funcional precisa ser mais investigada. $O$ objetivo do estudo foi verificar a associação entre força muscular, sarcopenia e OS com o desempenho funcional de idosas. Participaram 137 voluntárias $(67.76 \pm 5.67$ anos; $64.63 \pm 10.79 \mathrm{~kg}$; $154.13 \pm 0.06 \mathrm{~cm})$, submetidas à análise da composição corporal através de DXA. O desempenho funcional foi avaliado por meio dos testes de levantar e sentar, Timed $U_{p} \in$ Go, flexão de cotovelo e caminhada de 6 minutos. A força muscular foi avaliada por meio da dinamometria isocinética e pela preensão manual (FPM). A prevalência de sarcopenia e de OS foi de $13.9 \%$ e $23.4 \%$, respetivamente. Nenhuma das variáveis funcionais diferiu significativamente entre as mulheres sarcopénicas e não sarcopénicas. As voluntárias classificadas com OS apresentaram maior percentual de gordura e menor massa livre de gordura, porém, nāo houve diferença para as variáveis funcionais. Em contrapartida, a força muscular (i.e., pico de torque e FPM) apresentou associação com os testes funcionais. Os resultados indicam que não há associação entre as classificaçōes estudadas de sarcopenia e OS com os testes funcionais. Porém, a força muscular apresenta relação positiva com o desempenho funcional de idosas. Palavras-chave: envelhecimento, sarcopenia, obesidade sarcopénica, desempenho funcional, força muscular

ABSTRACT

Both sarcopenia and sarcopenic obesity (SO) are geriatric conditions well known to be associated with negative outcomes in the elderly. However, its association with functional capacity needs to be further investigated. The purpose of the study was to verify the association among muscle strength, sarcopenia and $\mathrm{SO}$ with functional performance in older women. 137 women $(67.76 \pm 5.67$ years; $64.63 \pm 10.79 \mathrm{~kg}$; $154.13 \pm 0.06 \mathrm{~cm}$ ) underwent body composition evaluation through DXA. Functional performance was evaluated by tests as chair stand, Timed Up \& Go, Arm Curl, and 6-Minute Walk. Muscle strength was evaluated with isokinetic dynamometry and hand grip strength. The prevalence of sarcopenia and SO were $13.9 \%$ and $23.4 \%$, respectively. None of the functional variables differed according to sarcopenia classifications. Although volunteers classified as SO presented higher body fat percentage and lower fat-free mass, there was no difference compared to the functional tests. Conversely, both muscle strength measurements (i.e., knee extensors isokinetic and hand grip) were significantly associated to the functional tests. In summary, there was no association between the evaluated classifications of sarcopenia and SO with functional capacity. Nevertheless, muscle strength presented a significant and positive relationship with the functional tests in older women.

Keywords: aging, sarcopenia, sarcopenic-obesity, functional performance, muscle strength

Artigo recebido a 05.07.2013; $1^{2}$ Revisāo 06.09.2013; $2^{2}$ Revisão 03.12.2013; Aceite 17.01.2014

${ }^{1}$ Universidade de Brasília, Distrito Federal, Brasil

- Autor correspondente: Universidade de Brasilia (UnB), Campus Universitário Darcy Ribeiro, Faculdade de Educaçāo Física, CEP: 70910-900 Brasilia - Distrito Federal, Brasil; E-mail: andrebonadias@ gmail.com 


\subsection{Anexo $G$ - Produção científica/Artigo científico}

10.7.1. Sarcopenia and sarcopenic obesity classifications and cardiometabolic risks in older women.

SANTOS, E. P. ; GADELHA, A. B. ; SAFONS, M. P. ; NOBREGA, O. T. ; OLIVEIRA, R. J. ; LIMA, R. M. Archives of Gerontology and Geriatrics ${ }^{\text {JCR }}$, v. 59, p. 56-61, 2014.

Archives of Gerontology and Geriatrics 59 (2014) 56-61

\begin{tabular}{lcl}
\hline & Contents lists available at ScienceDirect \\
\hline ELSEVIER & Archives of Gerontology and Geriatrics \\
\hline
\end{tabular}

\section{Sarcopenia and sarcopenic obesity classifications and cardiometabolic risks in older women}

Enivaldo Pereira dos Santos ${ }^{\mathrm{a}, \mathrm{b}}$, André Bonadias Gadelha ${ }^{\mathrm{a}, \mathrm{c} *}$, Marisete Peralta Safons ${ }^{c}$, Otávio Toledo Nóbrega ${ }^{c}$, Ricardo Jacó Oliveira ${ }^{c}$, Ricardo Moreno Lima a,c

APhysiology of Exercise and Health Research Group, Faculty of Physical Education of University of Brasilia, Campus Darcy Ribeiro, Brasilia, Brazil 'Federal institute of Piaut Floriano, Brazil

'University of Brasilia, Brasilia, Brazil

\begin{tabular}{|c|c|}
\hline$\overline{A R T I C L E ~ I N F O}$ & ABSTRACT \\
\hline
\end{tabular}

\section{Introduction}

The aging process is characterized by a decline in most physiological functions. The decline in both fat-free mass (FFM) and muscle strength (i.e., sarcopenia) is a well documented alteration with advancing age (Rosenberg, 1989). Sarcopenia has been described in both elderly men and women (Baumgartne et al., 1998; Newman et al., 2003; Rosenberg, 1989). It has been linked to multiple negative clinical outcomes (Baumgartner et al. 1998; Lima et al., 2009; Newman et al., 2003) and thus imposes an important economic burden on health care costs (Janssen, Shepard, Katzmarzyk, \& Roubenoff, 2004). Further, sarcopenia has also been argued that since women have less muscle mass compared to men,

\footnotetext{
- Corresponding author at: Universidade de Brasilia (UnB), Campus Universitário Darcy Ribeiro, Faculdade de Educação Fisica, Brasilia 70910-900, Distrito Federal, Brazil. Tel.: +5561 84908490; fax: +556131072500 ,

E-mail address: andrebonadiasegmail.mm (A.B. Gadelha).

http://dx.doi.org/10,1016/j.archger.2014.03.012

$0167-4943 / 02014$ Elsevier Ireland Itd. All rights reserved.
}

they may be at higher risk for sarcopenia-related functional limitations and disability (Newman et al., 2003).

There is a lack of clear criteria for sarcopenia identification. DXA has become a practical technique for measuring total body FFM and FM in clinical and research settings (Baumgartner et al., 1998. Gentil, Lima, Oliveira, Pereira, \& Reis, 2007; Hu et al., 2012; Lima et al., 2009; Oliveira et al., 2011). Moreover, DXA enables measurements of FFM and FM for the trunk, arms, and legs, and thus has important potential for assessment of age-associated body composition alterations. Baumgartner et al. (1998) identified a cut off value corresponding to an AFFM divided by height squared equal to or below $5.45 \mathrm{~kg} / \mathrm{m}^{2}$ for women, which was associated with a significantly higher risk of disability in older individuals. Additionally, it should be noted that besides the decline in FFM, older individuals also tend to gain weight, especially FM, as they age (Newman et al., 2003; Oliveira et al., 2011). Therefore, the literature in this area has been focusing on a high FM and low FFM combination (Newman et al., 2003), a condition referred to as SO (Bouchard \& Janssen, 2010; Jarosz \& Bellar, 2009). So has been 


\subsection{Anexo H-Produção científica/Artigo científico}

10.8.1. Diferenças entre os gêneros na resistência à fadiga e na recuperação do treinamento de força.

VIEIRA, A. ; GADELHA, A. B. Revista Brasileira de Reabilitação e Atividade Física, v. 3, p. 37-45, 2014

Revista Brasileira de Reabilitação e Atividade Física, Vitória, v.3 n.1, p. 37-45, abr.2014

ISSN $2238-5428$

\section{Artigo de Revisão \\ DIFERENÇAS ENTRE OS GÊNEROS NA RESISTÊNCIA À FADIGA E NA RECUPERAÇÃO DO TREINAMENTO DE FORÇA}

Amilton Vieira ${ }^{1}$ e André Bonadias Gadelha ${ }^{1}$

\section{RESUMO}

Introdução: Embora sejam reconhecidas diferenças entre os gêneros, as recomendações para a prescrição do treinamento de força (TF) não diferenciam homens de mulheres. A otimização dos benefícios advindos do TF depende do conhecimento e da manipulação de variáveis importantes.

Objetivo: investigar estudos que compararam diferenças no desempenho de homens e mulheres em resposta a manipulação do intervalo de recuperação, a resistência à fadiga e a recuperação após TF.

Métodos: Foi realizada uma busca eletrônica da literatura no PubMed em fevereiro de 2014. Dentre os descritores utilizados, foram encontrados 12 estudos.

Conclusão: Com base nos estudos investigados, destaca-se que a diferença entre homens e mulheres, em relação à força absoluta, pode ser considerada para a prescrição do treino. No entanto, outros aspectos contribuem para as disparidades físicas entre os gêneros.

Palavras chave: Diferenças entre gêneros, treinamento de força, exercício resistido.

\section{ABSTRACT}

Introduction: Although there are differences between genders, the strength training guidelines' recommendations do not differentiate men and women. There are evidences suggesting that women have better fatigue resistance and can recovery themselves faster than men. The benefits optimization of strength training is dependent of knowledge and manipulation of important variables, such as the rest interval between sets and training frequency.

objective: This review investigated the available literature studies that compared differences on performance of both men and women about the rest interval manipulation response, fatigue resistance, and recovery post strength training.

Methods: An electronic search of the literature in PubMed was performed in February 2014. Among the descriptors used, 12 studies were found.

Conclusion: The differences highlighted between men and women, regarding absolute strength, might be considered during training prescription. However, there are other aspects that contribute for disparities between genders. Future studies should consider these differences and compare men and women with similar strength capacities during high intensity effort.

Keywords: Differences between genders, strength training, resistance exercise.

1. Faculdade de Educação Física da Universidade de Brasilia (UnB), Brasilia, Distrito Federal, Brasil.

Endereço para correspondência Universidade de Brasília (UnB), Campus Universitário Darcy Ribeiro, Faculdade de Educação Física, Brasilia - Distrito Federal - Brasil. CEP: $70910-900$

E-mail

andrebonadias@gmail.com

Submetido em 01/03/2014

Aceito em 01/04/2014 


\subsection{Anexo I - Produção científica/Resumo publicado em anais de congresso}

GADELHA, A. B. ; SHIRAISHI, J. C. ; TELES, F. S. ; LIMA, R. M. ; PAIVA, F. M. L. ; GAUCHE, R. ; BEZERRA, L. M. A. . Efeitos da prática sistematizada de hatha yoga sobre indicadores da aptidão física de adultos jovens. In: 37 Simpósio Internacional de Ciências do Esporte - CELAFISCS 2014, 2014, são paulo. Lições e sonhos na atividade física e no exercício Edição especial da Revista Brasileira de Ciência e Movimento, 2014. v. 22.

\section{Efeitos da prática sistematizada de hatha yoga sobre indicadores da aptidão física de adultos jovens}

INTRODUÇÃO: A prática sistematizada do Hatha Yoga tem sido sugerida como intervenção capaz de promover benefícios às capacidades físicas e à funcionalidade de seus praticantes. Contudo, a temática precisa ser mais bem investigada. OBJETIVO: Avaliar os efeitos da prática sistematizada de Hatha Yoga sobre indicadores da aptidão física de adultos jovens. MÉTODOS: 22 voluntários (17 mulheres e 5 homens; $22.36 \pm 2.40$ anos; $1.66 \pm 0.10$ metros) foram submetidos a um programa sistematizado de 12 semanas de Hatha Yoga. As aulas foram conduzidas no período da manhã, duas vezes por semana e seguiram a seguinte rotina: meditação (5'), 15 posturas de hatha yoga $\left(40^{\prime}\right)$ e relaxamento (5'). Avaliações de massa corporal, estatura, circunferência de cintura (CC), flexibilidade (banco de Wells), massa gorda (7 dobras), resistência abdominal (RA), resistência de membros superiores (RMMSS) e teste de corrida (12') foram conduzidas pré e pósintervenção. A normalidade da amostra foi verificada por meio do teste de Shapiro-Wilk e as diferenças entre pré e pósintervenção foram observadas por meio dos testes $\mathbf{t}$ pareado e Wilcoxon pareado. RESULTADOS: A CC e a massa gorda (\%) apresentaram-se estatisticamente diminuídas após a intervenção de 12 semanas de Hatha Yoga. Além disso, flexibilidade e resistência abdominal foram aumentadas após o mesmo protocolo. Ainda que as demais variáveis não tenham apresentado diferenças significativas após a intervenção proposta, foi observado um tamanho do efeito pequeno para RMMSS e IMC. CONCLUSÕES: Com base nos resultados observados, conclui-se que a prática sistematizada de Hatha Yoga foi capaz de alterar significativamente indicadores da aptidão física, como CC, Massa Gorda, Flexibilidade e resistência abdominal de adultos jovens. Futuras investigações são necessárias para subsidiar o uso de práticas corporais alternativas, como o Hatha Yoga.

Tabela 1. Variáveis dependentes pré e pós-intervenção sistematizada de Hatha Yoga. Os dados são expressos em média, desvio padrão e tamanho do efeito.

\begin{tabular}{|c|c|c|c|}
\hline Variável & Pré-intervenção & Pós-intervenção & TE \\
\hline$n$ & 22 & 22 & \\
\hline Massa Corporal $(\mathrm{kg})^{a}$ & $62.73 \pm 12.74$ & $62.45 \pm 13.35$ & 0.02 \\
\hline $\operatorname{IMC}\left(\mathrm{kg} / \mathrm{m}^{2}\right)^{\mathrm{a}}$ & $22.67 \pm 3.19$ & $22.56 \pm 3.41$ & 0.14 \\
\hline $\mathrm{CC}(\mathrm{cm})^{\mathrm{a}}$ & $71.12 \pm 9.64$ & $69.23 \pm 10.20 *$ & 0.45 \\
\hline Massa Gorda (\%) ${ }^{a}$ & $25.11 \pm 5.56$ & $23.69 \pm 5.72 *$ & 0.54 \\
\hline Flexibilidade $(\mathrm{cm})^{b}$ & $26.55 \pm 8.78$ & $33.69 \pm 5.72 *$ & 0.81 \\
\hline RA (repetições) ${ }^{a}$ & $24.64 \pm 7.59$ & $29.23 \pm 7.08 *$ & 0.48 \\
\hline RMMSS (repetições) $^{b}$ & $21.45 \pm 9.61$ & $23.77 \pm 10.34$ & 0.23 \\
\hline 12 minutos $(\mathrm{m})^{\mathrm{b}}$ & $1683.18 \pm 321.65$ & $1686.68 \pm 360.87$ & 0.01 \\
\hline
\end{tabular}

TE = Tamanho do Efeito; IMC = Índice de Massa Corporal; CC = Circunferência de Cintura; RA = Resistência Abdominal; RMMSS $=$ Resistência de Membros Superiores; ${ }^{\mathrm{a}}=$ teste paramétrico; ${ }^{\mathrm{b}}=$ teste não paramétrico.

* = Diferença significativa entre pré e pós-intervenção sistematizada de Hatha Yoga $(p<0.01)$. 


\subsection{Anexo J - Produção científica/Resumo publicado em anais de congresso}

GADELHA, A. B. ; VIEIRA, A. ; SOARES, E. K. V. K. ; TELES, F. S. ; LIMA, R. M. ; BOTTARO, M. . Respostas Cardiovasculares agudas no treinamento resistido com e sem restrição do fluxo sanguíneo em adultos jovens. In: 36 Simpósio internacional de ciências do esporte (CELAFISCS), 2013, São Paulo. Edição especial da revista Brasileira de ciência e movimento (suplemento especial), 2013. v. 21. p. 38-38.

\section{Respostas cardiovasculares agudas no treinamento resistido com e sem restrição do fluxo sanguíneo em adultos jovens}

Introdução: $O$ treinamento resistido (TR) com restrição do fluxo sanguíneo (RFS) é uma estratégia interessante para populações que dependem da manipulação de baixas cargas de trabalho. Entretanto, o impacto cardiovascular deste método de treino precisa ser mais bem investigado. Objetivo: Verificar o comportamento da pressão arterial e duplo produto antes e depois de uma sessão de TR com e sem RFS para flexores do cotovelo em adultos jovens. Metodologia: Participaram do presente estudo 13 homens $(22,15 \pm 3,78$ anos; $179,35 \pm 9,09 \mathrm{~cm} ; 87,35 \pm 15,40 \mathrm{~kg})$ praticantes de TR há pelo menos 6 meses. A coleta de dados foi realizada em 3 dias não consecutivos, com intervalo de 48 a 96h. Após a determinação de uma repetição máxima (1RM), os sujeitos realizaram a sessão de alta intensidade ou de baixa intensidade com RFS, $80 \%$ e $50 \%$ de 1 RM, respectivamente. A ordem das sessões foi aleatória e contrabalanceada. O TR consistiu na realização de 3 séries de repetições máximas para flexores do cotovelo. O intervalo de recuperação entre as séries foi de 1 minuto. Para a sessão de baixa intensidade com RFS, foi utilizado um manguito de esfigmomanômetro insuflado a $110 \mathrm{mmHg}$ que envolveu a parte proximal do braço dominante dos voluntários. A pressão arterial foi medida pelo método oscilométrico (Microlife BP 3BPO-A) em situação de repouso, imediatamente após a intervenção e a cada cinco minutos até completar 30 minutos em repouso. O duplo produto (DP) foi calculado. Para análise dos dados foi aplicada uma ANOVA mista com post-hoc LSD. O nível de significância adotado foi de p<0,05. Resultados: A Figura 1 apresenta o comportamento das variáveis PAS, PAD e PAM antes e após os exercícios de alta intensidade e baixa intensidade com RFS. O DP aumentou de forma significativa no TR de alta intensidade (11530,31 $765,01 \mathrm{mmHg}$.bpm) quando comparado ao TR de baixa intensidade com RFS $(9686,15 \pm 647,43 \mathrm{mmHg} . \mathrm{bpm})$. Não foram observadas outras diferenças significativas entre as sessões de treino. A sessão de baixa intensidade e RFS apresentou tendência de aumento da PAM imediatamente após o exercício ( $\mathrm{p}<0,06)$. Já na sessão de TR de alta intensidade, a PAM apresentou-se aumentada imediatamente após o exercício e uma diminuição após 30 minutos em relação ao momento pré-intervenção. A PAS apresentou-se aumentada na sessão de baixa intensidade com RFS 5 minutos após a intervenção. Na sessão de alta intensidade, a PAS apresentou aumento significativo imediatamente após o exercício, em relação ao repouso. Entretanto, uma redução na PAS após 30 minutos de repouso foi observada. Não foram observadas diferenças significativas para a PAD.

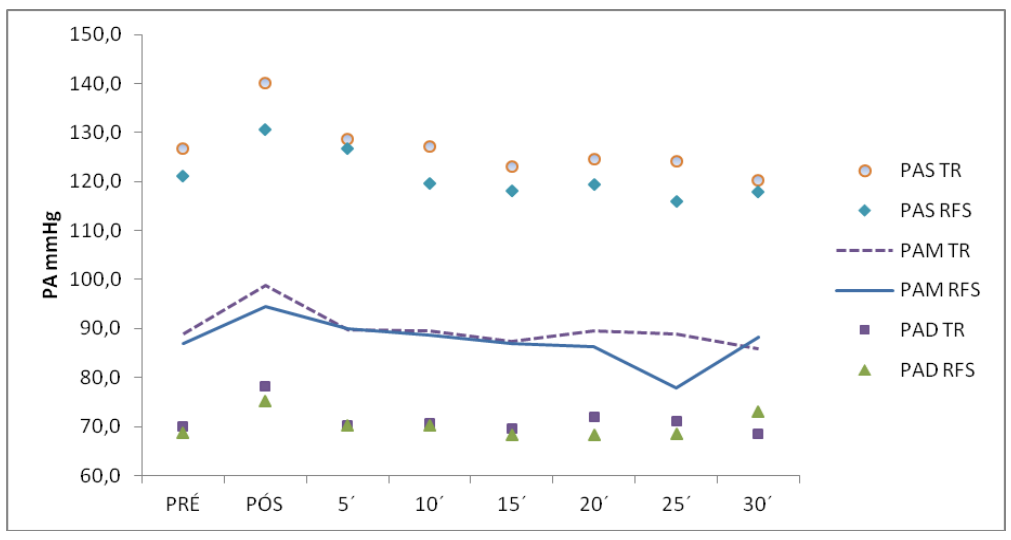

Figura 1. Comportamento das variáveis de PAS, PAD e PAM antes e após o TR de alta intensidade e baixa intensidade com RFS. Conclusão: Os dados apresentados no presente estudo demonstraram que o TR de alta intensidade proporcionou um aumento significativo no DP quando comparado ao TR de baixa intensidade com RFS. Ademais, não foram observadas diferenças nas variáveis cardiovasculares analisadas entre as sessões de TR de alta intensidade e baixa intensidade com RFS.

Palavras-chave: Treinamento Resistido, Restrição do fluxo sanguíneo, Pressão Arterial 